\title{
Extração e Consulta de Informações do Currículo Lattes baseada em Ontologias
}

\author{
Eduardo Ferreira Galego
}

DiSSERTAÇÃO APRESENTADA

$\mathrm{AO}$

Instituto DE MATEMÁticA E EstatísticA

DA

Universidade DE SÃo PAUlo

PARA

OBTENÇÃO DO TÍTULO

$\mathrm{DE}$

Mestre em CiênCias dA ComputaÇÃO

Área de Concentração: Ciência da Computação

Orientadora: Prof ${ }^{\mathrm{a}}$. Dr ${ }^{\mathrm{a}}$. Renata Wassermann 


\section{Extração e Consulta de Informações do Currículo Lattes baseado em Ontologias}

Esta versão da dissertação contém as correções e alterações sugeridas pela Comissão Julgadora durante a defesa da versão original do trabalho, realizada em 06/11/2013. Uma cópia da versão original está disponível no

Instituto de Matemática e Estatística da Universidade de São Paulo.

Comissão Julgadora:

- Prof ${ }^{\mathrm{a}}$. Dr ${ }^{\mathrm{a}}$. Renata Wassermann (orientadora) - IME-USP

- Prof. Dr. Jaime Simão Sichman - EP-USP

- Prof. Dr. Jesús Pascual Mena-Chalco - CCMFT-UFABC 


\section{Agradecimentos}

Em primeiro lugar, agradeço a Deus por me conceder sabedoria, paciência e vitalidade necessária para poder chegar até aqui. Foram $n$ vezes em que os pensamentos negativos e o cansaço me abateram, entretanto foram $n+1$ em que Deus ajudou a superar os obstáculos.

Agradeço minha esposa Cíntia pelas inúmeras palavras de incentivo, por vezes ignoradas, mas que foram extremamente necessárias para que pudessemos comemorar juntos mais esta vitória.

Agradeço também minha família: Meu pai Donisete, minha mãe Eliana e minha irmã Patrícia. Eles foram testemunhas de que não é nada fácil concluir um mestrado.

Agradeço pela minha orientadora Renata Wassermann por todo apoio, atenção e confiança. Uma grande parcela deste sucesso é devido a ela, no qual não mediu esforços para auxiliar, seja pelas minhas visitas pela manhã ou meus e-mails respondido durante a noite.

Agredeço imensamente pela oportunidade de pertencer ao LIAMF (mesmo que comparado a um filho rebelde, que poucas vezes aparece em casa). Antes de entrar no IME-USP, foram inúmeras vezes que visitava o site e sonhava em pertencer a esta equipe tão especial.

Aos colegas: Fabiano Luz, Felipe Martins, Rafael Will, Paulo Carlos Santos, Sylvio Azevedo, Lucas Vicente, Paulo de Tarso e Fillipe Resina, que me acompanharam durante esta jornada.

À todos os professores: Alair Pereira do Lago, Yoshiko Wakabayashi, Routo Terada, Flávio Soares, Marcelo Finger, Leliane Nunes de Barros e Francisco Reverbel. Cada um deles me auxiliou o formar uma nova concepção da Ciência da Computação. 


\section{Resumo}

\section{GALEGO, E. F. Extração e Consulta de Informações do Currículo Lattes baseado em}

Ontologias. 2013. Dissertação (Mestrado) - Instituto de Matemática e Estatística, Universidade de São Paulo, São Paulo, 2013.

A Plataforma Lattes é uma excelente base de dados de pesquisadores para a sociedade brasileira, adotada pela maioria das instituições de fomento, universidades e institutos de pesquisa do País. Entretanto, é limitada quanto à exibição de dados sumarizados de um grupos de pessoas, como por exemplo um departamento de pesquisa ou os orientandos de um ou mais professores.

Diversos projetos já foram desenvolvidos propondo soluções para este problema, alguns inclusive desenvolvendo ontologias a partir do domínio de pesquisa. Este trabalho tem por objetivo integrar todas as funcionalidades destas ferramentas em uma única solução, a SOS Lattes. Serão apresentados os resultados obtidos no desenvolvimento desta solução e como o uso de ontologias auxilia nas atividades de identificação de inconsistências de dados, consultas para construção de relatórios consolidados e regras de inferência para correlacionar múltiplas bases de dados.

Além disto, procura-se por meio deste trabalho contribuir com a expansão e disseminação da área de Web Semântica, por meio da criação de uma ferramenta capaz de extrair dados de páginas Web e disponibilizar sua estrutura semântica. Os conhecimentos adquiridos durante a pesquisa poderão ser úteis ao desenvolvimento de novas ferramentas atuando em diferentes ambientes.

Palavras-chave: Web Semântica, Ontologias, Plataforma Lattes, Currículo Lattes, OWL, SPARQL, Inferência. 


\section{Abstract}

GALEGO, E. F. Ontology-based Queries and Information Extraction from the Lattes CV. 2013. Dissertação (Mestrado) - Instituto de Matemática e Estatística, Universidade de São Paulo, São Paulo, 2013.

The Lattes Platform is an excellent database of researchers for the Brazilian society, adopted by most Brazilian funding agencies, universities and research institutes. However, it is limited as to displaying summarized data from a group of people, such as a research department or students supervised by one or more professor. Several projects have already been developed which propose solutions to this problem, including some developing ontologies from the research domain.

This work aims to integrate all the functionality of these tools in a single solution, SOS Lattes. The results obtained in the development of this solution are presented as well as the use of ontologies to help identifying inconsistencies in the data, queries for building consolidated reports and rules of inference for correlating multiple databases.

Also, this work intends to contribute to the expansion and dissemination of the Semantic Web, by creating a tool that can extract data from Web pages and provide their semantic structure. The knowledge gained during the study may be useful for the development of new tools operating in different environments.

Keywords: Semantic Web, Ontologies, Lattes Plataform, Lattes CV, OWL, SPARQL, Inference. 


\section{Sumário}

Lista de Abreviaturas $\quad$ xi

Lista de Figuras $\quad$ xiii

1 Introdução $\quad 1$

1.1 Motivação . . . . . . . . . . . . . . . . . . . . . . . . . . . . 1

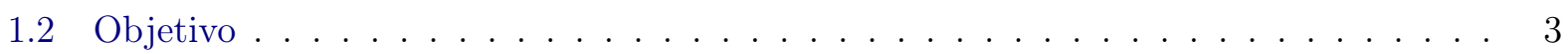

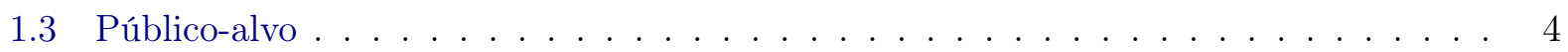

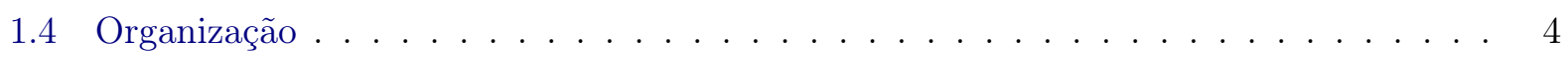

2 Web Semântica $\quad 5$

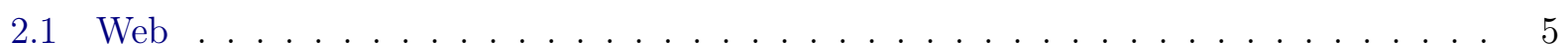

2.1 .1 Protocolos e Linguagens . . . . . . . . . . . . . . . . . 5

2.1 .2 Motores de Buscas . . . . . . . . . . . . . . . . . . . . . 6

2.2 Web Semântica . . . . . . . . . . . . . . . . . . . . 7

3 Ontologias $\quad 9$

3.1 Representação de Conhecimento . . . . . . . . . . . . . . . . . . . . . . . . . . . . . . . . . . .

3.1 .1 Ontologias . . . . . . . . . . . . . . . . . . . . 10

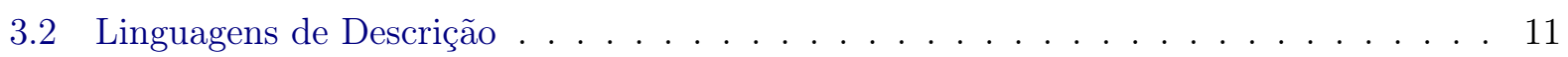

3.2 .1 XML e Linguagens Correlatas . . . . . . . . . . . . . . . . . . 12

$3.2 .2 \mathrm{RDF} / \mathrm{RDF}$ Schema . . . . . . . . . . . . . . . . . . 13

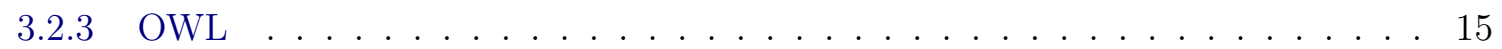

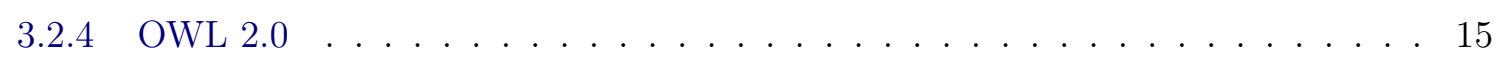

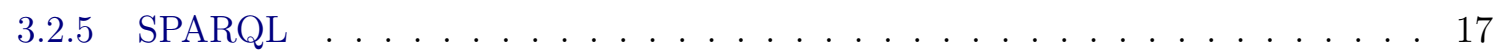

3.2 .6 Ferramentas e Implementações . . . . . . . . . . . . . . . . . . . . . 18

4 Plataforma Lattes $\quad 21$

4.1 A Plataforma . . . . . . . . . . . . . . . . . . . . 21

4.1 .1 Captação e Armazenamento dos Dados . . . . . . . . . . . . . . . . 21

4.1 .2 Consultas de Dados . . . . . . . . . . . . . . . . . . . . . . . 22

4.1 .3 Limitações . . . . . . . . . . . . . . . . . . . . . . . . . . . . . . . . . . . . .

4.2 Trabalhos que Utilizam a Base Lattes . . . . . . . . . . . . . . . . . . . 28

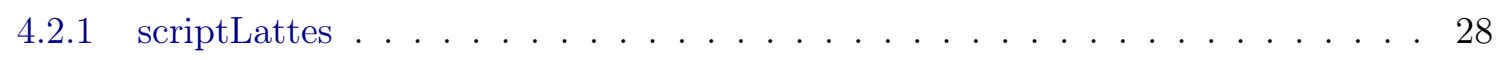

4.2 .2 OntoLattes . . . . . . . . . . . . . . . . . . . . . . 29

4.2 .3 Exportação de Currículos para Outros Formatos . . . . . . . . . . . . . 29 
4.2 .4 Semantic Lattes . . . . . . . . . . . . . . . . . . . . . . 30

4.2 .5 Projeto Sucupira . . . . . . . . . . . . . . . . . . . . 31

$5 \quad$ SOS Lattes $\quad 33$

5.1 Requisitos Funcionais e Não-Funcionais . . . . . . . . . . . . . . . . 33

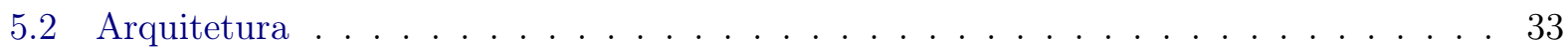

5.3 Funcionalidades . . . . . . . . . . . . . . . . . . . . . . 35

5.3.1 Obtenção dos Dados e Geração das Instâncias . . . . . . . . . . . . . . . . 35

5.3 .2 Relatórios Consolidados . . . . . . . . . . . . . . . . . . . 35

5.3 .3 Uso de Propriedades Simétricas . . . . . . . . . . . . . . . . . . . 36

5.3.4 Consultas em mais de uma base de dados . . . . . . . . . . . . . . . . . 36

5.3 .5 Propriedades Inferidas Utilizando Regras . . . . . . . . . . . . . . . 37

5.3 .6 Sugestão para Inclusão de Novos Membros . . . . . . . . . . . . . . . . . . . 38

6 Resultados $\quad 39$

6.1 Acesso Inicial . . . . . . . . . . . . . . . . . . . . . . . . . . . . . 39

6.2 Carregar Dados da Base Lattes . . . . . . . . . . . . . . . . . . . . . . . 39

6.3 Lista de Membros . . . . . . . . . . . . . . . . . . . . . . . . . . . 40

6.4 Listagem de Produções Bibliográficas . . . . . . . . . . . . . . . . . . . . . . 40

6.5 Listagem de Orientações . . . . . . . . . . . . . . . . . . . . . . . . . . . 42

6.6 Inconsistências entre Orientações e Formações . . . . . . . . . . . . . . . . . . . . 42

6.7 Módulo de Perguntas . . . . . . . . . . . . . . . . . . . . . . . 43

7 Considerações Finais $\quad 45$

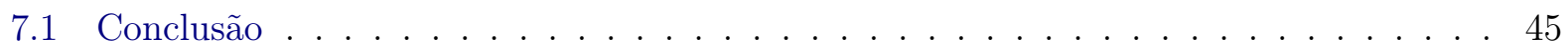

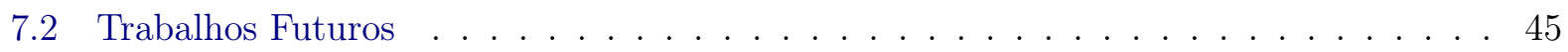

$\begin{array}{ll}\text { Referências Bibliográficas } & 47\end{array}$

$\begin{array}{ll}\text { Apêndice A } & 49\end{array}$

$\begin{array}{ll}\text { Apêndice B } & 53\end{array}$ 


\section{Lista de Abreviaturas}

\begin{tabular}{|c|c|}
\hline AJAX & JavaScript assíncrono e XML (Asynchronous JavaScript and XML) \\
\hline API & Interface de Programação de Aplicativos (Application \\
\hline & Programming Interface) \\
\hline CONSCIENTIAS & $\begin{array}{l}\text { Comunidade para Ontologias em Ciência, Tecnologia e Informações } \\
\text { de Aperfeiçoamento de Nível Superior }\end{array}$ \\
\hline CSS & Folhas de Estilos em Cascata (Cascading Style Sheets) \\
\hline DTD & Definição de Tipo de Documento (Document Type Definition) \\
\hline FTP & Protocolo de Transferência de Arquivos (File Transfer Protocol) \\
\hline HTTP & Protocolo de Transferência de Hipertexto (Hypertext Transfer Protocol) \\
\hline IME-USP & Instituto de Matemática e Estatística da Universidade de São Paulo \\
\hline IP & Protocolo de Interconexão (Internet Protocol) \\
\hline IR & Recuperação de Informação (Information Retrieval) \\
\hline JSON & Notação de Objeto JavaScript (JavaScript Object Notation) \\
\hline LIAMF & $\begin{array}{l}\text { Laboratório de Lógica, Inteligência Artificial e Métodos Formais (Logics, } \\
\text { Artificial Intelligence and Formal Methods) }\end{array}$ \\
\hline OWL & Linguagem de Ontologia Web (Web Ontology Language) \\
\hline $\mathrm{RDF}$ & Framework de Descrição de Recursos (Resource Description Framework) \\
\hline RDFS & RDF Schema \\
\hline SGML & Standard Generalized Markup Language \\
\hline SPARQL & $\begin{array}{l}\text { Protocolo SPARQL e Linguagem de Consulta RDF (SPARQL Protocol } \\
\text { and RDF Query Language) }\end{array}$ \\
\hline SSL & Protocolo de Camada de Sockets Segura (Secure Sockets Layer) \\
\hline TCP & Protocolo de Controle de Transmissão (Transmission Control Protocol) \\
\hline TLS & Segurança da Camada de Transporte (Transport Layer Security) \\
\hline URI & Identificador de Recurso Uniforme (Uniform Resource Identifiers) \\
\hline URL & Localizador Padrão de Recursos (Uniform Resource Locator) \\
\hline W3C & World Wide Web Consortium \\
\hline XML & Linguagem de Marcação Extensível (Extensible Markup Language) \\
\hline $\mathrm{PL}$ & Plataforma Lattes \\
\hline HTML & Linguagem de Marcação de Hipertexto (HyperText Markup Language) \\
\hline XHTML & $\begin{array}{l}\text { Linguagem de Marcação de Hipertexto Extensível (Extensible Hypertext } \\
\text { Markup Language) }\end{array}$ \\
\hline
\end{tabular}




\section{Lista de Figuras}

3.1 Exemplificação de uma estrutura tipo Dicionário. . . . . . . . . . . . . . . . . . 9

3.2 Exemplificação de uma estrutura tipo Thesaurus. . . . . . . . . . . . . . . . . . 9

3.3 Exemplificação de uma estrutura tipo Taxonomia. . . . . . . . . . . . . . . . . . . . 10

3.4 Camadas RDF e RDFS. . . . . . . . . . . . . . . . . . . . . . 13

3.5 Grafo representando um exemplo de base de conhecimento entre pessoas. . . . . . . . 17

4.1 Página de um currículo, com ênfase no identificador. . . . . . . . . . . . . . . . . . 22

4.2 Tela principal da busca por currículo. . . . . . . . . . . . . . . . . . . 22

4.3 Tela com o resultado da busca por "Renata Wassermann" . . . . . . . . . . . . . . 23

4.4 Tela principal da busca avançada por currículo. . . . . . . . . . . . . . . . 23

4.5 Rede de Colaboração do professor Marcelo Finger. . . . . . . . . . . . . . . . . . . 24

4.6 Tela principal do sistema Painel Lattes. . . . . . . . . . . . . . . . . . . . . 25

4.7 Relatório do Painel Lattes, contendo a Evolução da Formação de Mestres. . . . . . . 26

4.8 Indicadores de Produção do currículo da Professora Doutora Renata Wassermann. . 27

4.9 Grafo de Colaboração entre Pesquisadores. . . . . . . . . . . . . . . . . . . . . . . . 29

5.1 Gráfico representando a arquitetura do sistema e suas camadas. . . . . . . . . . . . . . 34

5.2 Exemplo de uma propriedade inferida. . . . . . . . . . . . . . . . 37

6.1 Página Inicial. . . . . . . . . . . . . . . . . . . . . . . . . . . . . . . . . . . . . 39

6.2 Página de membros do LIAMF do SOS Lattes. . . . . . . . . . . . . . . . . . . 40

6.3 Página de Artigos Publicados. . . . . . . . . . . . . . . . . . . . . . . . . 41

6.4 Página de Orientações em Andamento. . . . . . . . . . . . . . . . . . . . . . . . . . 42

6.5 Página de Inconsistências. . . . . . . . . . . . . . . . . . . . . . . . . 43

6.6 Exemplo de Pergunta e Resultados Obtidos. . . . . . . . . . . . . . . . . . . . . . 44 


\section{Capítulo 1}

\section{Introdução}

Neste capítulo vamos discutir a problemática existente na Web referente a dificuldade de desenvolvimento de agentes de software para navegação e extração de informações. Discutiremos também o caso real de aplicação deste problema abordado neste trabalho, a Plataforma Lattes, bem como as propostas de soluções já desenvolvidas para sua resolução. Ao final, constam os objetivos que propomos atingir neste trabalho e o público-alvo.

\subsection{Motivação}

Diversos foram os benefícios que a Web trouxe para a sociedade. Inicialmente, ela foi concebida apenas para compartilhar documentos (denominados páginas) e estabelecer vínculos entre estes (por meio de hiperlinks). As páginas disponibilizadas eram estáticas, ou seja, não tinha interação com o consumidor.

Com o passar do tempo, a Web passou a oferecer uma interface de fácil comunicação entre consumidores e produtores, tornando difícil definir seus papéis (um exemplo bem conhecido são os blogs, em que um leitor pode expressar sua opinião sobre a postagem, fomentando a discussão). A esta nova era na Web chamamos de Web 2.0.

O termo "Web 2.0" foi cunhado por Tim O'Reilly (apud. Governor et al. (2009)). Ele afirma "Web 2.0 é revolução dos negócios na indústria de computadores causada pelo movimento da internet como uma plataforma, e uma tentativa de entender as regras do sucesso desta nova plataforma. A regra principal é a seguinte: a construção de aplicações que aproveitem os efeitos da rede para que mais pessoas possam utilizá-las".

Todavia, houve também o crescimento colossal da quantidade de informação disponível e acessada na rede. Este volume teve um crescimento ainda mais acelerado com o advento da Web 2.0 (a partir do ano de 2004).

Segundo Allemang e Hendler (2008), "uma informação 'web' é uma entidade orgânica que cresce por meio da Internet e pela energia da comunidade que a apoia". Pode-se afirmar, portanto, que a quantidade de informações da Web cresce em proporção à adoção e utilização dos usuários.

Stair e Reynolds (2009) afirmam que nos últimos anos, a Web evoluiu de um recurso unidirecional, em que os usuários apenas obtinham informações, para um recurso bidirecional, em que os usuários obtêm informações e contribuem com elas.

Baeza-Yates e Ribeiro-Neto (1999) chamam esta evolução de "Era e-Publishing". Eles afirmam que as pessoas podem publicar suas ideias na Web e atingir milhões de pessoas em uma noite, sem pagar nada por isto e sem ter que convencer um conselho editorial de uma grande empresa de publicação.

Além disto, Heath e Bizer (2011) citam que "a habilidade para qualquer um adicionar novos documentos na Web e estes serem descobertos automaticamente pelos motores de buscas e pelos usuários em seus navegadores, tem sido (historicamente) os principais impulsionadores do crescimento explosivo da Web". 
Os motores de buscas (descrito com mais detalhes na seção 2.1.2) foram uma das ferramentas que ganhou grande destaque na busca de informações na Web. "Dado que a Web cresce de modo mais rápido e extenso que qualquer outra coleção de textos anterior, os motores de buscas agora tem que gerenciar um volume de texto que excede 20 bilhões de páginas", afirmam Baeza-Yates e Ribeiro-Neto (1999).

Entretanto, o que impede os motores de buscas evoluir na qualidade dos resultados é a forma como a Web disponibiliza seu conteúdo. Souza e Alvarenga (2004) afirmam que "a ênfase das tecnologias e linguagens atualmente utilizadas nas páginas Web focaliza os aspectos de exibição e apresentação dos dados, de forma que a informação seja pobremente descrita e pouco passível de ser consumida por máquinas e seres humanos" .

Para solucionar este problema, surge uma alternativa proposta e motivada por Berners-Lee et al. (2001): "A Web Semântica não é uma Web separada, mas uma extensão da atual, na qual a informação é fornecida com seu significado bem definido, permitindo que computadores e máquinas possam trabalhar melhor em cooperação". Descrevemos mais detalhes sobre Web Semântica no capítulo 2.

$\mathrm{Na}$ Web Semântica, a tecnologia está mais preocupada com a forma em que os dados são disponibilizados do que com a forma como são apresentados. Antoniou e Harmelen (2008) afirmam que "uma vez que os dados da Web estão organizados nestas estruturas, pesquisas baseadas em palavaschave serão substituídas por ferramentas que respondem perguntas". Esta estrutura é denominada ontologia (descrito em detalhes no capítulo 3).

Neste trabalho procuramos aplicar os conceitos da Web Semântica dentro de um contexto de busca de informações real: a Plataforma Lattes (PL).

A Plataforma Lattes é uma base de dados pública, disponibilizada pelo CNPq (Conselho Nacional de Desenvolvimento Científico e Tecnológico), que pretende reunir dados de currículos de pesquisadores, grupos de pesquisas e instituições de ensino. Agências de fomento, centros de pesquisas e departamentos das universidades utilizam a plataforma para extrair dados dos pesquisadores para análise de currículos.

Embora a Plataforma disponibilize diversas ferramentas para extração de informações, ela deixa a desejar quando solicitamos consultas sobre um conjunto específico de pessoas como, por exemplo, os funcionários de um departamento de pesquisa ou os orientandos de um grupo de orientadores.

Diversos trabalhos propuseram a resolução deste problema (descrito em detalhes no capítulo 4), dentre eles o Semantic Lattes e o OntoLattes que estruturam os dados em forma de ontologia. O scriptLattes, no entanto, provê uma forma de exportar relatórios consolidados em páginas HTML estáticas, sem manter uma estrutura de dados.

A tabela abaixo contém um resumo de funcionalidades alvo e em quais ferramentas são encontradas: 
Tabela 1.1: Tabela Comparativa de Funcionalidades e Ferramentas.

\begin{tabular}{|l|c|c|c|c|}
\hline Funcionalidade & scriptLattes & Semantic Lattes & OntoLattes & Projeto Sucupira \\
\hline $\begin{array}{l}\text { Extração dos dados da plata- } \\
\text { forma (XML e HTML) }\end{array}$ & $\sqrt{ }$ & $\chi$ & $\chi$ & $\chi$ \\
\hline $\begin{array}{l}\text { Relatórios Consolidados de } \\
\text { Produções Bibliográficas }\end{array}$ & $\sqrt{ }$ & $\sqrt{ }$ & $\chi$ & $\sqrt{ }$ \\
\hline $\begin{array}{l}\text { Relatórios Consolidados de } \\
\text { Orientações }\end{array}$ & $\sqrt{ }$ & $\sqrt{ }$ & $\chi$ \\
\hline $\begin{array}{l}\text { Consultas utilizando lingua- } \\
\text { gem natural }\end{array}$ & $\chi$ & $\chi$ & $\sqrt{ }$ & $\chi$ \\
\hline $\begin{array}{l}\text { Dados estruturados em onto- } \\
\text { logia }\end{array}$ & $\chi$ & $\sqrt{ }$ & $\chi$ \\
\hline Uso de regras de inferência & $\chi$ & $\checkmark$ & $\chi$ & $\chi$ \\
\hline $\begin{array}{l}\text { Detecção de inconsistências } \\
\text { entre diferentes currículos }\end{array}$ & $\chi$ & $\chi$ & $\chi$ & $\chi$ \\
\hline
\end{tabular}

Após a análise destas ferramentas, no capítulo 5 propomos o desenvolvimento do SOS Lattes, que integra grande parte das funcionalidades existentes das ferramentas estudadas. Além disto, adicionamos à ferramenta a funcionalidade de detecção de inconsistências e descoberta automática de conhecimento por meio de regras de inferência.

O nome SOS Lattes possui um dúbio sentido: O acrônimo de Semantic Ontology-based Script Lattes, as três ferramentas utilizadas como base deste trabalho, e $S O S$ devido à nova funcionalidade de deteç̧ão de inconsistência, considerada pelos autores um excelente auxílio.

Este trabalho foi apresentado no X Encontro Nacional de Inteligência Artificial e Computacional (ENIAC), em outubro de 2013.

\subsection{Objetivo}

O objetivo da presente dissertação é a elaboração uma ferramenta, nos moldes da Web Semântica, que auxilie nas tarefas de extração e consulta de informações da Plataforma Lattes de um grupo específico de pessoas. Também procuramos neste trabalho reaproveitar as funcionalidades existentes em outras ferramentas existentes que também extraem dados do Currículo Lattes.

Como objetivos específicos, procuramos adicionar as seguintes funcionalidades:

- Extração dos dados da plataforma, seja por HTML ou XML (como já é feito pelo scriptLattes).

- Capacidade de incluir novos currículos à lista de membros (sem que, para isto, possamos ter de desfazer dos dados já obtidos).

- Organizar os dados em forma em uma ontologia, para que pudéssemos utilizar de regras de inferência e fazer manutenção nos dados. Para isto, utilizamos as ontologias OntoLattes e Semantic Lattes.

- Exibir relatórios consolidados de produções bibliográficas e orientações (semelhante ao scrip tLattes).

- Relacionar dados existentes entre dois ou mais currículos e exibir inconsistências.

- Reaproveitar consultas por meio de linguagem natural (já desenvolvido no Semantic Lattes). 


\subsection{Público-alvo}

O público-alvo que buscamos atingir com este trabalho é:

- Organizações que lidam com informações relacionadas aos pesquisadores: Agências de fomento, centros de pesquisas e departamentos de universidades;

- Empresas e pessoas interessadas em Web Semântica;

- Cientistas na área de Inteligência Artificial, Linguística, Engenharia de Software, Organização e Recuperação da Informação.

\subsection{Organização}

Este documento está organizado da seguinte forma:

- O capítulo 2 tem por objetivo apresentar os principais conceitos e tecnologias acerca do tema Web e Web Semântica, para servir de arcabouço para o desenvolvimento do projeto.

- O capítulo 3 apresenta os conceitos sobre ontologias (estruturas de dados utilizadas pelas aplicações Web Semânticas).

- O capítulo 4 apresenta o caso de uso investigado neste trabalho: A Plataforma Lattes. Iremos discorrer sobre suas ferramentas e limitações. Também são tratados neste capítulo os trabalhos que propuseram estender suas funcionalidades.

- O capítulo 5 apresenta os esforços feitos no desenvolvimento da ferramenta SOS Lattes.

- No capítulo 6 é possível consultar os resultados obtidos da ferramenta desenvolvida.

- No capítulo 7 apresentamos as conclusões deste trabalho, bem como as propostas de trabalhos futuros.

- O Apêndice A contém as consultas SPARQL criadas para a aplicação e o Apêndice B contém as regras de inferências. 


\section{Capítulo 2}

\section{Web Semântica}

Neste capítulo descrevemos alguns dos conceitos aplicados à Web e Web Semântica.

\subsection{Web}

World Wide Web (WWW), ou simplesmente Web, é um espaço de informações na qual os itens de interesse, chamados de recursos, são localizados por um identificador global chamado de identificador de recurso uniforme (URI). Em razão da vasta quantidade de informações disponíveis na Web e da ampla variedade de meios, tornou-se o meio mais popular de acesso às informações.

Ela foi desenvolvida por Tim Berners-Lee em 1989, inicialmente para ser um sistema interno de gerenciamento de documentos. Desse modesto início, cresceu para um conjunto de dezenas de milhões de computadores servidores que trabalham em conjunto como um único.

A Web foi construída sobre a plataforma da Internet, composta por uma série de dispositivos interconectados, computadores e redes e que trabalham de forma interoperável a partir de um conjunto de padrões e protocolos, por exemplo: TCP/IP, TLS/SSL, FTP, etc. O fato da Web ser hoje a maior rede de dispositivos conectados se dá graças à arquitetura em que a Internet foi construída. Governor et al. (2009) diz que "a Internet é, de fato, uma ambiente do tipo Bus (canal compartilhado comum, através do qual as comunicações podem ser encaminhadas para vários nós registrados); ou seja, componentes podem ser adicionados e excluídos sem afetar o estado global do sistema. A Internet não precisa que todos os dispositivos estejam conectados simultaneamente".

O World Wide Web Consortium (W3C ${ }^{1}$ ) é uma comunidade internacional onde os membros organizadores (trabalhando em tempo integral) e o público somam esforços para desenvolver padrões para a Web. Liderado pelo inventor da Web Tim Berners-Lee e por Jeffrey Jaffe, o W3C tem a missão de liderar o WWW para o seu potencial máximo, desenvolvendo protocolos e diretrizes que garantam o crescimento à longo prazo da Web.

\subsubsection{Protocolos e Linguagens}

$\mathrm{Na}$ Web, assim que um Agente Web informa um URI em um navegador, é esperado que o resultado obtido seja uma representação do recurso em algum formato padronizado, de forma que o navegador saiba renderizar os dados recebidos. Estes recursos estão armazenados em Servidores Web, todos conectados à Internet. Dizemos "formato padronizado" pois um dos objetivos da Web, desde do início, tem sido a construção de uma comunidade global, no qual qualquer um pode compartilhar informações com qualquer outro. Para tanto, faz-se necessário uma adoção global de protocolos para facilitar esta interação.

Normalmente a representação dos recursos são disponibilizados em formato de páginas Web, formatadas por meio de hipertexto (documentos que podem ser compostos por textos, imagens, sons, vídeos, animação, aplicativos e vínculos para outros documentos).

Dentre os protocolos mais amplamente difundidos desenvolvidos pela W3C estão:

\footnotetext{
${ }^{1}$ http://www.w3.org/Consortium/
} 
1. HTTP: Hypertext Transfer Protocol, ou Protocolo de Transferência de Hipertexto, é um protocolo de mensagens baseado em textos construído sobre outro protocolo (TCP/IP Transmission Control Protocol / Internet Protocol ou Protocolo de Controle de Transmissão / Protocolo de Interconexão) e manipula as ações solicitadas dos navegadores Web para interagir com recursos Web (Governor et al. (2009)).

2. HTML: Hypertext Markup Language, ou Linguagem de Marcação para Hipertexto, é um padrão de linguagem baseado em rótulos (tags) em que as páginas Web são escritas. Por meio de rótulos já pré-definidos, os navegadores são capazes de interpretar um documento em HTML e renderizar seu conteúdo, formando uma página Web. É derivado de outra linguagem, chamada SGML (Standard Generalized Markup Language).

3. XML: Extensible Markup Language, ou Linguagem de Marcação Extensível, é um padrão de linguagem baseado em rótulos, também derivado do SGML. Diferentemente do HTML, seus rótulos não são pré-definidos, mas extensíveis utilizando DTD (Document Type Definition) ou XML Schema.

4. XHTML: Definições dos rótulos HTML utilizando o padrão XML.

Protocolos e linguagens desenvolvidos por outras comunidades também possuem boa aceitação na Web, como por exemplo: JavaScript e JSON. Este primeiro trata-se de uma linguagem de programação utilizada pelos navegadores para alterar o conteúdo de um documento HTML ou XHTML, permitindo ainda solicitar recursos do servidor (conhecido como AJAX). JSON (Javascript Object Notation) é um formato de estrutura de dados compatível com a linguagem JavaScript.

\subsubsection{Motores de Buscas}

Como descrito na seção 1.1, muitos foram os fatores que contribuíram para o aumento exponencial na quantidade de dados na Web. Devido a esta evolução, a área de Recuperação de Informação (IR ou Information Retrieval) teve papel fundamental no desenvolvimento de técnicas e propostas de soluções para recuperar páginas Web.

Uma das grandes contribuições foi o desenvolvimento de Motores ou Máquinas de Buscas. Seu principal objetivo é percorrer as páginas Web, formar um enorme índice e disponibilizar consultas por palavras-chave aos usuários. Laudon e Laudon (2011) afirmam que as primeiras máquinas de busca eram simplesmente índices de palavras-chave oriundas de todas as páginas que elas visitavam.

Larry Page e Sergey Brin, ao criarem o motor de busca da Google ${ }^{2}$, adicionaram um algoritmo de ordenação chamado PageRank System, que mede a popularidade de uma página Web calculando quais outros sites fazem referência para aquela página. Além disto, o programa que vasculha a Web (também chamado de crawler) indexava não somente palavras-chave, mas também combinações de palavras.

Com o aumento na receita da publicidade pela Web, os motores de busca ganharam destaque no chamado marketing de máquina de busca. Quando um usuário insere um termo de busca, recebe dois tipos de listas: os links patrocinados, quem levam ao site dos anunciantes que pagaram para ser listados; e os resultados de busca "orgânicos", ou não patrocinados. Neste sentido, é possível vislumbrar a urgência que o mercado possui para a criação de ferramentas que consigam captar, de maneira mais assertiva, a necessidade do usuário em visualizar resultados com o máximo de relevância.

Entretanto, segundo Souza e Alvarenga (2004), "a ênfase das tecnologias e linguagens atualmente utilizadas nas páginas Web focaliza os aspectos de exibição e apresentação dos dados, de forma que a informação seja pobremente descrita e pouco passível de ser consumida por máquinas e seres humanos".

\footnotetext{
${ }^{2}$ www.google.com
} 
Berners-Lee et al. (2001) confirmam ao dizer que "grande parte do conteúdo disponível hoje na Web é projetado para leitura humana, e não para programas de computadores que manipulam significados". Isto dificulta o trabalho dos motores de buscas, empobrecendo a qualidade das consultas.

\subsection{Web Semântica}

Para solucionar este problema, surge uma alternativa proposta e motivada por Berners-Lee et al. (2001): "A Web Semântica não é uma Web separada, mas uma extensão da atual, na qual a informação é fornecida com seu significado bem definido, permitindo que computadores e máquinas possam trabalhar melhor em cooperação".

Antoniou e Harmelen (2008) citam que o objetivo da Web Semântica é representar o conteúdo da web de uma forma que seja mais fácil para máquinas processarem e usar técnicas inteligentes que se beneficie destas representações.

Abaixo consta um exemplo simples (porém didático) de como funciona a Web Semântica, adaptado do site How Stuff Works ${ }^{3}$ :

Digamos que alguém esteja interessado na compra de um determinado item pela Web e tenha alguns critérios básicos, como: Modelo, cor, menor preço disponível no mercado; precisa ser novo; não gostaria de pagar caro para entrega, mas não gostaria de esperar muito.

A rotina para executar esta tarefa através da Web como conhecemos hoje seria olhar diversos sites de compras de varejistas, comparando preços e condições de entrega. Além disto, poderíamos utilizar e-Shopping Agregation, sites que oferecem uma lista de ofertas de diferentes fornecedores e varejistas para um determinado item, como o Buscapé ${ }^{4}$ e Zoom ${ }^{5}$. Uma vez escolhido o local de compra e as condições, ainda seria necessário fazer todo o trabalho para compra (como cadastro no site, montagem e finalização do pedido de venda e pagamento).

Na Web Semântica, um agente de software receberia suas preferências e condições de compras. Este, então ,irá pesquisar na Web, encontrando a melhor opção e fará o pedido. Este ainda pode informar em um software de finanças pessoais o gasto e incluir na agenda o dia da chegada do item. Este agente também irá aprender sobre os hábitos e preferências para utilizar nas próximas compras.

Neste caso, o agente não irá observar páginas Web como o humano faz: Lendo textos e interpretando figuras. Sua pesquisa será feita por meio dos metadados (dados sobre dados; captura parte do significado dos dados) que identificam de forma clara o que o agente precisa saber. Parafraseando Tim Berners-Lee, estas ferramentas transformarão a Web - atualmente similar a um enorme livro em uma enorme base de dados.

Para que isto se torne realidade, Antoniou e Harmelen (2008) citam as tecnologias necessárias para sua implementação:

Metadados Explícitos Não é objetivo da Web Semântica desenvolver agentes superinteligentes capazes de ler páginas Web da mesma forma que humanos leem. Ao invés disto, propõem adicionar mais conteúdo às páginas, adicionando metadados. Estes serão utilizados para identificar e extrair informações das fontes da Web.

Ontologias Tipicamente, ontologias consistem de uma lista finita de termos e seus relacionamentos. Estes termos denotam importantes conceitos (classes de objetos) de um domínio. Estes serão utilizados como suporte nas buscas na Web, interpretar as informações coletadas e comunicar com outros agentes (discorreremos sobre este assunto em detalhes no capítulo 3).

Lógica O uso de reasoners (raciocinadores) automáticos, que podem deduzir (inferir) conclusões a partir de um determinado conhecimento, são importantes para a Web Semântica no sentido de

\footnotetext{
${ }^{3}$ http://computer.howstuffworks.com/semantic-web1.htm

${ }^{4}$ http://www.buscape.com.br/

${ }^{5}$ http://www.zoom.com.br/
} 
prover explicações de suas conclusões. Isto permitirá a construção de agentes Web semânticos mais confiáveis aos usuários.

Agentes São fragmentos de software que trabalham de forma autônoma e pró-ativa. Não se trata de agentes que irão substituir os usuários, mas que os auxiliarão nas tarefas de: vasculhar informações na Web, comunicar-se com outros agentes, comparar informações sobre as necessidades e preferências do usuário, selecionar certas escolhas e dar opções de escolhas ao usuário.

O próximo capítulo apresenta os conceitos que servirão de arcabouço para criação de ferramentas para a Web Semântica. 


\section{Capítulo 3}

\section{Ontologias}

Esta seção tem por objetivo apresentar os principais conceitos e tecnologias disponíveis na literatura sobre ontologia.

\subsection{Representação de Conhecimento}

King e Reinold (2009) descrevem as estruturas mais comuns utilizadas para organizar informação eletrônica:

- Dicionário: A principal proposta do dicionário é a definição de conceitos, haja vista que podem existir uma ou mais definições para cada termo. Alguns dicionários também exibem relações entre os conceitos, como sinônimo e antônimo. A figura 3.1 apresenta o conceito de dicionário em formato gráfico:

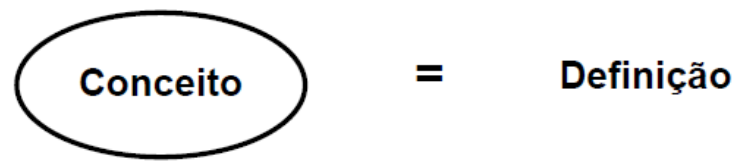

Figura 3.1: Exemplificação de uma estrutura tipo Dicionário.

- Thesaurus: Seu objetivo é listar palavras e seus sinônimos (um conceito é igual ou similar a outro conceito, no qual é igual a um terceiro, quarto e quinto conceito). Além da similaridade, pode-se incluir uma lista com mais relações, como antônimo, referência cruzada, derivação, variante e termo mais geral e mais específico. Sua limitação está no fato de não prover a definição e a maioria dos relacionamentos são construídos por igual ao, oposto ao, mais geral do que e mais específico do que. A figura 3.2 apresenta o conceito de forma gráfica:

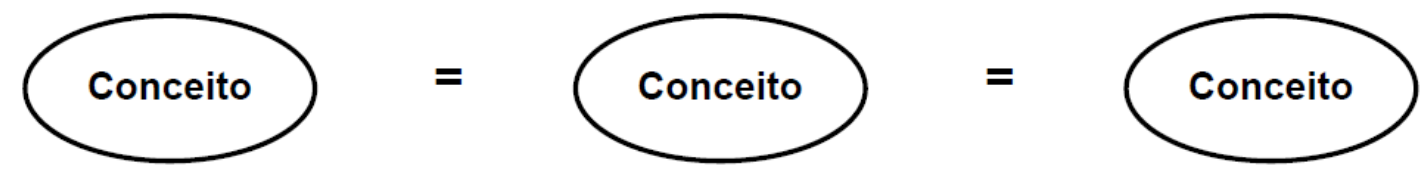

Figura 3.2: Exemplificação de uma estrutura tipo Thesaurus.

- Taxonomia: A principal proposta da taxonomia é posicionar conceitos de forma hierárquica, na qual cada conceito aparece, de preferência, em apenas uma categoria. A estrutura é definida na maneira como um conceito engloba outro conceito, em que engloba outro, estabelecendo 
um agrupamento de conceitos mais específicos e mais generalizados. A figura 3.3 exemplifica o conceito de taxonomia:

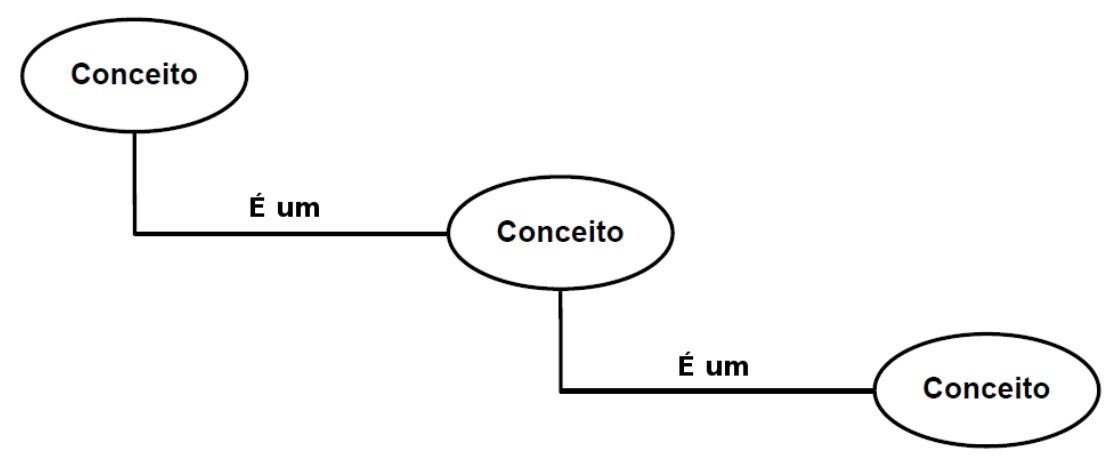

Figura 3.3: Exemplificação de uma estrutura tipo Taxonomia.

\subsubsection{Ontologias}

King e Reinold (2009) também afirmam que nenhuma das estruturas citadas na seção anterior oferecem definição, relacionamento e classificação ao mesmo tempo. Ontologias combinam elementos das três estruturas, permitindo a capacidade de exploração por todos estes ângulos.

Gruber (1993) define ontologia como "uma especificação explícita de uma conceitualização". Studer (apud Antoniou e Harmelen (2008)) refina esta definição como "uma especificação explícita e formal de uma conceitualização".

O trabalho de Guarino e Giaretta (1995) foi elucidar as implicações das diversas interpretações de termos como ontologia, conceitualização e compromisso ontológico. Seu objetivo foi definir uma terminologia clara para ser utilizada na comunidade de Engenharia do Conhecimento. Segundo eles:

- Ontologia (com 'O' maiúsculo) é o ramo da filosofia que lida com a natureza e a organização da realidade.

- ontologia (com 'o' minúsculo) pode significar tanto 'uma teoria lógica de uma explicitação, explicação parcial de uma conceitualização', quanto 'sinônimo de conceitualização'.

- Conceitualização é uma estrutura semântica intencional que codifica as regras implícitas e restringe a estrutura de parte da realidade.

\section{Linguagens}

Antoniou e Harmelen (2008) apresenta uma lista das mais importantes linguagens para Web que lidam com ontologias:

- RDF: Modelo de dados para objetos ("recursos") e suas relações. Provê uma semântica simples e podem ser representados por XML.

- RDF Schema: É a linguagem de descrição do vocabulário para descrever propriedades e classes de recursos RDF.

- OWL: É uma linguagem de descrição de ontologias mais rica.

\section{Suposição}

Antoniou e Harmelen (2008) destacam duas suposições importantes para ontologias aplicadas à Web Semântica, devido ao fato do conhecimento ser distribuído ao longo da Web. São elas: 
Suposição de mundo aberto Diz que nós não podemos concluir que alguma afirmação $x$ seja falsa simplesmente porque nós não podemos mostrar que $x$ é verdadeira. Em outras palavras, nós não concluímos falsidade a partir da ausência da verdade. Um exemplo: Se perguntarmos "Choveu em Tóquio ontem?", a suposição de mundo aberto diria "Eu não sei se choveu, mas isto não é o bastante para concluir que não tenha chovido".

Suposição de nomes não únicos Diz que dois nomes diferentes podem referenciar o mesmo individuo. Em um cenário social, em que os nomes "Prof. van Harmelen" e "Frank" dizem respeito a mesma pessoa, esta suposição faz sentido. Entretanto, em certos cenários esta suposição pode causar inconsistência, como por exemplo códigos de produtos em um catálogo, em que podemos afirmar que dois produtos são conhecidos por diferentes códigos.

\section{Lógica e Regras de Inferência}

Antoniou e Harmelen (2008) definem lógica como sendo a disciplina que estuda os princípios do raciocínio. Em geral, lógica oferece:

1. Conhecimento expresso por uma linguagem formal.

2. Semântica formal compreensível. Na maioria das lógicas, o significado das sentenças é definido sem a necessidade de operacionalizar o conhecimento.

3. Reasoners (motores de inferência) podem deduzir (inferir) a partir de um dado conhecimento, explicitando assim conhecimento implícito.

Segundo Berners-Lee et al. (2001), "Regras de inferência em ontologias fornecem mais possibilidades. Uma ontologia pode expressar a regra: 'Se o código de uma cidade está associado a um código de estado, e um endereço possui um código de cidade, então um endereço tem associação com o código de estado'. O computador não entende 'verdadeiramente' as informações, mas pode manipular os termos com muito mais eficácia, em se tratando de utilidade e significado, para os usuários humanos".

Costa e Yamate (2009) descrevem que, para que seja possível realizar inferências com uma ontologia e obter o conteúdo das informações, é necessário que essa representação seja composta por:

- Classes que descrevem os conceitos;

- Relacionamentos entre as classes;

- Propriedades das classes, e seus valores permitidos;

- Axiomas que representam as sentenças para restringirem o conhecimento;

- Instâncias de elementos individuais das classes para compor a base de conhecimento.

\subsection{Linguagens de Descrição}

Antoniou e Harmelen (2008) afirmam que os principais requisitos de uma linguagem utilizada para descrever ontologias são:

- uma sintaxe bem definida;

- uma semântica formal;

- conveniência (facilidade) de expressão;

- suporte a raciocínio eficiente; 
- suficiente poder de expressão (cobre casos suficientes).

As seções a seguir descrevem as principais linguagens utilizadas na Web Semântica para compartilhamento de informações e conhecimento.

\subsubsection{XML e Linguagens Correlatas}

XML (extensible markup language) é um formato de texto baseado em marcações (tags), criado pela W3C.

Segundo a especificação ${ }^{1}$, um objeto de dados é um documento XML se este está bem formatado e se cumpre certas restrições adicionais. Podemos dizer que um documento está bem formatado se:

- Observando-o como um todo, corresponde a um documento rotulado.

- Atende a todas as restrições de boa formatação presente na especificação.

- Cada uma das entidades referenciadas no documento (seja direta ou indiretamente) também estão bem formatadas.

Castaño (2008) comenta que "XML tem por objetivo principal facilitar o compartilhamento de dados estruturados através de sistemas de informações diferentes, principalmente via internet".

Este formato é aplicado para representação de estruturas em geral, não se limitando apenas em representar ontologias.

Antoniou e Harmelen (2008) citam que a principal vantagem do XML sobre o HTML é que a principal utilização do segundo é apresentar informações, sendo que o primeiro separa o conteúdo da formatação. Além disto, XML é uma metalinguagem de marcação, ou seja, não têm a função de fixar um conjunto de marcações (como HTML faz), mas permite aos usuários definir suas próprias. Eles apresentam um exemplo de código XML (adaptado para melhor compreensão):

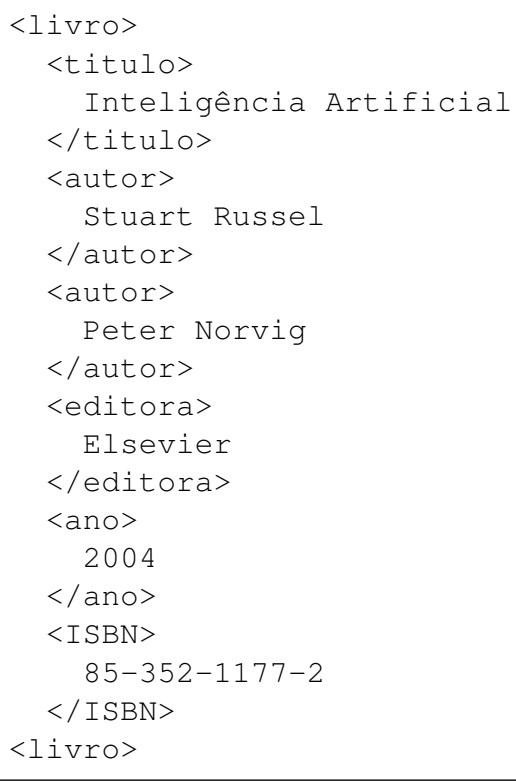

Tanto arquivos HTML quanto XML são facilmente compreendidos por leitores humanos. Entretanto, documentos XML são mais acessíveis por máquinas porque cada bloco de informação é descrito. No exemplo acima, a máquina é capaz de deduzir que o elemento autor refere-se ao elemento livro.

Para definir as estruturas de documentos XML, são utilizadas duas outras linguagens: DTD e XML Schema. A primeira é mais antiga e mais restrita, como por exemplo tipo de dados delimitados apenas como textos. Já XML Schema oferece uma linguagem mais rica porque ela mesma é baseada em XML, logo provê um importante ganho de legibilidade e permite reuso de tecnologia. Além disto,

\footnotetext{
${ }^{1}$ http://www.w3.org/TR/REC-xml/
} 
com XML Schema podemos definir novos tipos, estendendo ou restringindo tipos já existente, e provê um sofisticado conjunto de tipo de dados.

XSLT é uma linguagem de transformação de documentos XML em outros documentos.

Antoniou e Harmelen (2008) afirmam que "XSLT especifica regras com as quais um documento XML de entrada é transformado em outro documento XML, um documento HTML ou um texto simples".

\subsubsection{RDF / RDF Schema}

Costa e Yamate (2009) definem RDF como uma linguagem criada para ser utilizada na representação de recursos usado um vocabulário formal. As propriedades destes recursos são especificadas através de declarações (statements), que são expressas através de triplas. Uma tripla RDF é formada por: Um sujeito, um predicado e um objeto.

Antoniou e Harmelen (2008) afirmam que "embora seja frequentemente chamado de 'linguagem', RDF é essencialmente um modelo de dados. Seu bloco de construção padrão são triplas objetoatributo-valor, chamados de declarações. Tais declarações precisam de uma sintaxe concreta para ser representada e transmitida, e RDF tem sido amplamente representado utilizando XML (denominado $R D F / X M L)$ ". Entretanto, é importante ressaltar que representações sintáticas não baseadas em XML também são possíveis, como veremos a seguir.

Souza e Alvarenga (2004) listam alguns benefícios do padrão RDF:

- Provê um ambiente consistente para a publicação e utilização de metadados na web utilizando a infra-estrutura do XML;

- Provê uma sintaxe padronizada para a descrição dos recursos e propriedades dos documentos na Web;

- Permite que aplicações possam agir de forma inteligente e automatizada sobre as informações publicadas na Web, uma vez que seus significados são mais facilmente inteligíveis.

Em RDF Schema podemos definir o vocabulário, especificar quais propriedades são aplicadas a quais tipos de objetos e os valores que estes podem assumir, e descrever o relacionamento entre objetos.

Para exemplificar as diferenças entre RDF e RDFS, Costa e Yamate (2009) apresentam a figura 3.4 .

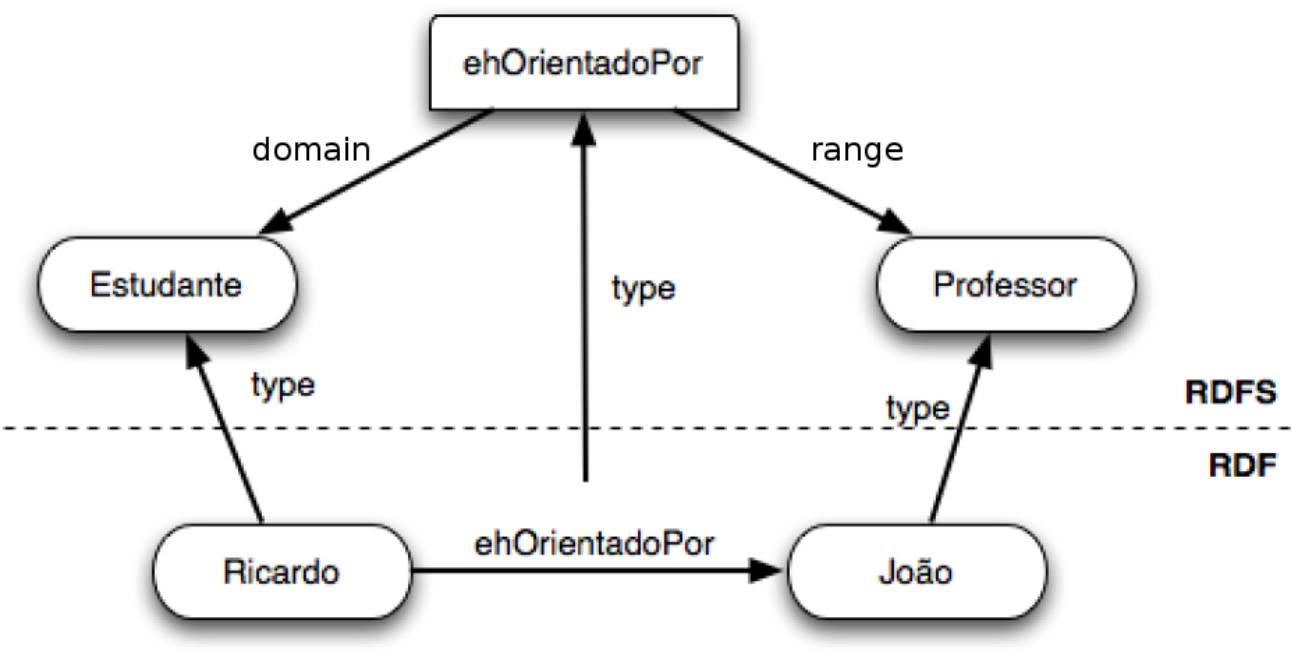

Figura 3.4: Camadas RDF e RDFS.

Um exemplo de RDF expresso em uma sintaxe baseada em XML é apresentado abaixo. Este define um professor e um curso: 


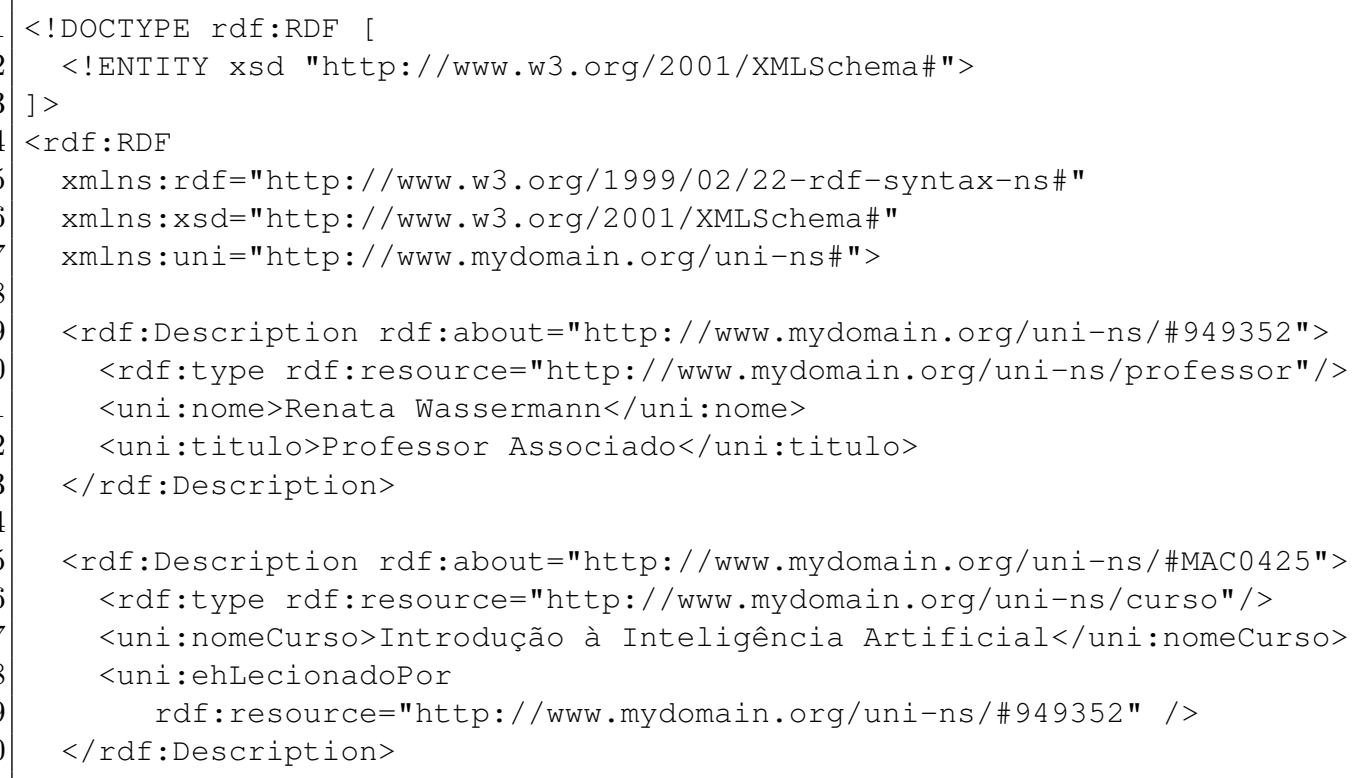

As linhas 5 a 7 definem três namespaces que serão utilizados nas próximas declarações. Eles são referências a documentos contendo outras declarações, auxiliando na tarefa de reuso de recursos.

As linhas 9 a 13 definem uma instância da classe professor, definindo as propriedades uni:nome e uni:titulo. As linhas 15 a 20 define uma instância da classe curso, definindo as propriedades uni:nomeCurso e uni:ehLecionadoPor. Todas as propriedades são referenciadas por um valor literal, com exceção deste último, que contém uma referência à instância professor.

As mesmas declarações acima são expressas abaixo utilizando outra forma de notação, chamada Notation 3 ou $N 3^{2}$ :

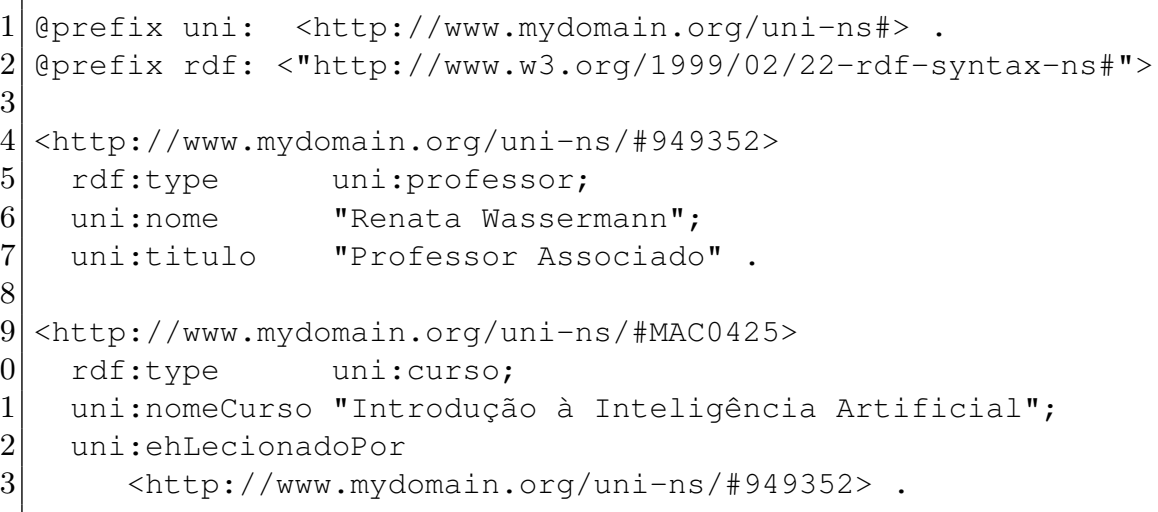

A notação N3 é equivalente a notação RDF-XML, porém sua estrutura facilita o entendimento para leitura humana.

O W3C concebiu uma sintaxe textual para RDF chamada de Turtle ${ }^{3}$ que permite que grafos RDF sejam completamente escritos em um formulário de texto natural e compacto, com abreviações para os padrões e tipo de dados mais utilizados. Trata-se de um subconjunto da sintaxe N3.

Um exemplo de outra notação (baseada em N3) chamada $N$-Triple $e^{4}$ é mostrado abaixo:

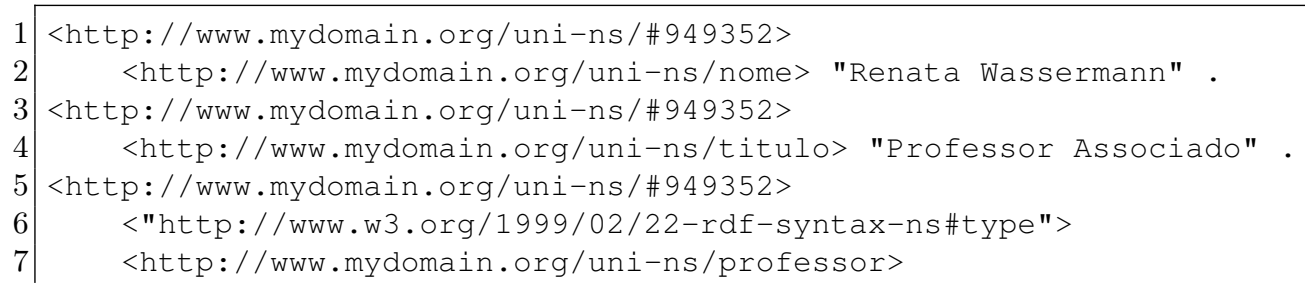

\footnotetext{
${ }^{2}$ http://www.w3.org/DesignIssues/Notation3.html

${ }^{3}$ http://www.w3.org/TR/turtle/

${ }^{4}$ http://www.w3.org/TR/n-triples/
} 
8

$9<$ http://www.mydomain.org/uni-ns/\#MAC0425>

$10<$ http://www.mydomain.org/uni-ns/nomeCurso>

11 "Introdução à Inteligência Artificial".

$12<$ http://www.mydomain.org/uni-ns/\#MAC0 425>

$13<$ <ttp://www.mydomain.org/uni-ns/ehLecionadoPor>

$14<$ http://www.mydomain.org/uni-ns/\#949352>.

$15<$ http://www.mydomain.org/uni-ns/\#MAC0 425>

16 <"http://www.w3.org/1999/02/22-rdf-syntax-ns\#type">

17 <http://www.mydomain.org/uni-ns/curso>

\subsubsection{OWL}

Segundo Antoniou e Harmelen (2008), Web Ontology Language - Linguagem de Ontologia Web (OWL) foi estabelecido pelo Grupo de Trabalho em Ontologia para Web do W3C como linguagem padrão para descrição de ontologia para a Web Semântica. Ela é o fruto da fusão de duas outras linguagens de descrição: DAML-ONT ${ }^{5}$ e $\mathrm{OIL}^{6}$. Por isto, inicialmente, era conhecida como DAML$\mathrm{OIL}^{7}$.

Antoniou e Harmelen (2008) dizem que "a linguagem OWL pode ser entendida como uma extensão do RDF Schema, utilizando dos conceitos já definidos (como rdfs:Class e rdfs: subclass) com objetivo de aumentar sua expressividade, tornando-a mais rica".

A linguagem com todos os recursos (chamada de OWL Full) é totalmente compatível com RDF, tanto sintaticamente quanto semanticamente: Qualquer documento RDF legal é também um documento OWL Full legal, e qualquer conclusão RDF/RDFS válida é também uma conclusão OWL Full válida. Entretanto, OWL Full, ao mesmo tempo que é poderosa, é também indecidível, ou seja, não existe atualmente um motor de inferência que seja completo e eficiente.

Para contornar o problema, o W3C propôs outras linguagens derivadas da OWL: OWL DL (description logic - lógica de descrição) e OWL Lite. Embora estes tenham algumas restrições no uso dos recursos (o que ocasiona expressividade restrita e perca da completa compatibilidade com $\mathrm{RDF}$ ), possuem motores de inferência mais eficientes.

\subsubsection{OWL 2.0}

Em 2009, o W3C estendeu as funcionalidades do OWL, definindo uma nova linguagem chamada OWL 2 (por causa disto, a definição anterior agora é chamada OWL 1). Os documentos técnicos de definições podem ser encontrados no site do W3C OWL Working Group ${ }^{8}$.

A compatibilidade do OWL 2 com OWL 1 é total e completa: Toda ontologia no formato OWL 1 permanece válida para OWL 2, com inferências idênticas em todos os casos práticos.

Foram inclusas novas funcionalidades. Algumas destas são "açúcar sintático" (por exemplo: união disjunta de classes), enquanto outras oferecem novas funcionalidades, como:

- Definições de chaves para identificar indivíduos de forma única, por exemplo: CPF de uma pessoa, número da placa e estado para um veículo automotivo.

- Propriedades em cadeia: Provê uma forma de definir propriedades a partir de uma composição de outras propriedades. Por exemplo: para definirmos a propriedade TIO, podemos utilizar as propriedades $P A I$ e IRMÃO.

- Tipo de dados mais ricos, faixa de dados.

- Restrições de cardinalidade qualificadas.

\footnotetext{
${ }^{5}$ http://www.daml.org/2000/20/daml-ont.html

${ }^{6}$ http://www.ontoknowledge.org/oil/

${ }^{7}$ http://www.daml.org/2001/03/daml+oil-index.html

${ }^{8}$ http://www.w3.org/TR/owl2-overview/
} 
- Propriedades assimétricas, reflexivas e disjuntas.

- Estende o uso de anotações, como um comentário ou uma descrição, permitindo aplicar na ontologia, entidades, indivíduos anônimos, axiomas e nas próprias anotações.

Foram definidos também três novos perfis (ou sub-linguagens):

- OWL 2 EL: É capaz de executar algoritmos em tempo polinomial para todas as tarefas padrões de raciocínio. É particularmente adequado para aplicações com grandes ontologias, nas quais capacidade de expressão pode ser trocada por garantia de performance.

- OWL 2 QL: É capaz de retornar consultas conjuntivas em tempo LogSpace usando tecnologia de banco de dados relacional. É particularmente adequado para aplicações nas quais ontologias relativamente leves são usadas para organizar um extenso número de indivíduos e nas quais é útil ou necessário acessar dados diretamente via consultas relacionais (exemplo: SQL).

- OWL 2 RL: É capaz de executar algoritmos de raciocínio em tempo polinomial usando tecnologias de banco de dados com regras estendidas diretamente sobre as triplas RDF. É particularmente adequado para aplicações que exigem alto grau de raciocínio (por meio de regras de inferência) sem, no entanto, comprometer o poder de expressividade.

A especificação também define uma sintaxe chamada de Estilo-Funcional ( Functional-Style Syntax $)^{9}$. Segue abaixo algumas declarações descritas nesta sintaxe:

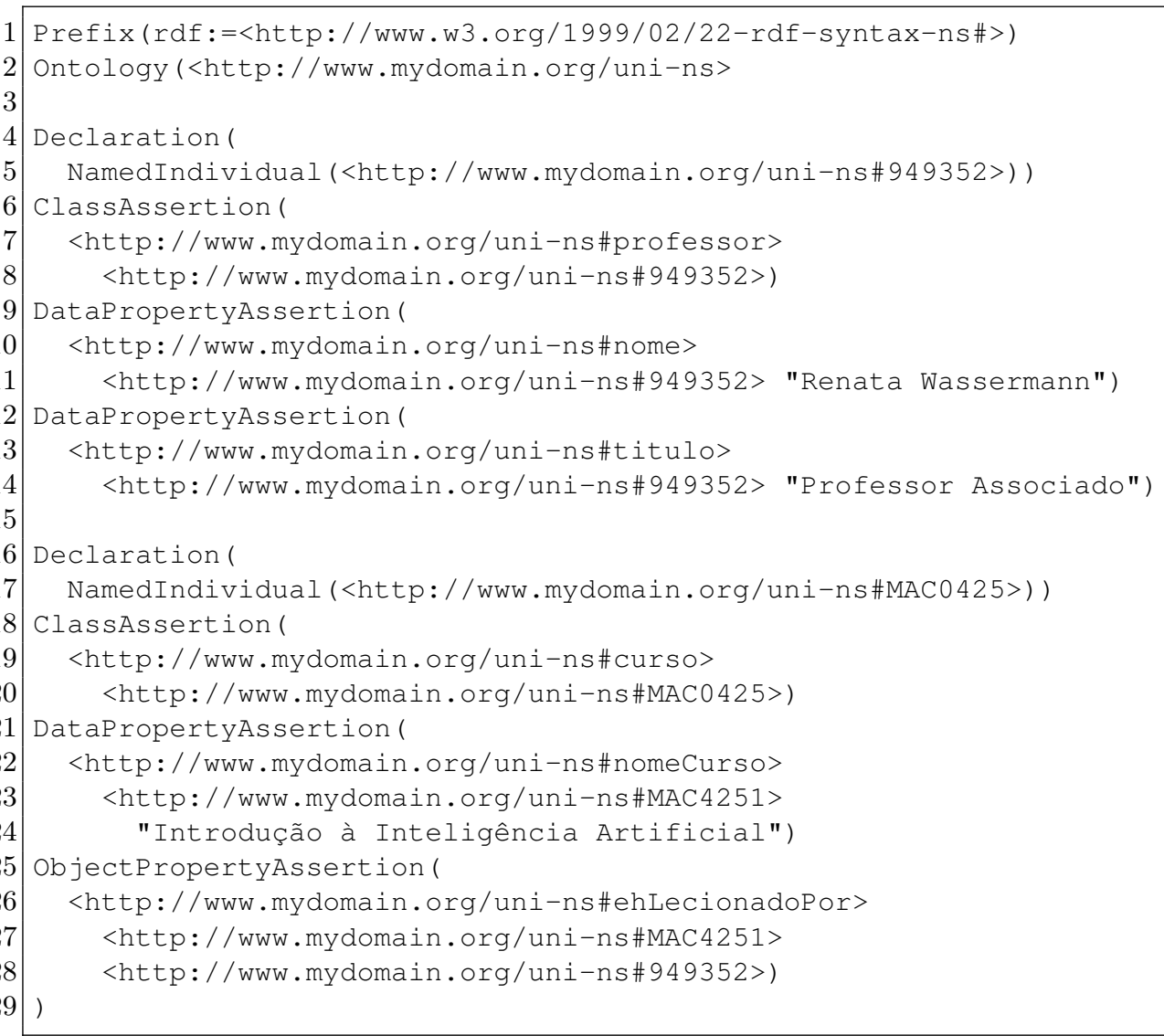

Foi adicionada também uma nova sintaxe, chamada OWL 2 Manchester ${ }^{10}$. É uma sintaxe mais amigável, definida para ser facilmente lida por usuários não-lógicos. Já existia na versão OWL 1, mas foi atualizada e formalmente adicionada na versão 2. Segue abaixo exemplo de expressões nesta sintaxe:

\footnotetext{
${ }^{9}$ http://www.w3.org/TR/owl2-syntax/

${ }^{10}$ http://www.w3.org/TR/owl2-manchester-syntax/
} 


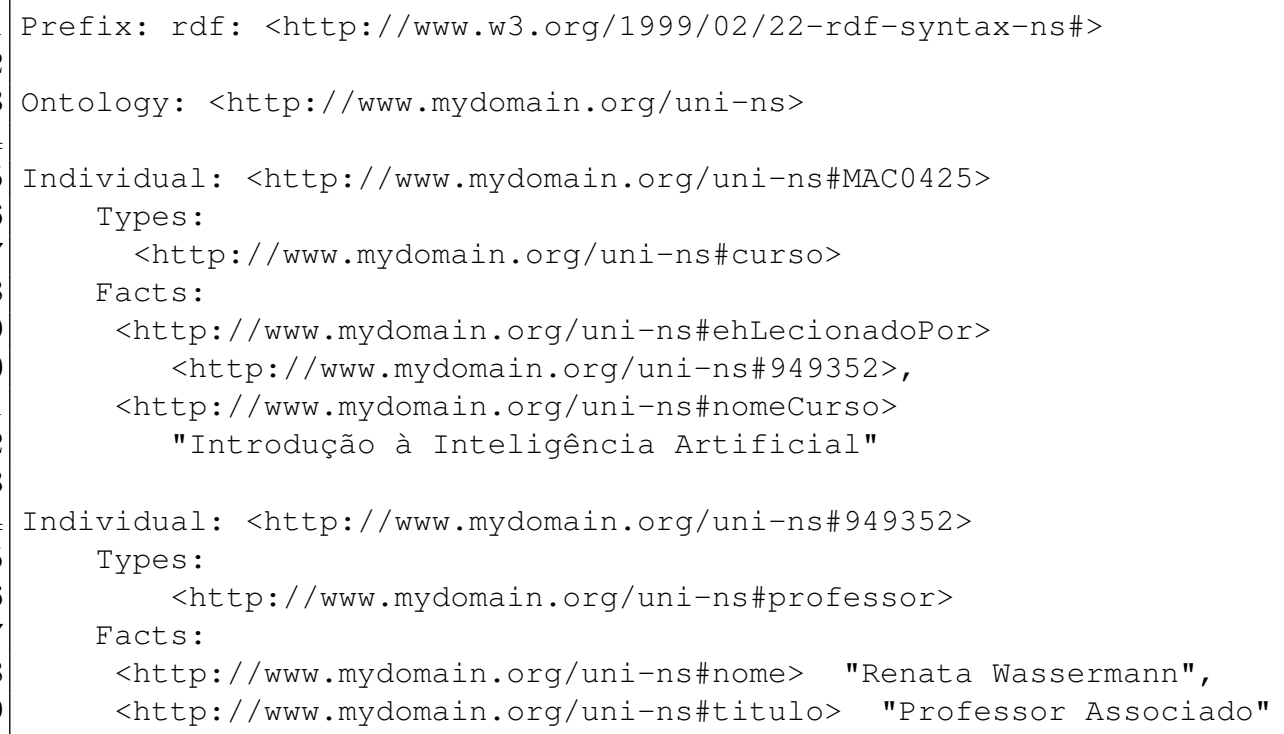

\subsubsection{SPARQL}

Segundo a especificação" , "SPARQL (atualmente na versão 1.1) é um conjunto de especificações que provê linguagens e protocolos para consultar e manipular grafos RDF disponíveis na Web ou em uma base de dados RDF. Assumindo que os dados estejam carregados em um serviço SPARQL, a linguagem de consultas SPARQL 1.1 pode ser usada para formular consultas que vão desde um simples esquema de reconhecimento de padrões até consultas complexas".

O documento também apresenta um exemplo de consulta (adaptado para o português):

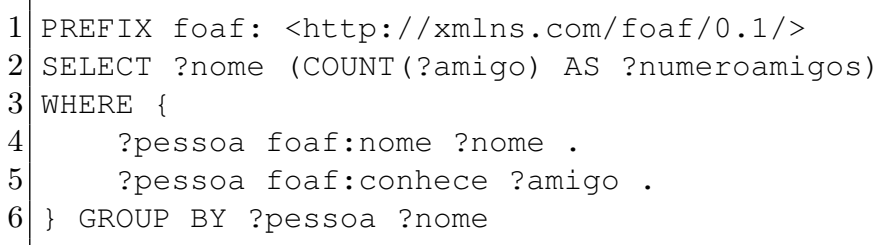

Neste exemplo (tirado de um cenário de redes sociais), a consulta irá retornar o nome e o número de pessoas que são seus amigos, podendo ser em diferentes formatos: XML, JSON (JavaScript Object Notation), CSV (Comma Separated Values) e TSV (Tab Separated Values).

Considerando que temos como exemplo uma base de conhecimento expressa na figura $3.5 \mathrm{em}$ formato de grafos:

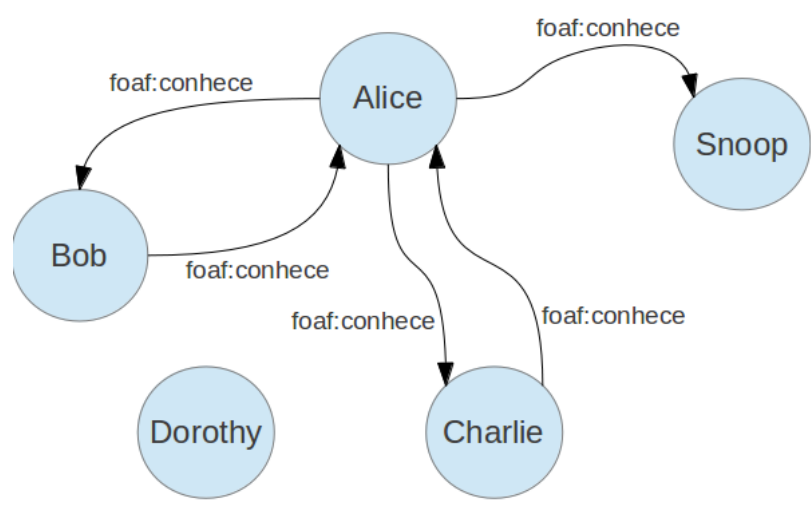

Figura 3.5: Grafo representando um exemplo de base de conhecimento entre pessoas.

\footnotetext{
${ }^{11}$ http://www.w3.org/TR/sparql11-overview/
} 
Segue abaixo um exemplo do resultado da consulta acima no formato CSV:

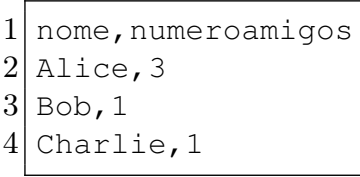

A especificação também define uma linguagem de manipulação de dados, chamada de Linguagem de Atualização SPARQL 1.1. No documento, são definidas as operações de atualização, criação e remoção de grafos RDF na base de dados RDF. O comando a seguir solicita ao serviço SPARQL a inserção de uma nova amiga para Alice chamada Dorothy e, posteriormente, apaga todos os nomes dos amigos de Alice que falam inglês:

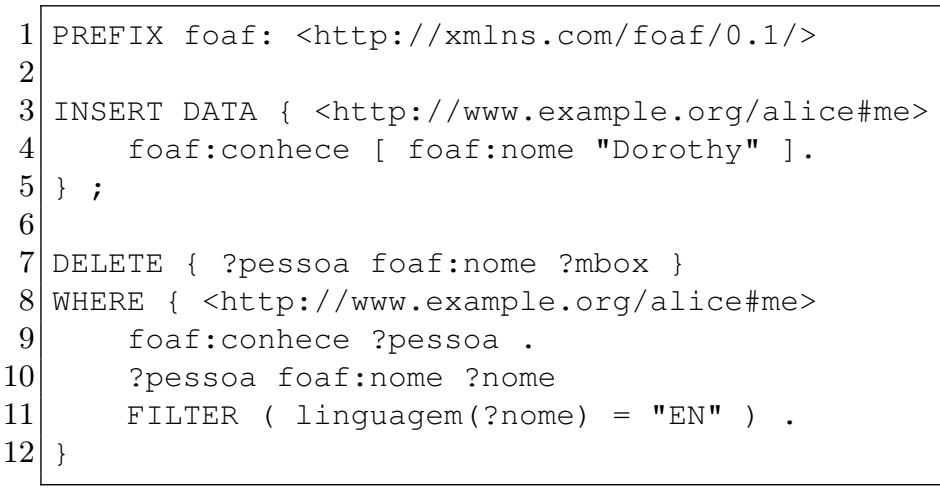

\subsubsection{Ferramentas e Implementações}

Abaixo iremos apresentar algumas das implementações existentes para manipular base de dados baseadas em ontologias utilizadas neste trabalho

\section{Frameworks}

Apache Jena ${ }^{12}$ é um Framework Java para construção de aplicações Web Semânticas. Jena provê uma coleção de ferramentas e bibliotecas Java para ajudar no desenvolvimento de aplicações, ferramentas e servidores para Web Semânticas e Linked-data. Este contém:

- Uma API para leitura, processamento e escrita de dados RDF nos formatos XML, N3 e Turtle.

- Uma API de manipulação de ontologias OWL e RDFS.

- Um motor de inferências baseado em regras para base de dados RDF e OWL.

- Permite armazenar eficientemente um alto número de triplas RDF em disco.

- Um motor de consultas compatível com a última especificação SPARQL.

- Servidores que permitem publicar dados RDF para outras aplicações utilizando uma variedade de protocolos, incluindo SPARQL.

OWL $A P I^{13}$ é outra API Java open source e implementação de referência para criação, manipulação e serialização de ontologias OWL. Sua última versão já implementa OWL 2.0. Este inclui os seguintes componentes:

- Uma API para OWL 2.0.

- Interpreta textos nos seguintes formatos: RDF/XML, OWL/XML, Sintaxe funcional OWL, Turtle, KRSS e OBO Flat.

\footnotetext{
${ }^{12}$ http://jena.apache.org/

${ }^{13}$ http://owlapi.sourceforge.net/
} 
- Interfaces para os reasoners $\mathrm{FaCT}++$, HermiT, Pellet e Racer.

RDFLib ${ }^{14}$ é um pacote desenvolvido em Python para trabalhar com RDF, contendo:

- Serializadores e analizadores para diversos formatos: RDF/XML, N3, N-Quads, Turtle, TriX, RDFa e Microdata.

- Implementações para armazenamento em memória e persistência utilizando Berkeley DB (banco de dados embarcado).

- Suporte a última especificação da Linguagem de Consultas e Atualização SPARQL.

\section{Motores de Inferência}

Segundo Dentler et al. (2011), um motor de inferência (ou reasoner) é um programa que infere consequências lógicas a partir de um conjunto de afirmações ou axiomas explicitamente declarados. A seguir estão alguns exemplos de motores de inferências disponíveis:

Pellet Mantido pela empresa Clark \& Parsiaß, o reasoner Pellet ${ }^{15}$ foi o primeiro motor de inferência que suportou todo OWL-DL e foi estendido para OWL 2.

Fact ++ Acrônimo de Fast Classification of Terminologies, o Fact $++{ }^{16}$ é mantido pela Universidade de Manchester. Suporta OWL-DL e um subconjunto de OWL 2. Foi implementado utilizando $\mathrm{C}++$ e com base em algoritmos otimizados de tableaux.

HermiT mantido pela Universidade de Oxford, HermiT ${ }^{17}$ pode determinar se uma determinada ontologia é consistente e identificar relações de subsunções entre conceitos, entre outras características. HermiT é baseado no cálculo "Hiper tableau", o qual providencia raciocínio mais eficiente do que os algoritmos conhecidos anteriores. Suporta todos os perfis de OWL 2.

RacerPro Versão comercial do software Racer (acrônimo de Renamed ABox and Concept Expression Reasoner), o motor de inferência RacerPro ${ }^{18}$ é mantido pela empresa Racer Systems $($. Implementa a lógica de descrição $\mathcal{S H \mathcal { L }}$ e contém otimizações dedicadas para OWL2-EL.

Dentler et al. (2011) contém um comparativo entre os motores de inferência citados acima e outros, como: CEL, Snorocket e TrOWL.

\footnotetext{
${ }^{14}$ https://rdflib.readthedocs.org

${ }^{15}$ http://clarkparsia.com/pellet

${ }^{16} \mathrm{http}: / /$ code.google.com/p/factplusplus/

${ }^{17} \mathrm{http:} / /$ www.hermit-reasoner.com/

${ }^{18}$ http://www.racer-systems.com/products/racerpro/
} 


\section{Capítulo 4}

\section{Plataforma Lattes}

Nossa principal proposta é aplicar os conceitos da Web Semântica dentro de um contexto real de busca de informações. O estudo de caso escolhido é o caso da Plataforma Lattes.

O capítulo a seguir apresenta a Plataforma Lattes, suas aplicações, funcionalidades e limitações. Apresentaremos também outras ferramentas que utilizam os seus dados e adicionam novas funcionalidades.

\subsection{A Plataforma}

Plataforma Lattes é uma base de dados pública, disponibilizada pelo CNPq (Conselho Nacional de Desenvolvimento Científico e Tecnológico), que pretende reunir dados de currículos de pesquisadores, grupos de pesquisas e instituições de ensino. Agências de fomento, centros de pesquisas e departamentos das universidades utilizam a plataforma para extrair dados dos pesquisadores para análise de currículos.

De acordo com a própria página da Plataforma Lattes ${ }^{1}$, "a disponibilização pública dos dados da Plataforma na internet dão maior transparência e mais confiabilidade às atividades de fomento do CNPq e das agências que a utilizam, fortalecem o intercâmbio entre pesquisadores e instituições e é fonte inesgotável de informações para estudos e pesquisas. Na medida em que suas informações são recorrentes e cumulativas, têm também o importante papel de preservar a memória da atividade de pesquisa no país".

\subsubsection{Captação e Armazenamento dos Dados}

Pesquisadores podem preencher os dados do seu currículo através do endereço https://wwws. cnpq.br/cvlattesweb/pkg_cv_estr.inicio. Os dados podem ser:

1. Dados pessoais do autor do currículo.

2. Dados da formação acadêmica e titulação.

3. Atuações profissionais.

4. Trabalhos em projetos de pesquisa.

5. Produções (bibliográficas, técnicas ou artísticas).

6. Apresentações em eventos.

7. Orientações em andamento ou concluídas.

\footnotetext{
${ }^{1}$ http://lattes.cnpq.br/
} 
Os dados preenchidos serão armazenados na Plataforma e disponibilizados publicamente na Web, tanto em formato HTML quanto em XML. Entretanto, certos dados somente são exibidos no formato XML.

A Comunidade para Ontologias em Ciência, Tecnologia e Informações de Aperfeiçoamento de Nível Superior (CONSCIENTIAS) ${ }^{2}$ é responsável pela concepção, elaboração, recomendação e manutenção das gramáticas relacionadas às ontologias submetidas pelas agências ou instituições conselheiras. Um de seus trabalhos foi estabelecer a padronização do formato XML dos Currículos Lattes.

Cada currículo armazenado na base Lattes recebe um número identificador. Este número tem especial atenção neste trabalho, pois é utilizado no momento da extração dos dados do currículo. Podemos encontrá-lo dentro do campo Endereço, conforme mostra a figura 4.1.

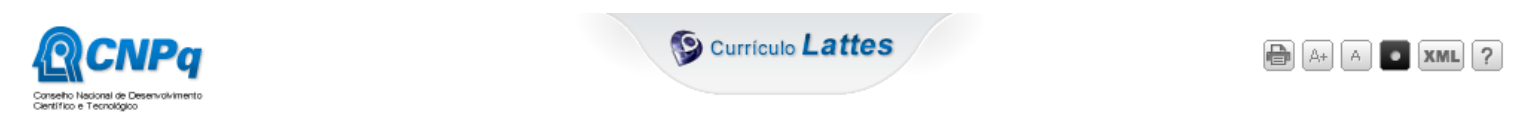

Dados gerais | Formaçâo | Atuaçầo |+

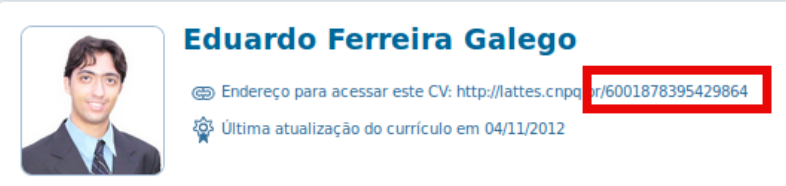

Possui graduação em Ciências da Computação pelo Centro Universitário Adventista de São Paulo(2006) e especialização em Desenvolvimento de Soluções Corporativas Java pela Faculdade de Informática e Administração Paulista(2009). Atualmente é Professor Titular da Faculdade Nossa Cidade,

Figura 4.1: Página de um currículo, com ênfase no identificador.

\subsubsection{Consultas de Dados}

A Plataforma também disponibiliza uma ferramenta para busca de currículos, através do endereço http://buscatextual.cnpq.br/buscatextual/busca.do?metodo=apresentar.

Os usuários que desejam procurar o currículo de alguma pessoa (seja ela professor, pesquisador, orientador, aluno, profissional etc.) armazenado na plataforma, poderão fazê-lo por meio de uma busca por nome. A figura 4.2 mostra a tela principal do sistema de busca:

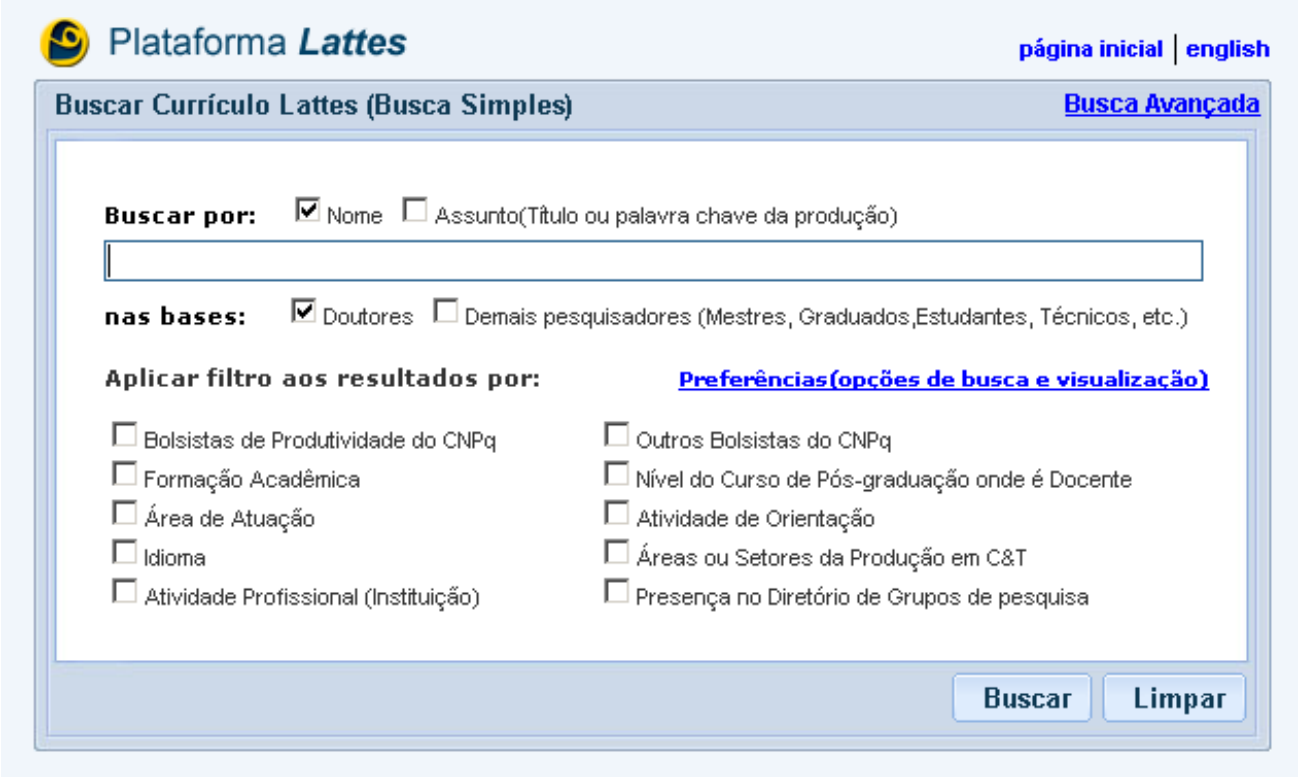

Figura 4.2: Tela principal da busca por currículo.

\footnotetext{
${ }^{2}$ http://lmpl.cnpq.br/lmpl/
} 
Para exemplificar, digamos que o usuário deseja buscar o currículo Lattes da Professora Doutora Renata Wassermann. Ao digitar o nome no campo de texto correspondente e solicitar a busca, o sistema faz uma busca pelo nome do pesquisador. A figura 4.3 traz a tela com o resultado obtido:

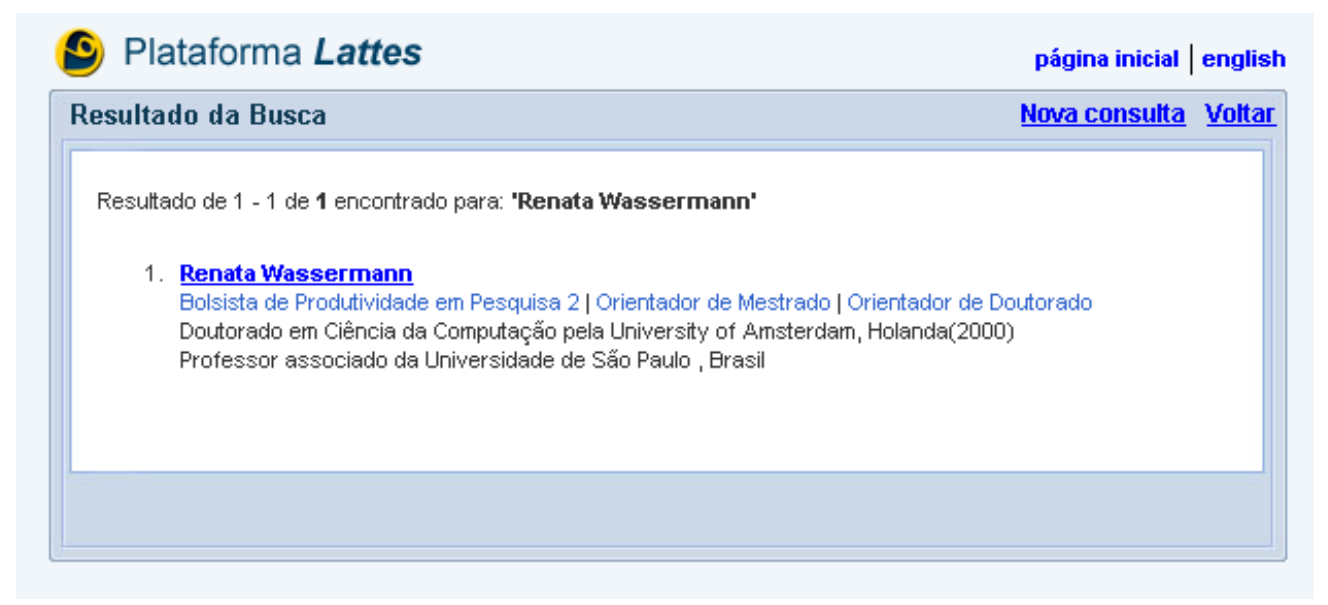

Figura 4.3: Tela com o resultado da busca por "Renata Wassermann"

A figura 4.4 mostra a busca para a opção "Avançada", caso um usuário deseje buscar um currículo por meio de palavras que estejam no currículo:

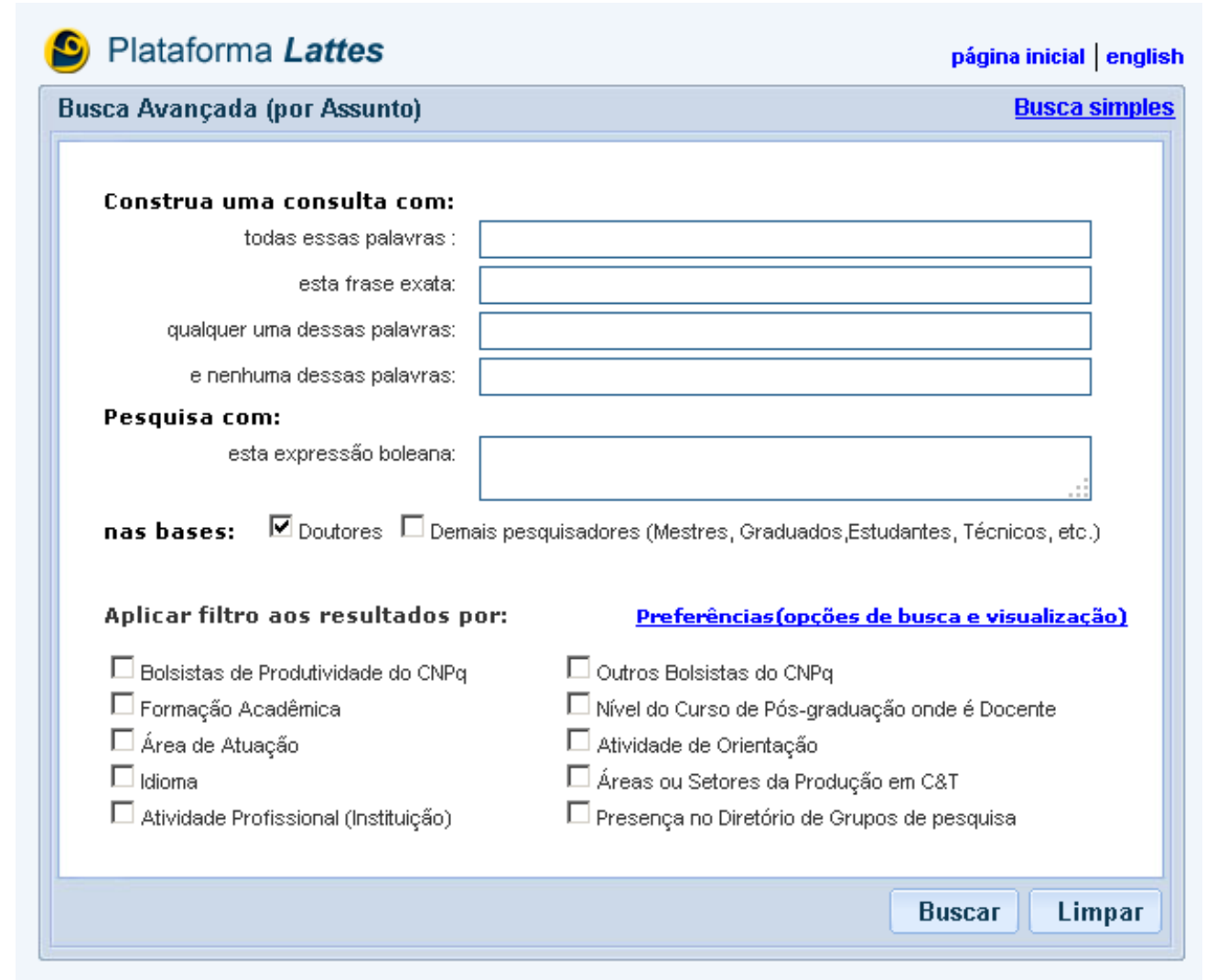

Figura 4.4: Tela principal da busca avançada por currículo.

\section{Rede de Colaboração}

A Plataforma Lattes exibe, na própria página do currículo, a rede de colaboração de um pesquisador em forma de grafo, na qual os vértices são os pesquisadores e as arestas são as co-autorias ou colaborações. 
Por se tratar de uma ferramenta interativa, podemos navegar entre os pesquisadores, visualizando o seu currículo, as colaborações, as áreas de atuação e sua rede de colaboração. A figura 4.5 apresenta um exemplo:

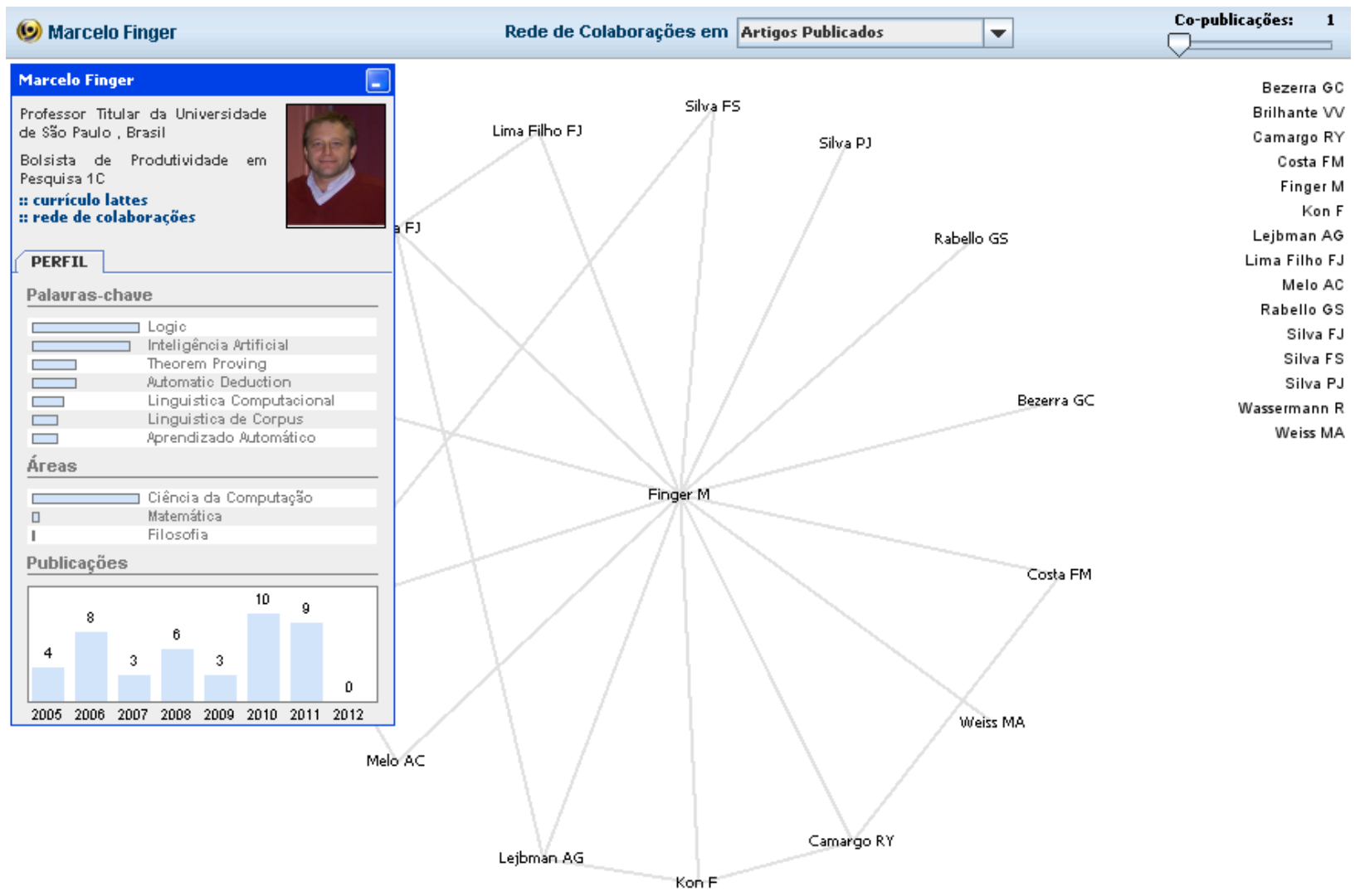

Figura 4.5: Rede de Colaboração do professor Marcelo Finger.

\section{Painel Lattes}

A Plataforma oferece relatórios estatísticos sintéticos dos dados armazenados por meio do endereço http://estatico.cnpq.br/painelLattes/.

A figura 4.6 traz a tela principal do Painel Lattes: 


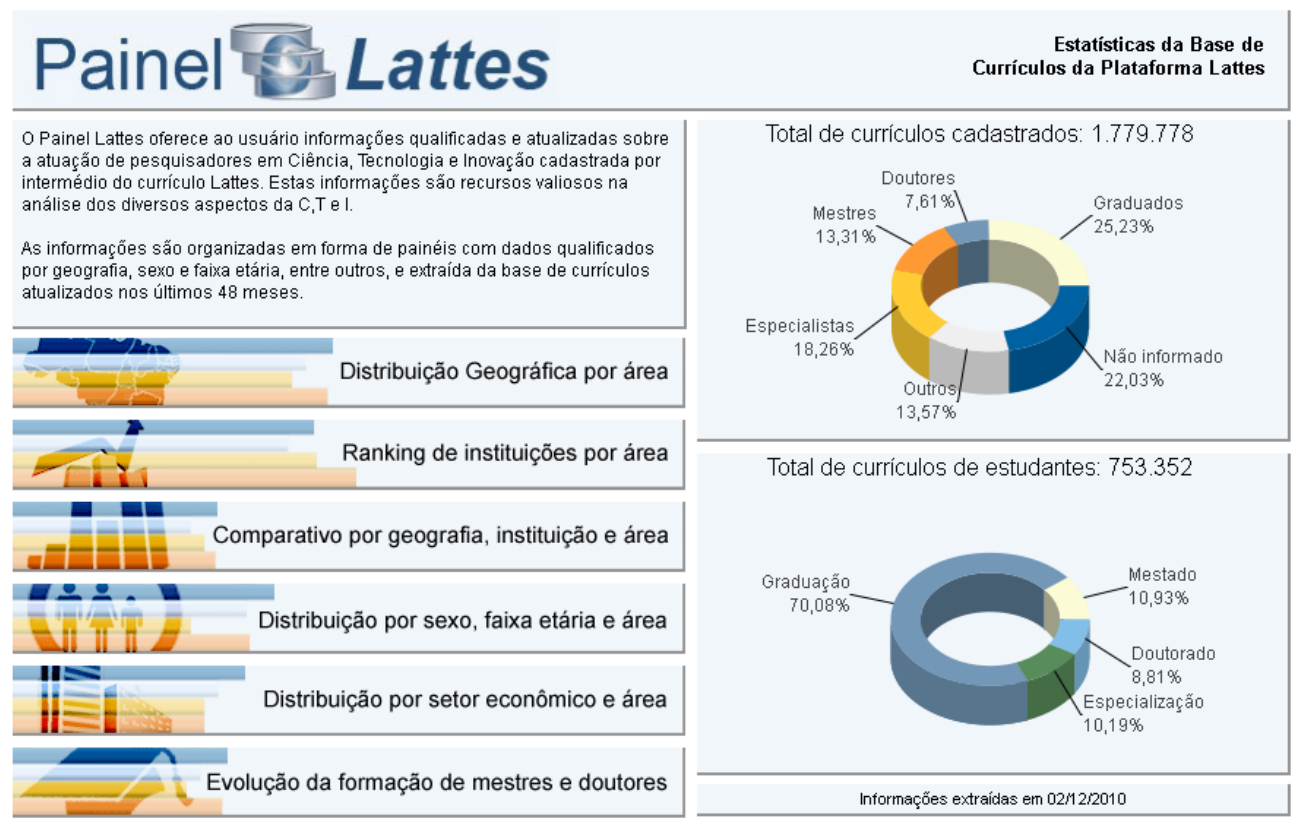

Figura 4.6: Tela principal do sistema Painel Lattes.

Segundo a página do Painel Lattes ${ }^{3}$, "o Painel Lattes oferece ao usuário informações qualificadas e atualizadas sobre a atuação de pesquisadores em Ciência, Tecnologia e Inovação cadastrada por intermédio do currículo Lattes. As informações são organizadas em forma de painéis com dados qualificados por geografia, sexo e faixa etária, entre outros, e extraída da base de currículos atualizados nos últimos 48 meses".

Trata-se de uma ferramenta valiosíssima para comparativos de desempenho entre instituições e regiões, além de exibir a evolução de formação de mestres e doutores no país.

A figura 4.7 abaixo apresenta um exemplo destes relatórios. Do lado esquerdo encontra-se a Evolução da Formação de Mestres no Brasil desde 1990 até 2012. Do lado direito está o número de mestres formados em 2012, agrupados por grande área (gráfico acima) e pelas Áreas de Ciências Exatas e da Terra (gráfico abaixo). Estes números correspondem aos dados extraídos em 18/12/2012 da Plataforma Lattes.

\footnotetext{
${ }^{3}$ http://lattes.cnpq.br/painelLattes/
} 


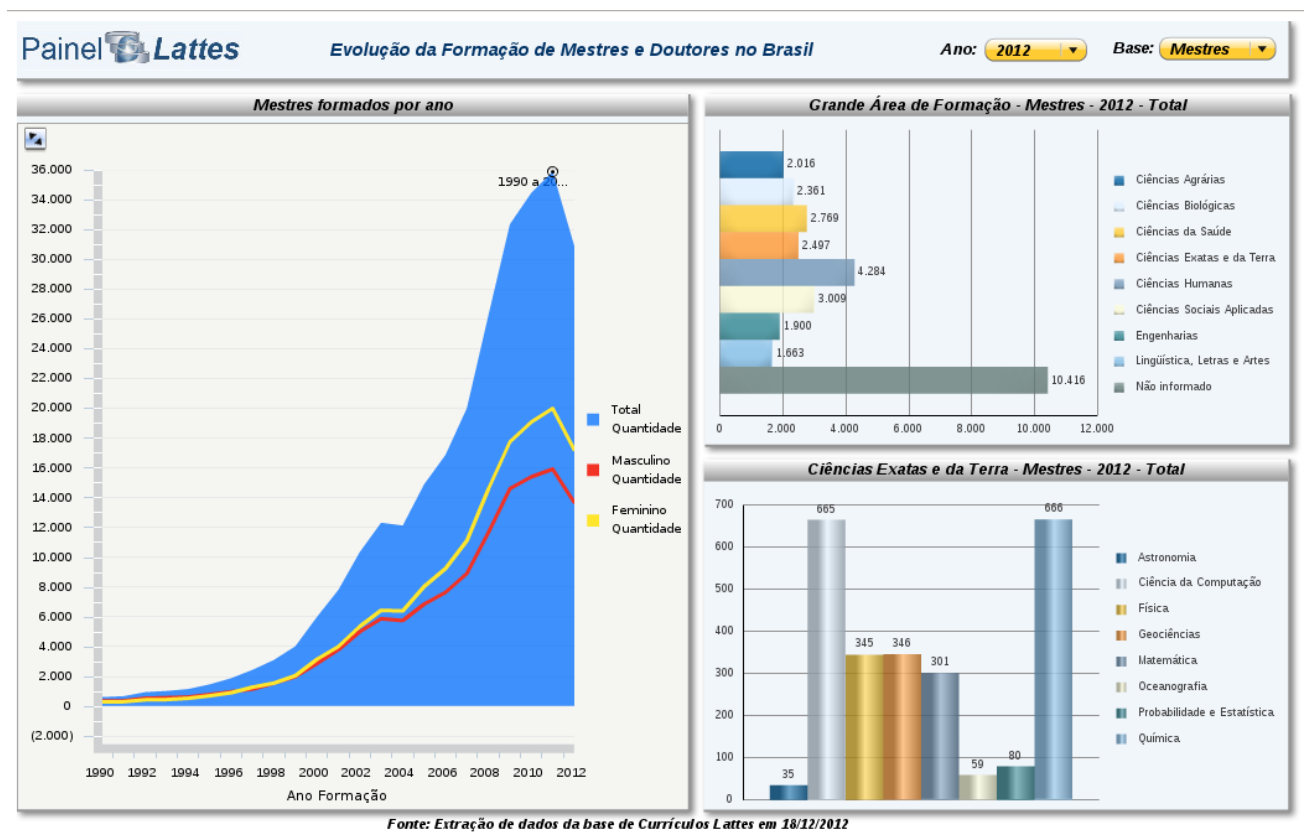

Figura 4.7: Relatório do Painel Lattes, contendo a Evolução da Formação de Mestres.

\section{Indicadores de Produção}

Podemos visualizar diversos gráficos a partir de um currículo, contendo informações como: Produções referenciadas em base de dados de citações (como Scopus ${ }^{4}$ e Web of Science ${ }^{5}$ ), quantidade de produções agrupadas por ano e tipo, quantidade de orientações concluídas agrupadas por ano e nível, número de produções agrupadas por periódico, número de produções agrupadas por co-autor.

A figura 4.8 contém um exemplo destes indicadores, obtidos a partir do currículo da Professora Doutora Renata Wassermann.

\subsubsection{Limitações}

Embora haja diversos meios e ferramentas para extração de informações da Plataforma, certas consultas são de difícil obtenção. Costa e Yamate (2009) trazem uma lista de perguntas que não são respondidas pela plataforma. Segue abaixo uma parte da lista:

1. Quais professores/pesquisadores publicaram em 2013? Destes, quantas publicações em conferências internacionais? E nacionais?

2. Quais são os professores/pesquisadores do Departamento de Matemática da USP? Quais destes possuem registro de publicação? Quais publicaram livros? Quais publicaram capítulos de livros?

3. Quais são os professores/pesquisadores que publicaram em coautoria com o $<$ nome pesquisador/professor $>$ ?

4. Quais são as teses de doutorado e dissertações de mestrado finalizadas sob orientação de algum professor do grupo nos últimos 5 anos?

5. Está havendo um crescimento no número de publicações se comparado aos anos anteriores?

6. Os dados de orientações informados pelo <nome pesquisador/professor $>$ estão condizentes com os informados pelos orientados?

\footnotetext{
${ }^{4}$ http://www.scopus.com

${ }^{5}$ http://thomsonreuters.com/web-of-science/
} 


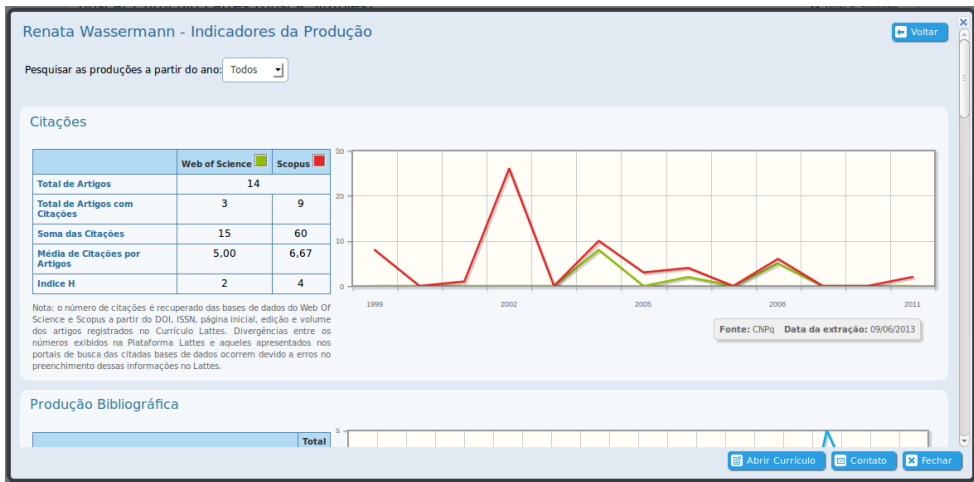

(a) Produções referenciadas em base de dados de citações.

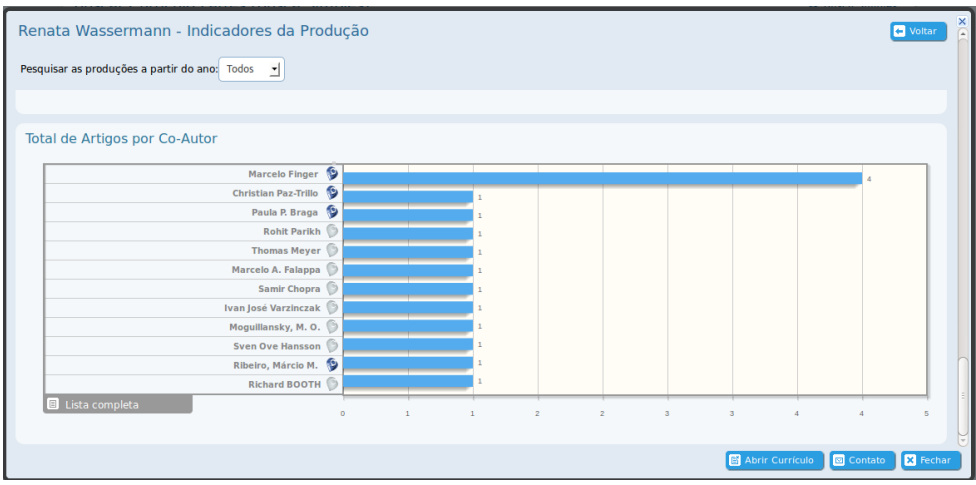

(b) Número de produções agrupadas por co-autor.

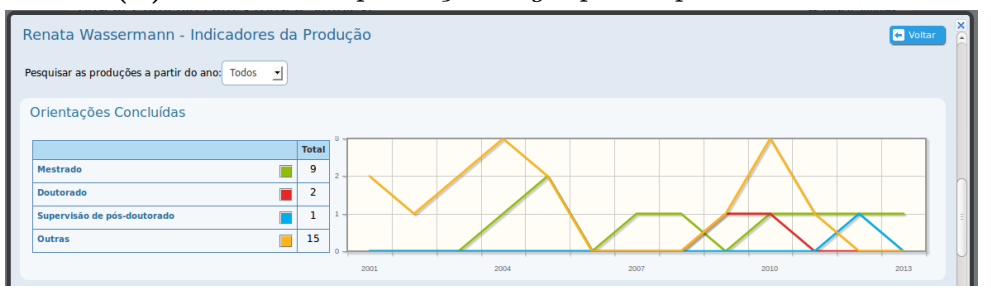

(c) Quantidade de orientações concluídas agrupadas por ano e nivel.

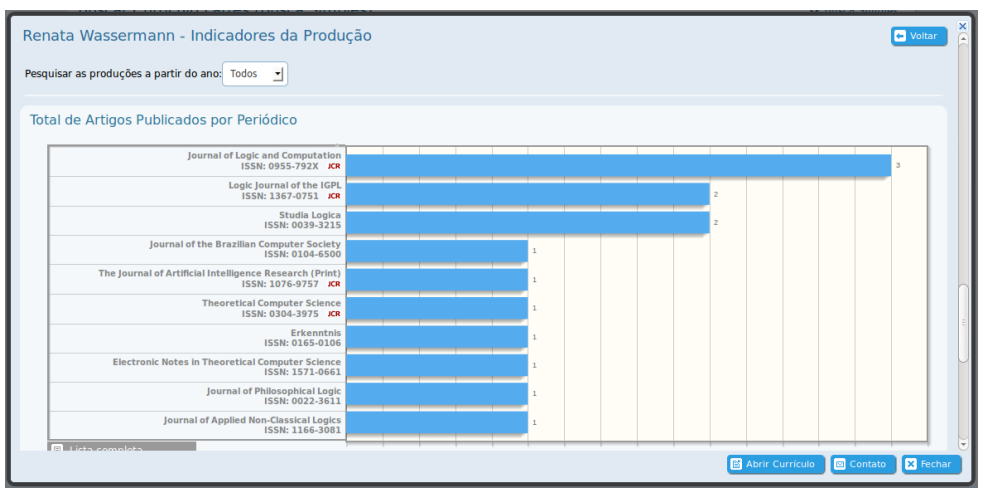

(d) Número de produções agrupadas por periódico.

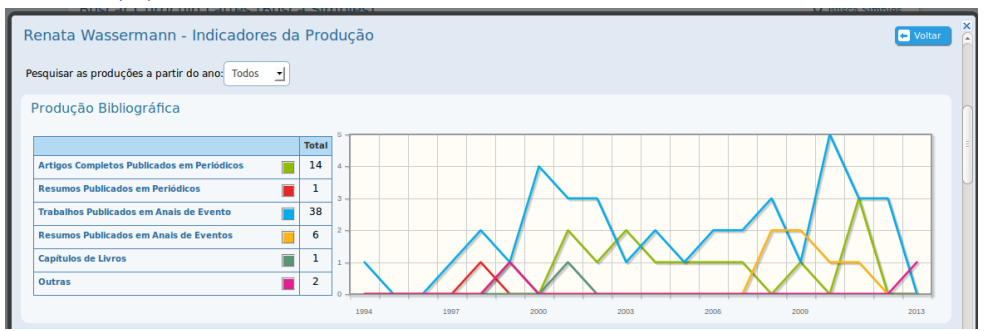

(e) Quantidade de produções agrupadas por ano e tipo.

Figura 4.8: Indicadores de Produção do currículo da Professora Doutora Renata Wassermann. 
Podemos reparar que parte desta lista diz respeito a um conjunto limitado de pesquisadores, estando relacionados: pela co-autoria de produções bibliográficas, por orientações, por local de trabalho etc.

\subsection{Trabalhos que Utilizam a Base Lattes}

A seguir serão apresentados alguns dos trabalhos que utilizam dos dados da Base Lattes e propuseram solucionar a limitação de busca de informações.

\subsection{1 scriptLattes}

scriptLattes é um software open source, criado por Jesús Mena-Chalco e Roberto M. Cesar-Jr, que cria relatórios gerenciais obtidos a partir de um conjunto de currículos em formato HTML.

Diferentemente das outras soluções, o scriptLattes não cria uma ontologia. Todas as estruturas de dados foram construídas utilizando o conceito de orientação à objetos. Estes objetos são instanciados a medida em que a ferramenta faz a leitura e extração das informações do currículo HTML.

A saída deste software é uma página Web estática. Nela podemos encontrar respostas as seguintes perguntas:

- Quantas produções bibliográficas, técnicas ou artísticas foram elaboradas?

- Qual é o perfil (ou seja, proporção de publicação) dos diferentes tipos de produções bibliográficas?

- Como é a regularidade e a evolução das publicações ao longo dos anos?

- Como é a colaboração / cooperação entre os pesquisadores?

- Quantas teses e dissertações foram concluídas?

- Qual é a distribuição geográfica dos pesquisadores?

- Qual é a influência a formação científica dos pesquisadores considerados?

A ferramenta possui um módulo para tratar produções referenciadas em dois currículos, evitando redundâncias. Mena-Chalco e Cesar Junior (2009) ressaltam sua importância: "as produções duplicadas são usadas para detectar colaboração: Dois pesquisadores são definidos no software como colaboradores se eles possuem uma produção em comum detectada por este módulo". Estas informações são essenciais para gerar o grafo de colaboração, como exemplificado na figura 4.9.

No Grafo de Colaboração, os pesquisadores são os vértices e as publicações são as arestas. Caso dois ou mais pesquisadores tenham produzido uma publicação, uma aresta irá interligar estes pesquisadores e incrementar o peso da aresta. 


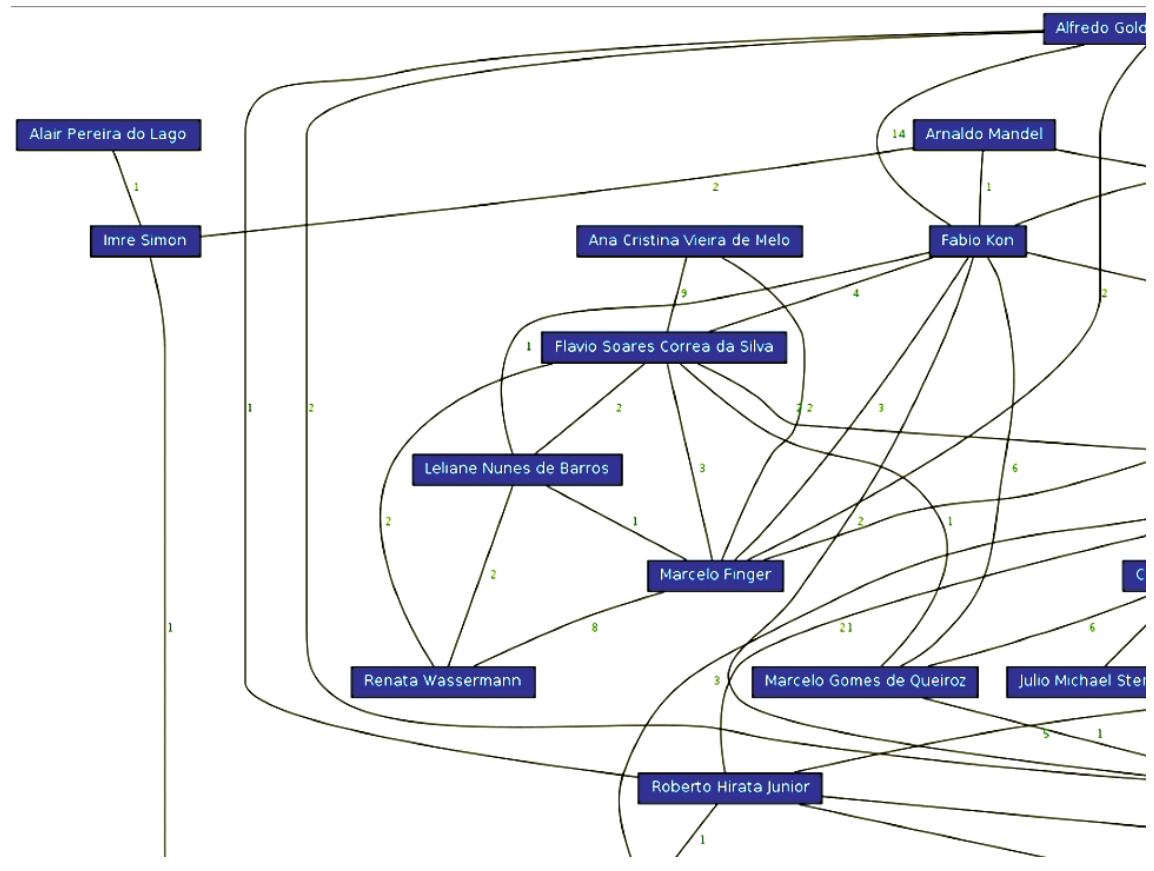

Figura 4.9: Grafo de Colaboração entre Pesquisadores.

Nas primeiras versões, a linguagem de programação utilizada foi o Perl. Mas a partir da versão 8, o software foi reescrito em Python.

Importante ressaltar a grande popularização da ferramenta entre os centros de pesquisas, laboratórios e institutos de ensino em todo o país, confundindo-se muitas vezes com uma ferramenta

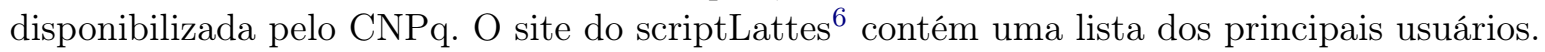

\subsubsection{OntoLattes}

O objetivo do trabalho de Ailton Bonifácio (Bonifácio (2002)) é a construção de uma ontologia (no formato DAML-OIL) para comportar os dados dos currículos dos pesquisadores, batizado como OntoLattes. Para isto, Bonifácio recorreu à especificação definida pela CONSCIENTIAS.

O primeiro passo foi identificar as classes, subclasses e propriedades. Houve especial atenção em manter a mesma nomenclatura das classes do DTD na ontologia. Além disto, foram criadas outras classes além das especificadas, por exemplo, Unidade Federativa (UF), para armazenar dados sobre os estados brasileiros.

Foram adicionados alguns axiomas para aumentar a expressividade de algumas propriedades, por exemplo: O inverso da propriedade temEspecialidade é pertenceASubArea e a propriedade cooperaCom é simétrica (duas pessoas cooperam-se mutuamente).

Esta mesma ontologia foi revista e atualizada por Nakashima (2004), que a converteu para o formato OWL e aperfeiçoou. O autor questiona a forma como o conceito de hierarquia entre classes foi utilizado. Devido ao trabalho de Bonifácio seguir a risca o DTD, relações como Produção Técnica é um Currículo Vitae foram criadas, sendo que o correto é Currículo Vitae possui Produção Técnica.

Ele também inclui o uso da propriedade Datatype para relacionar uma instância de uma classe com um tipo de dado, uma expressão literal ou um valor. Na ontologia de Bonifácio, todas as propriedades são Object.

\subsubsection{Exportação de Currículos para Outros Formatos}

Em seu site ${ }^{7}$, Alexandre Rademaker apresenta sua ferramenta capaz de converter um currículo em formato XML para o formato BibTex (ferramenta de formatação utilizada pela $\mathrm{H}_{\mathrm{E}} \mathrm{X}$ para

\footnotetext{
${ }^{6}$ http://scriptlattes.sourceforge.net/links.html

${ }^{7}$ http://arademaker.github.com/blog/2012/02/15/lattes-to-bibtex.html
} 
facilitar o uso de referências bibliográficas).

Teixeira (2009) desenvolveu uma ferramenta de conversão de currículo em formato XML para um documento em formato $\mathrm{AAT}_{\mathrm{E} X}$. Além da conversão do currículo no formato para o formato $\mathrm{AT}_{\mathrm{E}} \mathrm{X}$, Marcelo Teixeira cita que há possibilidade de validar os dados durante a conversão. Um exemplo de validação é verificar se os anos de publicações estão abaixo do ano corrente.

O trabalho de André Casado Castaño (Castaño (2008)) foi desenvolver uma ferramenta que possui como entrada o currículo de um pesquisador no formato XML e obtém como saída instâncias das classes do OntoLattes (descrito em 4.2.2).

Nos currículos em formato HTML não existem marcas que delimitam a localização de uma determinada informação, apenas marcas que dizem respeito a forma de apresentação da página. Por isto, um dos trabalhos de Castaño foi analisar o conteúdo da página a procura de marcas que delimitam seções (como dados pessoais, formação acadêmica e atuação profissional). Logo após, ele identificou padrões no texto para localização de cada uma das informações, as quais eram convertidas em instâncias OWL.

Em um trabalho similar, Rademaker e Haeusler (2013) desenvolveram uma ferramenta para exportar dados da plataforma em triplas RDF. Mas, ao invés de desenvolverem sua própria estrutura, utilizaram vocabulários e ontologias já padronizados, como $\mathrm{FOAF}^{8}, \mathrm{BIBO}^{9}, \mathrm{SKOS}^{10}$, entre outros.

\subsubsection{Semantic Lattes}

Costa e Yamate (2009) propõem em seu trabalho o desenvolvimento de uma ferramenta, chamada Semantic Lattes, que realiza as tarefas de importação de currículos e lista de veículos de publicações científicas (obtidos do Qualis ${ }^{11}$ ) em uma ontologia, permitindo consultas às instâncias.

O Semantic Lattes possui dois módulos principais:

Server Módulo responsável pela persistência dos dados, consultas e inferências. Foi utilizada para implementação a linguagem JRuby, o framework Jena e o motor de inferências Pellet.

Web Módulo responsável pela camada de apresentação, conversão do currículo no formato XML para instâncias OWL e interpretação das perguntas (feitas em linguagem natural) para consultas SPARQL. Foi utilizada para implementação a linguagem Ruby e o framework Sinatra.

Para este trabalho, foram criadas duas ontologias (utilizando OWL): Uma para armazenar dados de pesquisadores, publicações e orientações, outra da dados da base Qualis. Ambas foram baseadas em perguntas elaboradas por especialistas do domínio (denominadas Questões de Competência), as quais não são respondidas pela Plataforma Lattes.

Semelhante a um motor de busca, é oferecido ao usuário apenas um campo para informar um texto e um botão 'Buscar'. Ele deve digitar a pergunta em linguagem natural e o software, por meio de identificação das palavras-chave, reconhece a pergunta e faz a respectiva consulta em SPARQL. Para esta identificação foram utilizadas expressões regulares.

Dentre todas as ferramentas pesquisadas, o Semantic Lattes se destacou em prover uma interface simples e clara ao usuário, abstraindo a complexidade de operar com softwares no modo console (utilizando linhas de comando).

Importante citar que a ontologia criada para captação dos dados da Plataforma Lattes expressa apenas parte das estruturas existentes. A decisão de inclusão de determinada estrutura foi feita para atender as Questões de Competências levantadas no início do projeto. Neste sentido, pode-se afirmar que o trabalho elaborado por Bonifácio (2002) e Nakashima (2004) contém muito mais estruturas, por se tratar de um trabalho de mapeamento de todos os dados.

\footnotetext{
${ }^{8} \mathrm{http}: / /$ www.foaf-project.org/

${ }^{9}$ http://bibliontology.com/

${ }^{10} \mathrm{http}: / /$ www.w3.org/TR/skos-reference/

${ }^{11} \mathrm{http}: / /$ qualis.capes.gov.br/webqualis/
} 


\subsubsection{Projeto Sucupira}

O projeto SUCUPIRA (acrônimo de "Sistema Unificado de Currículos e Programas: Identificação de Redes Acadêmicas") tem por objetivo a extração de informações da Plataforma Lattes para identificação de redes sociais acadêmicas (Alves et al. (2011)).

Uma das principais funcionalidades deste sistema é o gerenciamento de uma lista de pesquisadores definida pelo usuário. Desta forma, o usuário poderá fazer consultas pelo nome do pesquisador e solicitar ao sistema a importação dos dados do seu currículo na Plataforma Lattes. Esta importação é feita utilizando o sistema LattesMiner (Alves et al. (2012)), desenvolvido pelo mesmo grupo do Sucupira.

Uma vez importados os dados, é possível visualizar: Um mapa contendo a localização do endereço profissional dos pesquisadores, um gráfico sumarizado do número de publicações por ano e tipo, e um grafo relacionando os pesquisadores a outros currículos. 


\section{Capítulo 5}

\section{SOS Lattes}

Este capítulo apresenta os esforços feitos para elaboração da ferramenta proposta. Será mostrada a arquitetura adotada, bem como a aplicação das tecnologias e padrões descritos nas seções anteriores.

\subsection{Requisitos Funcionais e Não-Funcionais}

Com base na análise feita dos outros trabalhos, foram levantados os seguintes requisitos funcionais:

1. O usuário deverá informar ao sistema os identificadores dos currículos que deseja importar. Após informá-lo, o sistema deve automaticamente buscar os dados da base de dados da Plataforma Lattes e armazená-la em uma base de conhecimento.

2. O sistema deverá fornecer uma lista dos currículos já importados.

3. O sistema deverá fornecer relatórios sumarizados de Produções Bibliográficas, Técnicas e Artísticas.

4. O sistema deverá fornecer relatórios sumarizados de Orientações em Andamento e Concluídas.

5. O sistema deverá informar um relatório que compara os dados informados na orientação e da formação já associados, com objetivo de encontrar inconsistências.

6. O usuário poderá informar perguntas ao sistema (obedecendo certas estruturas sintáticas), resultando em uma consulta à base de conhecimento.

Além disto, foram levantados os seguinte requisitos não-funcionais:

1. Obter os dados da Plataforma Lattes, seja por XML quanto HTML.

2. Os dados deverão ser armazenados e disponíveis para consultas em uma base de dados baseada em ontologias, para que seja possível o uso de motores de inferência.

\subsection{Arquitetura}

Tendo analisado as ferramentas que utilizam os dados da Plataforma Lattes e os requisitos funcionais e não-funcionais, propomos o desenvolvimento de uma nova ferramenta, reaproveitando as funcionalidades já desenvolvidas.

Batizamos com o nome "SOS Lattes", acrônimo de Semantic Ontology-based Script Lattes, as três ferramentas utilizadas como base deste trabalho. Além disto, $S O S$ é uma metáfora relacionada à nova funcionalidade de deteç̧ão de inconsistência, considerada pelos autores um excelente auxílio. 
A figura 5.1 apresenta a proposta de arquitetura de sistema que comporta tais funcionalidades. É representado o sistema e todas as suas camadas, bem como suas interações:

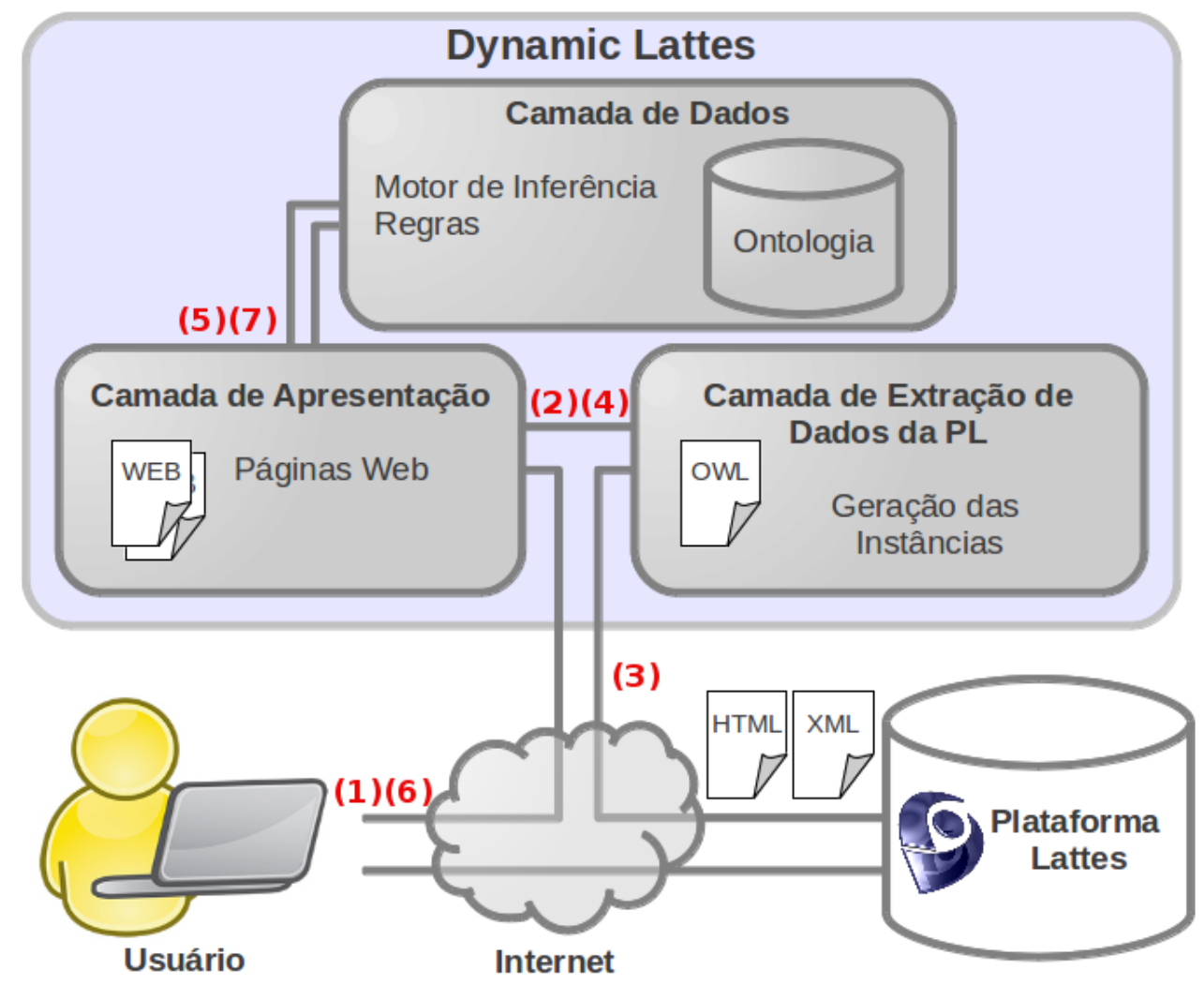

Figura 5.1: Gráfico representando a arquitetura do sistema e suas camadas.

A Camada de Apresentação tem por responsabilidade a interação do sistema com o usuário, por meio de páginas Web renderizadas de acordo com o conteúdo disponibilizado pela camada de dados.

A Camada de Dados tem por objetivo a persistência e a consulta dos dados. Este primeiro é obtido por meio da importação de um arquivo no formato OWL-XML. Já a obtenção dos dados é feita meio de consultas SPARQL. Também nesta camada estão o motor de inferência e as regras para obtenção de novas informações. Os dados persistidos nesta base de dados são os domínios e as instâncias das ontologias do OntoLattes e do Semantic Lattes.

A Camada de Extração de Dados da PL tem por objetivo extrair os dados da Plataforma (seja por HTML ou por XML), interpretar estes dados em forma de instâncias e exportar para o formato OWL-XML, para que sejam armazenados pela Camada de Dados.

Para facilitar o entendimento, seguem as iterações que ocorrem entre sistema e usuário (cada item abaixo está representado com seu respectivo número na figura 5.1):

1. Ao utilizar o sistema pela primeira vez, a lista de membros esta vazia. É preciso, portanto, que o usuário informe o identificador dos membros que se pretende visualizar os dados.

2. Ao obter a lista de identificadores, a Camada de Apresentação faz uma chamada à Camada de Extração de Dados da PL, passando a lista.

3. A Camada de Extração de Dados obtém os dados de cada currículo no formato HTML (ou XML, caso configurado) da Plataforma Lattes, e interpreta cada campo, para que seja possível gerar as instâncias no OntoLattes.

4. É obtido como resultado um OWL-XML contendo as instâncias dos dados. 
5. A camada de Aplicação faz uma chamada à Camada de Dados, solicitando o armazenamento das instâncias recém capturadas.

6. Uma vez armazenados os dados, o usuário poderá solicitar relatórios consolidados do sistema.

7. A camada de Apresentação consulta os dados na Camada de Dados por meio de consultas SPARQL, devolvidos no formato JSon. Estes dados são utilizados para construção dos relatórios consolidados e exibidos para o usuário.

\subsection{Funcionalidades}

A seguir apresentamos todas as alterações feitas nas ferramentas existentes para adequá-las à proposta, bem como a aplicação dos conceitos pesquisados nas seções anteriores.

\subsubsection{Obtenção dos Dados e Geração das Instâncias}

O scriptLattes foi a ferramenta escolhida para incorporar a Camada de Extração de Dados da PL, devido sua funcionalidade de interpretar dados no formato HTML ou XML. Entretanto, foi necessário fazer algumas modificações, para que pudesse interagir com o sistema, a saber:

1. Interpretar os dados de formação: O scriptLattes captura toda a seção de formação de um indivíduo disposto na Plataforma Lattes, mas não interpreta cada um de seus dados (como, por exemplo: ano início, título do trabalho, nome do orientador, nome da instituição etc). Esta etapa foi necessária para que, posteriormente, estes dados pudessem ser comparados com as orientações.

2. Exportar dados no formato OWL: Além da exportação para HTML e XHTML, incluímos o formato OWL-XML. Esta exportação consiste em criar as instâncias das classes já definidas no OntoLattes e Semantic Lattes, bem como definindo suas propriedades.

3. Tornar o scriptLattes disponível como serviço: Para que a ferramenta proposta pudesse comunicarse com o scriptLattes de forma automática, fez-se necessário torná-la um serviço, de modo que pudesse ser acionado por meio de uma requisição HTTP. Por exemplo: ao fazer uma requisição HTTP ao endereço: http://localhost:8080/scriptLattes?id=8571722708574643\&id= 8548608291351316 (onde ID representa uma lista de identificadores de currículo na plataforma Lattes) o sistema responde com as instâncias dos currículos informado no parâmetro ID no formato OWL-XML.

\subsubsection{Relatórios Consolidados}

A ferramenta Semantic Lattes foi escolhida para incorporar as Camadas de Dados e Apresentação. Também foram necessárias modificações para adaptar-se ao sistema:

1. Inclusão da base de conhecimento do OntoLattes e novas regras de inferências para interação entre as ontologias.

2. Atualização das bibliotecas do framework Jena, permitindo a utilização da nova versão da Linguagem SPARQL.

3. Inclusão de regras de inferência que adicionam à Pessoas sua Titulação a partir dos dados de formação.

Uma vez obtidas as instâncias por meio do scriptLattes, será necessário armazená-las e disponibilizálas através de um motor de inferências. Para isto, utilizamos a arquitetura já desenvolvida no Semantic Lattes Server para armazenamento e extração de consultas.

A ferramenta disponibiliza serviços capazes de fazer a manutenção de dados. Dentre as operações estão: 
1. Importar dados no formato OWL-XML e armazená-los.

2. Permitir a consulta destes dados no formato SPARQL. Esta consulta é retornada no formato JSON.

3. Permitir a manutenção dos dados (como alterações ou exclusões) por meio da Linguagem de Atualização SPARQL.

A apresentação dos dados foi feita utilizando os conceitos já estabelecidos no Semantic Lattes Web. Esta é feita por meio de diversas páginas Web, montadas de acordo com os dados obtidos das consultas SPARQL na base de dados.

Para mostrar a capacidade destas consultas, foram desenvolvidas páginas Web muito semelhantes as geradas pelo scriptLattes. O capítulo 6 contém exemplos destas páginas.

\subsubsection{Uso de Propriedades Simétricas}

Uma propriedade, digamos $\mathrm{P}$, é considerada simétrica para qualquer $x$ e qualquer $y: P(x, y)$ se e somente se $P(y, x)$.

Um exemplo de utilização desta propriedade é onto: estaRelacionadoCom. Ela relaciona dados descritos na formação de um orientando e da orientação de um orientador. Caso essa propriedade não fosse simétrica, a consulta somente retornaria as produções que explicitamente possuem relação com a formação, ignorando as formações relacionadas com as produções.

O SPARQL que contém a consulta utilizando esta propriedade é descrito no Apêndice A em Consulta entre os Dados Informados pelo Orientador e Orientando.

Para relacionar a formação com a orientação, o sistema fornece um mecanismo na listagem de orientações que permite ao usuário associar com um item da formação de um membro. O resultado deste mecanismo é a inclusão de um novo axioma à ontologia. Um exemplo da operação que gera este novo axioma é descrito abaixo:

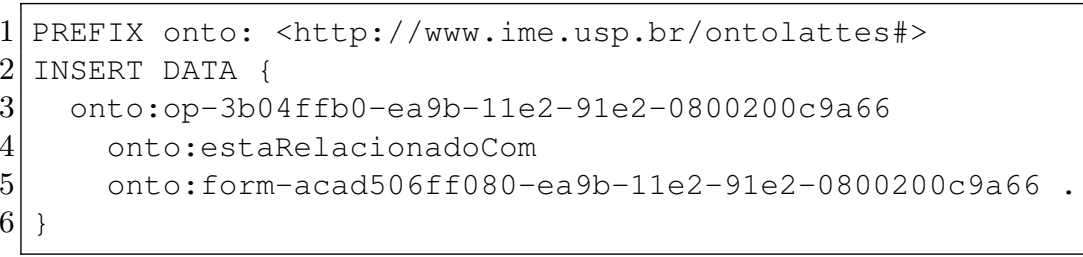

A operação INSERT foi adicionada recentemente à especificação SPARQL, como parte da Linguagem de Atualização SPARQL ${ }^{1}$.

\subsubsection{Consultas em mais de uma base de dados}

A linguagem SPARQL permite a construção de consultas em mais de uma base de dados. Para isto, informamos antes de uma propriedade ou classe a base de dados de origem.

Para facilitar a leitura, podemos utilizar namespaces. No código a seguir são definidos namespaces de duas ontologias, Semantic Lattes e OntoLattes:

1 PREFIX lattes: <http://www.semanticlattes.com.br/curriculo\#>

2 PREFIX onto: <http://www.ime.usp.br/ontolattes\#>

Após definido, podemos utilizá-los nas propriedades e classes em uma consulta SPARQL da seguinte forma: lattes: ou onto: .

A consulta por membros (descrito no Apêndice A em Pesquisa de Membros Utilizando Filtro por Nome) é um exemplo de consulta que utiliza duas bases de dados.

\footnotetext{
${ }^{1}$ http://www.w3.org/TR/sparql11-update/
} 


\subsubsection{Propriedades Inferidas Utilizando Regras}

Para permitir a integração entre as ontologias OntoLattes e Semantic Lattes, criamos uma estratégia que envolve regras de inferências e propriedades simétricas. A figura 5.2 apresenta um exemplo de seu funcionamento em formato gráfico.

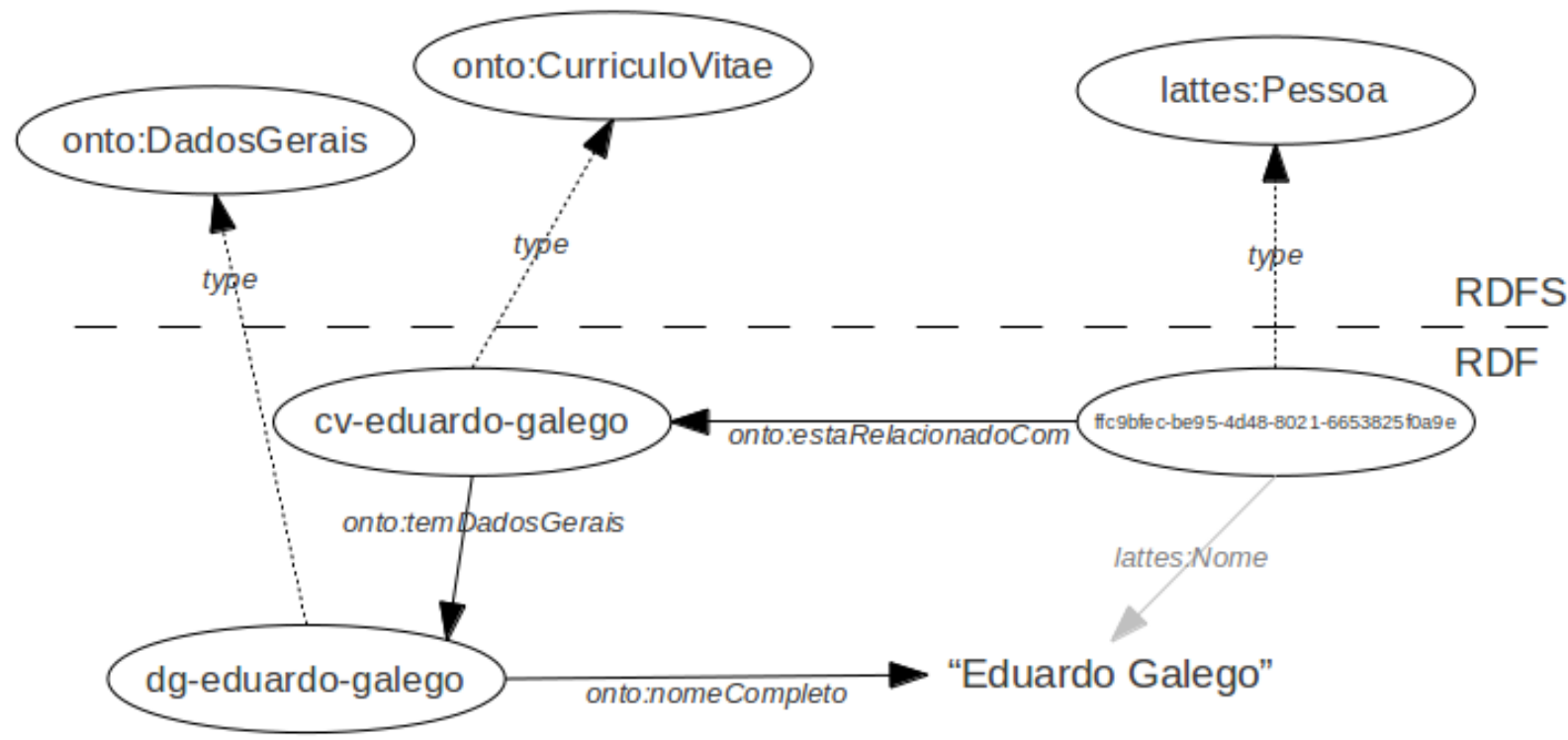

Figura 5.2: Exemplo de uma propriedade inferida.

$\mathrm{Na}$ figura, as elipses acima da linha tracejada representam classes, e abaixo representam instâncias. As setas de cor preta representam as propriedades declaradas e a de cor cinza representa a propriedade inferida. O texto entre aspas representa um literal.

Utilizamos esta estratégia para não ter que declarar explicitamente todas as propriedades da instância de lattes:Pessoa, uma vez que identificamos que este está relacionado com uma instância de onto:CurriculoVitae e suas propriedades estão definidas. Com isto, evitamos redundância de dados, uma vez que lattes:Pessoa e onto:CurriculoVitae são classes manipulando os mesmo dados.

Outros exemplos de classes similares:

- lattes:ArtigoPeriodico e onto:ArtigosPublicados;

- lattes:DissertacaoMestrado e onto:Mestrado;

- lattes:TeseDoutorado e onto:Doutorado;

- lattes:OrientacaoDoutorado e onto:OrientacoesConcluidasParaDoutorado;

- lattes:OrientacaoMestrado e onto:OrientacoesConcluidasParaMestrado;

- lattes:Instituicao e onto:InstituicaoEmpresa.

Utilizamos para criação de regras o Jena Rules ${ }^{2}$, subsistema do Jena para suporte a inferências.

Ele oferece uma interface para conexão com diversos motores de inferência e uma API para criação de regras. Para nosso sistema, estamos utilizando o Pellet. Jena Rules também define uma sintaxe para construção de regras que são carregados ao iniciar a aplicação.

A regra que infere o nome da pessoa está descrita no Apêndice B em Regra para Relacionar Membros entre OntoLattes e Semantic Lattes. Ela foi construída para inferir o nome de uma Pessoa e o nome utilizado em citações bibliográficas na ontologia Semantic Lattes a partir do que está declarado no OntoLattes.

\footnotetext{
${ }^{2}$ http://jena.apache.org/documentation/inference/
} 
O que está sendo descrito nesta regra é: "Caso uma instância, digamos pessoa, seja do tipo Pessoa, e haja outra instância, digamos $c v$, e este possui relação com pessoa (por meio da propriedade estaRelacionadoCom) e haja nomeCompleto, então pessoa possui como nome o mesmo valor de nome Completo".

A regra descrito no Apêndice B em Regra para Relacionar Artigos entre OntoLattes e Semantic Lattes é um outro exemplo de regras, mas para atribuir as propriedades dos artigos. Similar a regra anterior, propriedades de artigos, periódicos, edições e autores são atribuídos da base de dados OntoLattes para Semantic Lattes.

Uma vez construídas tais regras, as consultas à ontologia do Semantic Lattes podem ser feitas normalmente, como se possuíssem valores atribuídos. Esta funcionalidade é utilizada nas consultas obtidas por meio de linguagem natural (trabalho elaborado por Costa e Yamate (2009)).

Em resumo, a Camada de Extração de Dados da PL exporta todas as instâncias e propriedades do OntoLattes, mas apenas as instâncias do Semantic Lattes. As propriedades deste último são obtidas por meio de regras de inferência, aplicadas na Camada de Dados.

Além disto, alguns axiomas (adicionados durante a fase de criação das instâncias no Semantic Lattes) foram convertidos em regras de inferência. Um exemplo desta regra é a inclusão do axioma "Uma pessoa possui um título de mestre", como mostrado na regra descrito no Apêndice B em Regra para Determinar Título de Mestre.

Com isto expandimos a capacidade de expressividade da Base de Conhecimento, permitindo que novos axiomas sejam criados dependendo dos valores já informados, diminuindo assim a possibilidade de inconsistências de dados.

\subsubsection{Sugestão para Inclusão de Novos Membros}

Foi adicionado ao sistema uma consulta para sugestão de inclusão de novos membros. Esta consulta utiliza o operador MINUS, adicionado na versão 1.1 da especificação SPARQL.

Por meio deste recurso, podemos criar consultas por orientandos, desconsiderando aqueles que já foram importados pelo sistema. Esta consulta pode ser visualizada no Apêndice A em Consulta para Sugestão de Novos Membros. 


\section{Capítulo 6}

\section{Resultados}

Neste capítulo apresentaremos os resultados obtidos da implementação feita da ferramenta descrita no capítulo anterior.

No endereço https://github.com/efgalego/SOSLattes podemos encontrar o código-fonte da ferramenta, sob licença GNU General Public License.

Para os testes, tomamos por amostra alguns professores e pesquisadores do LIAMF (Laboratório de Lógica, Inteligência Artificial e Métodos Formais do IME/USP). São eles: Cinco professores (Ana Cristina Vieira de Melo, Marcelo Finger, Flavio Soares Correa da Silva, Renata Wassermann e Leliane Nunes de Barros) e três orientandos (Fillipe Manoel Xavier Resina, Paulo de Tarso Guerra Oliveira e Marcio Moretto Ribeiro). Ao todo este grupo totaliza: 451 produções bibliográficas, 51 produções técnicas, 1 produção artística e 201 orientações (sendo 170 concluídas).

\subsection{Acesso Inicial}

Toda interação com o usuário ocorre por meio de um servidor Web. Desta forma, ao executar, a ferramenta fica disponível no endereço http://<IPServidor $>: 9090$. Ao acessá-la, a figura 6.1 apresenta a página exibida.

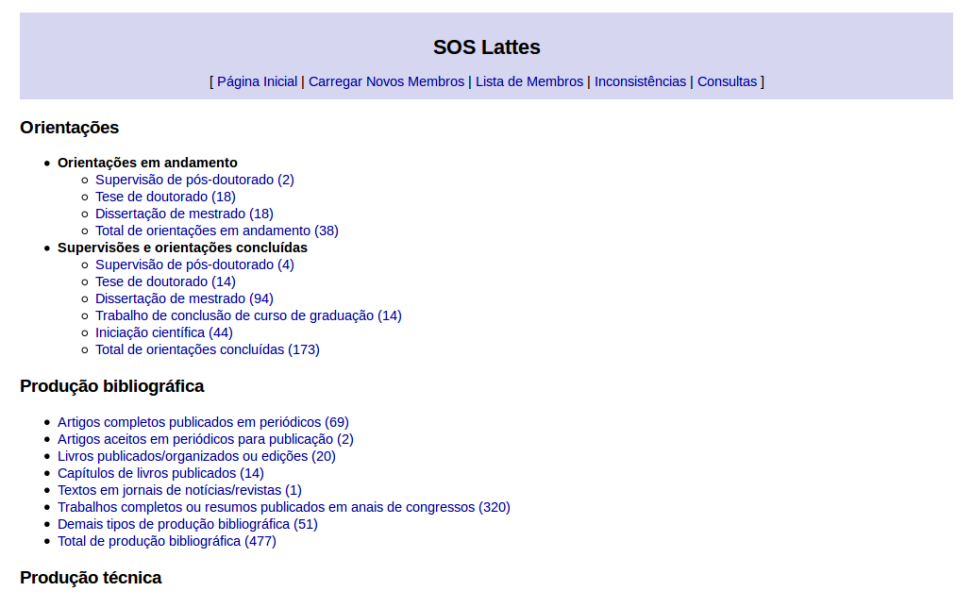

Figura 6.1: Página Inicial.

\subsection{Carregar Dados da Base Lattes}

Para incluir os currículos dos pesquisados, acesse o menu "Carregar Novos Membros". A página a ser exibida contém um campo de texto para informar os números identificadores dos currículos, separados por vírgula. 
Ao pressionar o botão "Consultar", o sistema irá carregar os currículos na Plataforma Lattes e exportar para o formato OWL-XML, o qual será carregado dentro da base de dados do sistema. A lista completa de currículos carregados pode ser visualizada em "Lista de Membros" (descrito na seção 6.3).

Caso haja currículos já carregados, o sistema oferece algumas sugestões de pessoas (descrito na seção 5.3.6).

Para limpar os dados informados, pressione "Limpar Dados". Todos os dados já carregados serão descartados, retornando ao estado inicial do sistema.

\subsection{Lista de Membros}

A figura 6.2 mostra a página de membros com o alguns professores e pesquisadores do LIAMF (Grupo de Lógica, Inteligência Artificial e Métodos Formais do Departamento de Ciência da Computação do IME-USP):

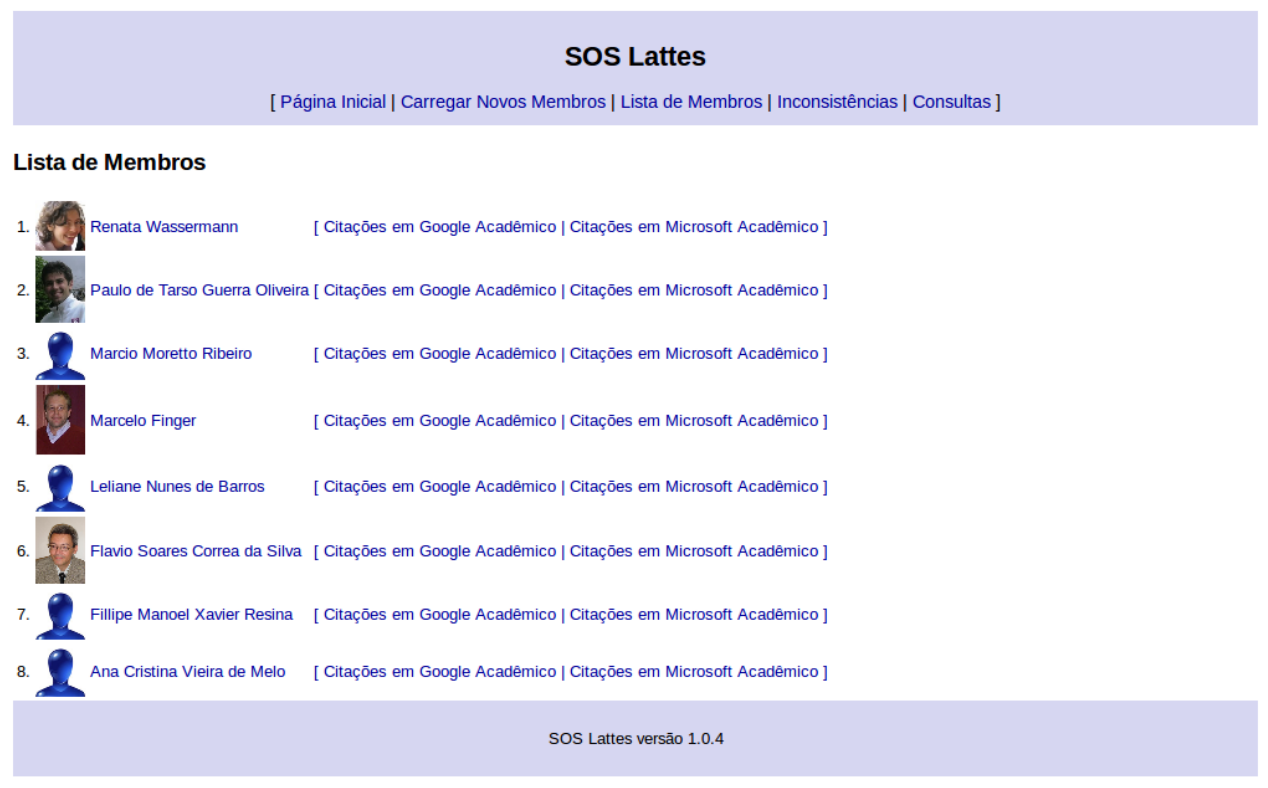

Figura 6.2: Página de membros do LIAMF do SOS Lattes.

Os dados informados nesta listagem foram obtidos por meio de uma consulta à classe CurriculoVitae da OntoLattes. No Apêndice A em Pesquisa de Todos os Membros podemos visualizar a consulta utilizada para obter este resultado.

\subsection{Listagem de Produções Bibliográficas}

Uma vez carregados os currículos, na página inicial é exibida a quantidade de Produções Bibliográficas (separadas por tipo de produção), a quantidade de Orientações em Andamento e Concluídas (separadas por nível).

Ao clicar sobre qualquer tipo de Produção, é exibida uma página contendo os detalhes das produções, agrupadas por ano. É exibido também um gráfico de barras contendo o número de produções por ano. A figura 6.3 mostra a página de Artigos Publicados para o grupo já mencionado.

Diferentemente do scriptLattes, estes relatórios foram obtidos por meio de consultas SPARQL na ontologia OntoLattes. A consulta SPARQL que originou os dados acima é apresentada no Apêndice A em Consulta da Listagem de Produções Bibliográficas - Artigo.

Uma vantagem deste modelo em comparação com o scriptLattes é a possibilidade de alteração do conteúdo dos dados do relatório sem necessidade de alteração da apresentação. Isto porque 


\section{SOS Lattes}

[ Página Inicial | Carregar Novos Membros | Lista de Membros | Inconsistências | Consultas ]

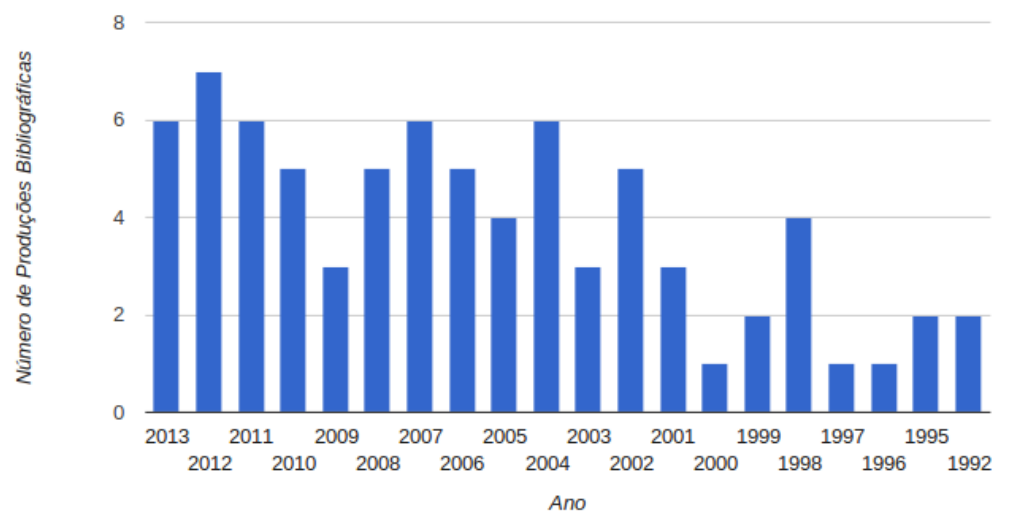

\section{Produções Bibliográficas (filtro: ArtigosPublicados)}

Número total de itens: 77

2013

1. DA SILVA, FLAVIO. Philosophy of Information: Views and Reflections on the Work of Luciano Floridi. Information. v. 4, p. 31 2013.

[ Citaçōes em Google Scholar | Citaçōes em Microsoft Acadêmico | Busca Google ]

2. ARRUDA, A. ; Finger, M. Completeness for cut-based abduction. Logic Journal of the IGPL (Print). v. 21, p. 1 - 1, 2013. [ Citaçōes em Google Scholar | Citaçōes em Microsoft Acadêmico | Busca Google ]

3. D'Agostino, Marcello ; Finger, Marcelo ; Gabbay, Dov. Semantics and proof-theory of depth bounded Boolean logics. Theoretical Computer Science. v. 480 , p. 43,2013

[ Citaçōes em Google Scholar | Citaçōes em Microsoft Acadêmico | Busca Google ]

4. Finger, Marcelo ; REIS, POLIANA. On the Predictability of Classical Propositional Logic. Information. v. 4, p. 60, 2013.

[ Citaçōes em Google Scholar | Citaçōes em Microsoft Acadêmico | Busca Google ]

5. RIBEIRO, MÁRCIO M. ; WASSERMANN, RENATA ; FLOURIS, GIORGOS ; ANTONIOU, GRIGORIS. Minimal change: Relevance and recovery revisited. Artificial Intelligence (General Ed.) v. 201, p. 59,2013

[ Citaçōes em Google Scholar | Citaçōes em Microsoft Acadêmico | Busca Google ]

6. RIBEIRO, MÁRCIO M. ; WASSERMANN, RENATA ; FLOURIS, GIORGOS ; ANTONIOU, GRIGORIS. Minimal change: Relevance and recovery revisited. Artificial Intelligence (General Ed.). v. 201, p. 59, 2013.

[ Citaçōes em Google Scholar | Citaçōes em Microsoft Acadêmico | Busca Google ]

2012

1. ARAUJO, C. J. A. ; CORREA DA SILVA, F. S.. A System for Governmental Virtual Institutions based on Ontologies and Interaction Protocols. International Journal of Distance Education Technologies. v. 10, p. 82, 2012.

[ Citaçōes em Google Scholar | Citaçōes em Microsoft Acadêmico | Busca Google ]

2. CORRÊA DA SILVA, FLÁVIO SOARES ; FERNÁNDEZ VENERO, MIRTHA LINA ; DAVID, DIEGO MIRA ; SALEEM, MOHAMMAD ; CHUNG, PAUL W.H.. Interaction protocols for cross-organisational workflows. Knowledge-Based Systems. v. 37, p. 1, 2012. [ Citaçōes em Google Scholar | Citaçōes em Microsoft Acadêmico | Busca Google ]

3. Peanho, Claudio Antonio ; Stagni, Henrique ; CORREA DA SILVA, F. S.. Semantic information extraction from images of complex documents. Applied Intelligence (Boston). v. 37, p. 1, 2012.

[ Citaçōes em Google Scholar | Citaçōes em Microsoft Acadêmico | Busca Google ]

4. do Lago Pereira, Silvio ; Nunes de Barros, Leliane ; de Barros, Leliane Nunes. A planner agent that tries its best in presence of nondeterminism. Journal of Applied Logic. v. 10, p. 1, 2012.

[ Citaçōes em Google Scholar | Citaçōes em Microsoft Acadêmico | Busca Google ]

5. Araújo, Anderson de ; Finger, Marcelo. Classical and quantum satisfiability. Electronic Proceedings in Theoretical Computer Science. v. 81 , p. 79,2012

[ Citaçōes em Google Scholar | Citaçōes em Microsoft Acadêmico | Busca Google ]

6. Finger, Marcelo. Towards automated first-order abduction: the cut-based approach. Logic Journal of the IGPL (Print). v. 20, p. $370,2012$.

[ Citaçōes em Google Scholar | Citaçōes em Microsoft Acadêmico | Busca Google ]

7. Moguillansky, M. O. ; Wassermann, R. ; FALAPPA, M. A.. Inconsistent-tolerant base revision through Argument Theory Change. Logic Journal of the IGPL (Online). v. 20, p. 154, 2012

[ Citaçōes em Google Scholar | Citaçōes em Microsoft Acadêmico | Busca Google ]

\section{1}

1. de Melo, Ana C.V. ; SILVEIRA, Paulo. Improving data perturbation testing techniques for Web services. Information Sciences. v. 181, p. 600,2011

[ Citaçōes em Google Scholar | Citaçōes em Microsoft Acadêmico | Busca Google ]

2. CORREA DA SILVA, F. S.. Knowledge-based interaction protocols for intelligent interactive environments. Knowledge and Information Systems. v. 30, p. 1, 2011.

[ Citaçōes em Google Scholar | Citaçōes em Microsoft Acadêmico | Busca Google ]

3. Delgado, Karina Valdivia ; Sanner, Scott ; de Barros, Leliane Nunes. Efficient solutions to factored MDPs with imprecise transition probabilities. Artificial Intelligence (General ed.). v. 175, p. 1498,2011

Figura 6.3: Página de Artigos Publicados. 
delegamos a responsabilidade de apresentação à Camada de Apresentação e os dados à Camada de Dados.

\subsection{Listagem de Orientações}

De volta à página inicial, ao clicar sobre qualquer nível de orientação é possível visualizar os detalhes das orientações, agrupadas por ano de conclusão (no caso de concluídas) ou por ano de início (no caso das orientações em andamento). Há também um gráfico de barras contendo o número de orientações por ano.

Um exemplo deste relatório pode ser visualizado na figura 6.4. Nele são exibidas uma parte das orientações em andamento de Doutorado do grupo do LIAMF.
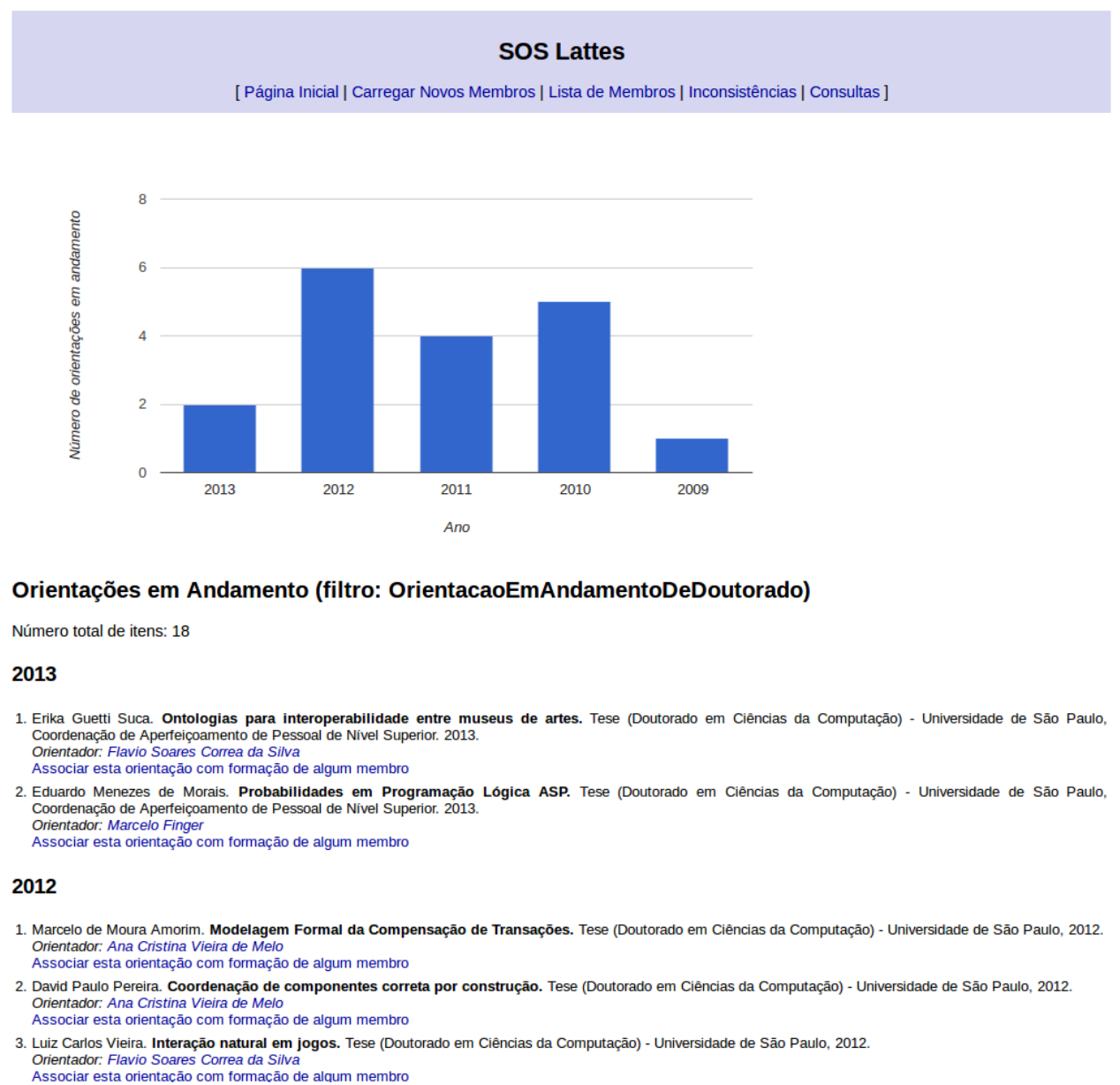

Figura 6.4: Página de Orientações em Andamento.

A consulta SPARQL que originou os dados é descrita no Apêndice A em Consulta da Listagem de Orientações em Andamento.

\subsection{Inconsistências entre Orientações e Formações}

Para cada orientação existe a opção de incluir (ou remover) associação com a Formação de algum membro. Este dado é utilizado na página exibida pela menu "Inconsistências", onde há uma tabela contendo o comparativo com os dados informados na Orientação com a Formação. Desta forma, é possível identificar inconsistências entre os dados informados pelo Orientador e o seu Orientado.

A figura 6.5 apresenta um exemplo de inconsistência, considerando uma orientação concluída. 


\section{Inconsistências}

\section{Orientações Concluídas relacionadas com Formações}

\begin{tabular}{|c|c|c|c|c|}
\hline Status & Atributo & Dados da Orientação & Dados da Formação & Mensagem \\
\hline \multicolumn{5}{|c|}{ Título do Trabalho: Revisāo de Modelos CTL } \\
\hline & $\begin{array}{l}\text { Nome do } \\
\text { Orientador }\end{array}$ & Renata Wassermann & Renata Wassermann & Dados conferem: Renata Wassermann. \\
\hline & $\begin{array}{l}\text { Nome do } \\
\text { Orientado }\end{array}$ & $\begin{array}{l}\text { Paulo de Tarso Guerra } \\
\text { Oliveira }\end{array}$ & $\begin{array}{l}\text { Paulo de Tarso Guerra } \\
\text { Oliveira }\end{array}$ & Dados conferem: Paulo de Tarso Guerra Oliveira. \\
\hline & $\begin{array}{l}\text { Nome da } \\
\text { Instituiçāo }\end{array}$ & $\begin{array}{l}\text { Universidade de Sāo } \\
\text { Paulo }\end{array}$ & \begin{tabular}{|l} 
Universidade de Sāo \\
Paulo, USP, Brasil
\end{tabular} & Dados divergem: Orientaçāo esta contido(a) em formaçāo. \\
\hline & $\begin{array}{ll}\text { Nome da } \\
\text { Agência }\end{array}$ & \begin{tabular}{|lr} 
Coordenaçāo & de \\
Aperfeiçoamento & de \\
Pessoal de Nivel Superior
\end{tabular} & $\begin{array}{l}\text { Conselho Nacional de } \\
\text { Desenvolvimento } \\
\text { Científico e Tecnológico. }\end{array}$ & $\begin{array}{l}\text { Dados divergem: Orientaçāo }=\text { Coordenaçāo de } \\
\text { Aperfeiçoamento de Pessoal de Nivel Superior | Formaçāo } \\
=\text { Conselho Nacional de Desenvolvimento Cientifico e } \\
\text { Tecnológico.. }\end{array}$ \\
\hline & \begin{tabular}{|l} 
Tipo de \\
Orientaçāo
\end{tabular} & Mestrado & $\begin{array}{l}\text { Mestrado em Ciências da } \\
\text { Computaçāo }\end{array}$ & Dados divergem: Orientaçāo esta contido(a) em formaçāo. \\
\hline & $\begin{array}{l}\text { Ano } \\
\text { Término }\end{array}$ & 2010 & 2010 & Dados conferem: 2010. \\
\hline & \begin{tabular}{|l} 
Titulo do \\
Trabalho
\end{tabular} & Revisāo de Modelos CTL & Revisāo de Modelos CTL & Dados conferem: Revisāo de Modelos CTL. \\
\hline
\end{tabular}

Figura 6.5: Página de Inconsistências.

A consulta utilizada pode ser visualizada na seção 5.3.3.

\subsection{Módulo de Perguntas}

No menu "Perguntas" encontramos um campo de texto para entrada de uma pergunta. Este corresponde ao trabalho do Semantic Lattes o qual foi possível graças à construção das regras de inferências que transcrevem as propriedades da OntoLattes para a ontologia do Semantic Lattes.

A figura 6.6 apresenta um exemplo desta pergunta, bem como os resultados obtidos. 


\section{Questão}

\section{Resultado}

A consulta retornou 3 resultado(s).

- Extração e consulta de informações do currículo Lattes baseadas em ontologias

Orientador: Renata Wassermann

Orientado: Eduardo Galego

EM ANDAMENTO 2010 N/A

- Revisão de Crenças em Lógicas de Descrição - Um Plug-In para o Protégé

Orientador: Renata Wassermann

Orientado: Fillipe Manoel Xavier Resina

EM ANDAMENTO 2011 N/A

- Revisão de conceitos (provisório)

Orientador: Renata Wassermann

Orientado: José David Curado

EM ANDAMENTO 2011 N/A

Figura 6.6: Exemplo de Pergunta e Resultados Obtidos.

As regras e consultas utilizadas foram descritas na seção 5.3.5.

É importante citar que na ferramenta desenvolvida, parte das perguntas foram retiradas porque utilizam dados de "local de trabalho" dos pesquisadores. Tais dados não são importados atualmente pelo scriptLattes, tampouco adicionados às ontologias. Não se trata de uma limitação da tecnologia, mas apenas da falta da implementação desta funcionalidade (como descrito em 7.2). 


\section{Capítulo 7}

\section{Considerações Finais}

\subsection{Conclusão}

Foi possível por meio deste trabalho explorar as ferramentas voltadas para a área de Web Semântica, aplicada em um contexto em que há diversos problemas de dados não relacionados e grande volume de dados: a Plataforma Lattes.

A ferramenta SOS Lattes, produto deste trabalho, podem auxiliar nas seguintes tarefas:

- Identificar inconsistência entre os dados informados no currículo do orientador, na seção Orientações, com os informados pelo orientado, na seção Formação.

- Busca de informações agrupadas por ano, como: Orientações e Produções Bibliográficas. Além disto, os gráficos que exibem os anos e a quantidade de itens pode auxiliar na tarefa de identificar a taxa de crescimento.

- Descoberta automática de dados, como no caso da titulação de um currículo a partir dos dados da formação.

Além disto, as regras de inferência se mostraram bastante úteis na tarefa de correlação entre duas ontologias. Neste sentido, é preciso aprimorar as funcionalidades do framework utilizado para auxiliar também a criação das instâncias (e não somente a atribuição das propriedades).

É importante citar, em comparação ao scriptLattes em que as páginas são estáticas (ou seja, os dados informados foram obtidos somente no momento da criação das páginas), as páginas do Semantic Lattes Web são dinâmicas. Em outras palavras, a cada nova requisição, as páginas podem mudar de acordo com os resultados obtidos pela consulta à ontologia. Neste sentido, podemos pensar em soluções que possibilitem a manutenção dos dados (como a inclusão de novos currículos ou associação com autores), sem que para isto seja alterada a apresentação das páginas.

Não é objetivo deste trabalho esgotar o tema, mas apresentar possíveis soluções que o uso de ontologias traz aos usuários e especialistas para facilitar tarefas como: Identificar inconsistências de dados, construção de relatórios consolidados, correlação entre base de dados e aumento de expressividade dos dados utilizando regras de inferência.

\subsection{Trabalhos Futuros}

Como proposta de trabalhos futuros, sugerimos:

- Inclusão de ferramentas na área de Combinação de Ontologias Cobe e Wassermann (2012) para combinar dados de currículos. Um exemplo real é a importação de dados de um currículo o qual já tenha sido importado anteriormente.

- Incluir a funcionalidade de busca de currículos na Plataforma Lattes por nome. Neste trabalho, somente é possível a inclusão de currículos pelo número identificador. 
- Incluir algoritmos mais precisos para identificar automaticamente autores e suas publicações.

- Explorar as funcionalidades de Linked Data ${ }^{1}$ para que seja possível integração com outras bases de conhecimentos.

- Exportar dados para outros formatos, por exemplo: ATEXe bibtex.

- Criar regras para associar Formação e Orientação automaticamente.

- Estender a funcionalidade de busca de inconsistência para produções bibliográficas, técnicas e artísticas.

Com relação a ferramenta, ainda há muito por se fazer, como por exemplo:

- Adaptar a ferramenta scriptLattes para importação dos dados profissionais, para que possamos fazer uma completa integração entre as ontologias OntoLattes e SemanticLattes.

- Incluir os relatórios consolidados de Produções Artísticas e Técnica.

- Apresentar Grafo de Colaborações e Mapas semelhante ao scriptLattes, mas obtendo os dados a partir de consultas às ontologias.

\footnotetext{
${ }^{1}$ http://linkeddata.org/
} 


\section{Referências Bibliográficas}

Allemang e Hendler(2008) Dean Allemang e Jim Hendler. Semantic Web for the Working Ontologist. Morgan Kaufmann Publishers. Citado na pág. 1

Alves et al.(2011) Alexandre Donizeti Alves, Horacio Hideki Yanasse e Nei Yoshihiro Soma. SUCUPIRA: a System for Information Extraction of the Lattes Platform to Identify Academic Social Networks. Em Information Systems and Technologies (CISTI), 2011 6th Iberian Conference on, páginas 1-6. Citado na pág. 31

Alves et al.(2012) Alexandre Donizeti Alves, Horacio Hideki Yanasse e Nei Yoshihiro Soma. LattesMiner: uma Linguagem de Domínio Específico para Extração Automática de Informações da Plataforma Lattes. XII Workshop de Computação Aplicada (WORCAP), páginas 1-6. Citado na pág. 31

Antoniou e Harmelen(2008) Grigoris Antoniou e Frank van Harmelen. A Semantic Web Primer. MIT Press, Londres, Inglaterra, 2 edição. Citado na pág. 2, 7, 10, 11, 12, 13, 15

Baeza-Yates e Ribeiro-Neto(1999) Ricardo A. Baeza-Yates e Berthier Ribeiro-Neto. Modern Information Retrieval. Addison-Wesley Longman Publishing Co., Inc., Boston, MA, USA. ISBN 020139829X. Citado na pág. 1, 2

Berners-Lee et al.(2001) T Berners-Lee, James Hendler e Ora Lassila. The Semantic Web. Scientific American, 284(5):34-43. Citado na pág. 2, 6, 7, 11

Bonifácio(2002) Ailton Sérgio Bonifácio. Ontologia e Consulta Semântica: Uma Aplicação ao Caso Lattes. Dissertação de mestrado, Universidade Federal do Rio Grande do Sul, Porto Alegre, RS. Citado na pág. 29, 30

Castaño(2008) André Casado Castaño. Populando Ontologias Através de Informações em HTML - O Caso do Currículo Lattes. Dissertação de mestrado, Instituto de Matemática e Estatística, Universidade de São Paulo, São Paulo, SP. Citado na pág. 12, 30

Cobe e Wassermann(2012) Raphael Cobe e Renata Wassermann. Ontology Merging and Conflict Resolution. Em Workshop on Belief Change, Non-monotonic Reasoning and Conflict Resolution (BNC). Citado na pág. 45

Costa e Yamate(2009) Anauê Pereira Da Costa e Fabio Sendoda Yamate. Semantic Lattes: Uma Ferramenta de Consulta de Informações Acadêmicas da Base Lattes Baseada em Ontologias. Trabalho de Conclusão de Curso, Escola Politécnica da Universidade de São Paulo, São Paulo, SP. Citado na pág. 11, 13, 26, 30, 38

Dentler et al.(2011) Kathrin Dentler, Ronald Cornet, Annette ten Teije e Nicolette de Keizer. Comparison of reasoners for large ontologies in the OWL 2 EL profile. Semant. web, 2(2):71-87. ISSN 1570-0844. Citado na pág. 19

Governor et al.(2009) James Governor, Dion Hinchcliffe e Duane Nickull. Web 2.0 Architectures What entrepreneurs and information architects need to know. O'Reilly. ISBN 978-0-596-51443-3. Citado na pág. 1, 5, 6 
Gruber(1993) Thomas R. Gruber. A Translation Approach to Portable Ontology Specifications. Scientific Literature Digital Library and Search Engine. Citado na pág. 10

Guarino e Giaretta(1995) N. Guarino e P. Giaretta. Ontologies and Knowledge Bases: Towards a Terminological Clarification. Towards Very Large Knowledge Bases: Knowledge Building and Knowledge Sharing, páginas 25-32. Citado na pág. 10

Heath e Bizer(2011) Tom Heath e Christian Bizer. Linked Data: Evolving the Web into a Global Data Space. Synthesis Lectures on the Semantic Web. Morgan \& Claypool Publishers. Citado na pág. 1

King e Reinold(2009) Brandy King e Kathy Reinold. Finding the Concept, Not Just the Word: A Librarian's Guide to Ontologies and Semantics. The Journal of Academic Librarianship, 35 (6). Citado na pág. 9,10

Laudon e Laudon(2011) Kenneth C Laudon e Jane P Laudon. Sistemas de Informação Gerenciais. Pearson Education do Brasil. Citado na pág. 6

Mena-Chalco e Cesar Junior(2009) Jesús Pascual Mena-Chalco e Roberto Marcondes Cesar Junior. ScriptLattes: an Open-source Knowledge Extraction System from the Lattes Platform. Journal of the Brazilian Computer Society, 15(4):31-39. Citado na pág. 28

Nakashima(2004) Marcos Yoshinori Nakashima. Currículo Lattes e Web Semântica. Trabalho de Conclusão de Curso, Instituto de Matemática e Estatística, Universidade de São Paulo, São Paulo, SP. Citado na pág. 29, 30

Rademaker e Haeusler(2013) Alexandre Rademaker e Edward Hermann Haeusler. Semantic Lattes and VIVO Project. Em Proceedings of VIVO 2013, St. Louis, MO. Citado na pág. 30

Souza e Alvarenga(2004) Renato Rocha Souza e Lídia Alvarenga. A Web Semântica e suas Contribuições para a Ciência da Informação. Ciência da Informação, 33(1):132-141. Citado na pág. $2,6,13$

Stair e Reynolds(2009) Ralph M Stair e George W Reynolds. Principles of Information Systems. Cengage Learning, 9 edição. Citado na pág. 1

Teixeira(2009) Marcelo Alves Teixeira. lattes2latex: Uma Ferramenta para Conversão de Currículos Lattes em Documentos LaTeX. Projeto de iniciação científica, Universidade Federal do Rio Grande do Sul, Porto Alegre, RS. Citado na pág. 30 


\section{Apêndice A}

Este apêndice apresenta as instruções SPARQL geradas para consultas dos dados na base de conhecimento.

\section{Consulta entre os Dados Informados pelo Orientador e Orientando}

A consulta abaixo busca dos dados informados na orientação pelo orientador e da formação do orientado. É utilizado para mostrar inconsistência entre o dados informados nos dois currículos.

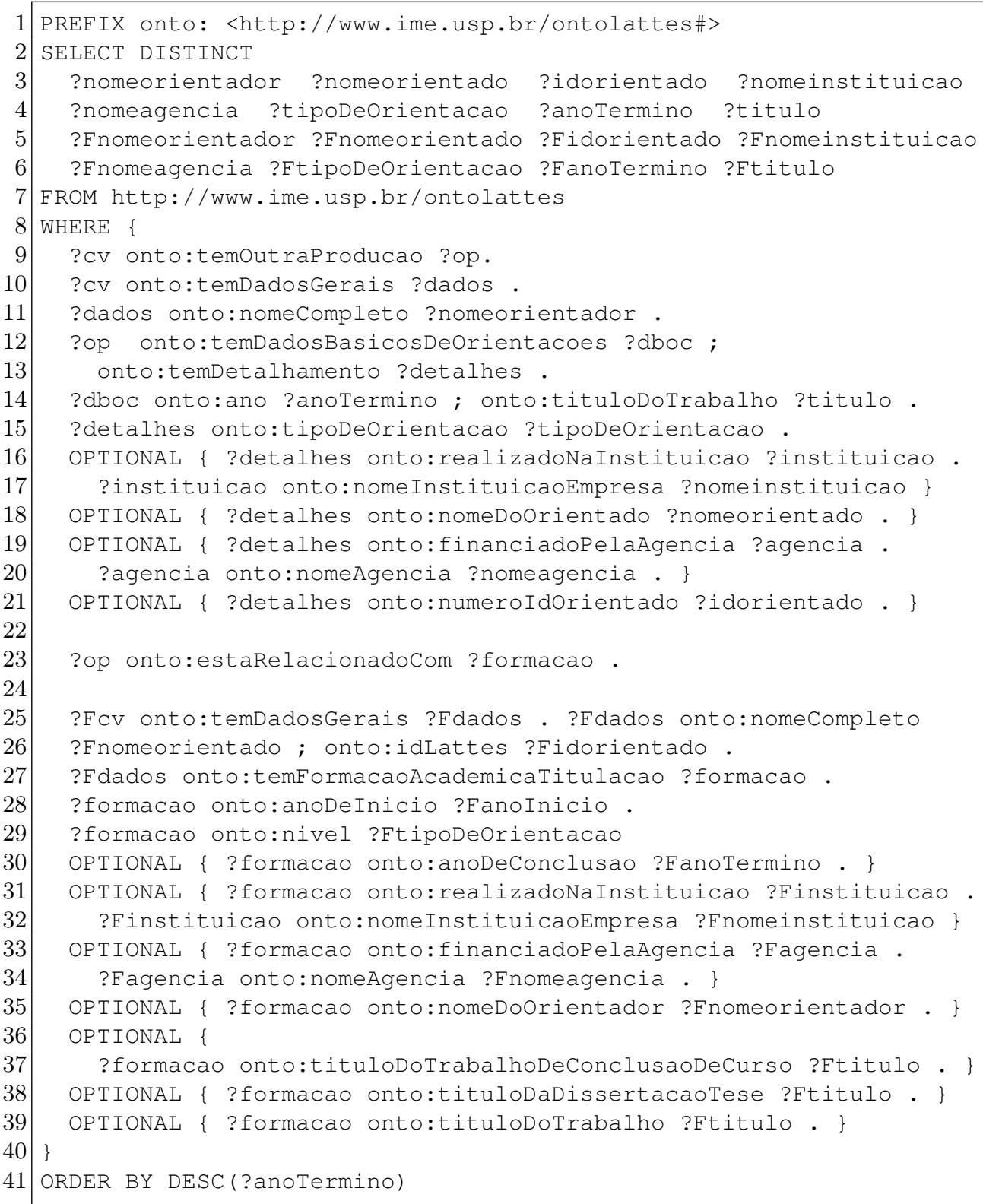




\section{Pesquisa de Todos os Membros}

A consulta abaixo retorna o nome, o número identificador e o endereço da foto de todos os membros. É utilizado na ferramenta para listar todos os membros.

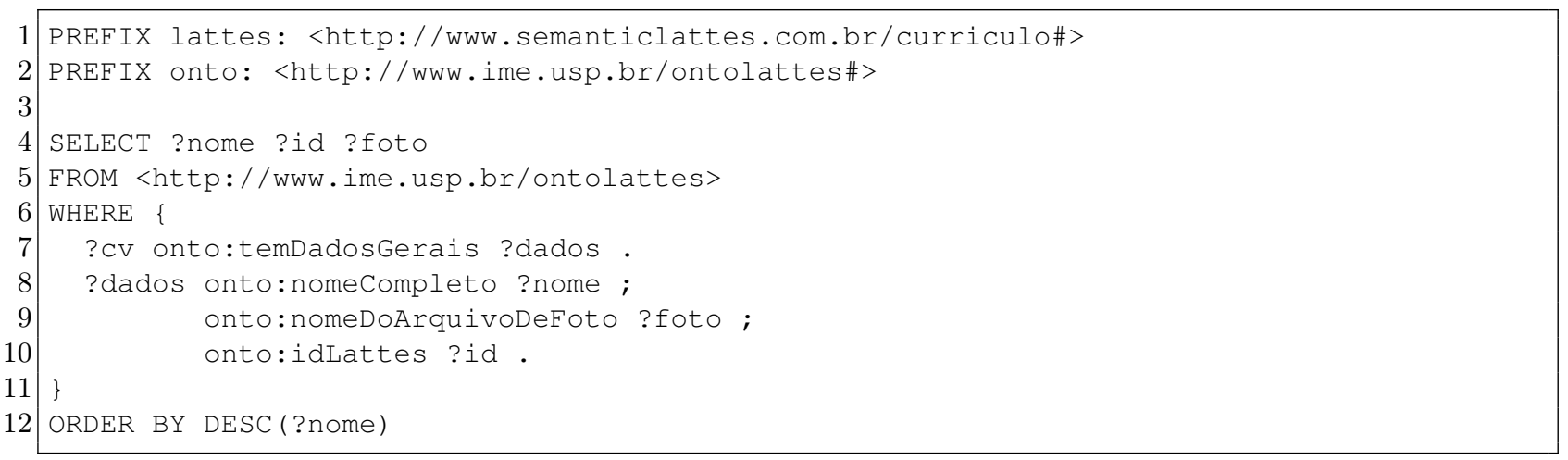

\section{Pesquisa de Membros Utilizando Filtro por Nome}

A consulta abaixo faz uma busca pelos membros através do nome. É utilizado pela consulta por linguagem natural, na seguinte estrutura: "Buscar por pessoa cujo nome contém ..." ou "Buscar por pessoa cujo nome começa com ...".

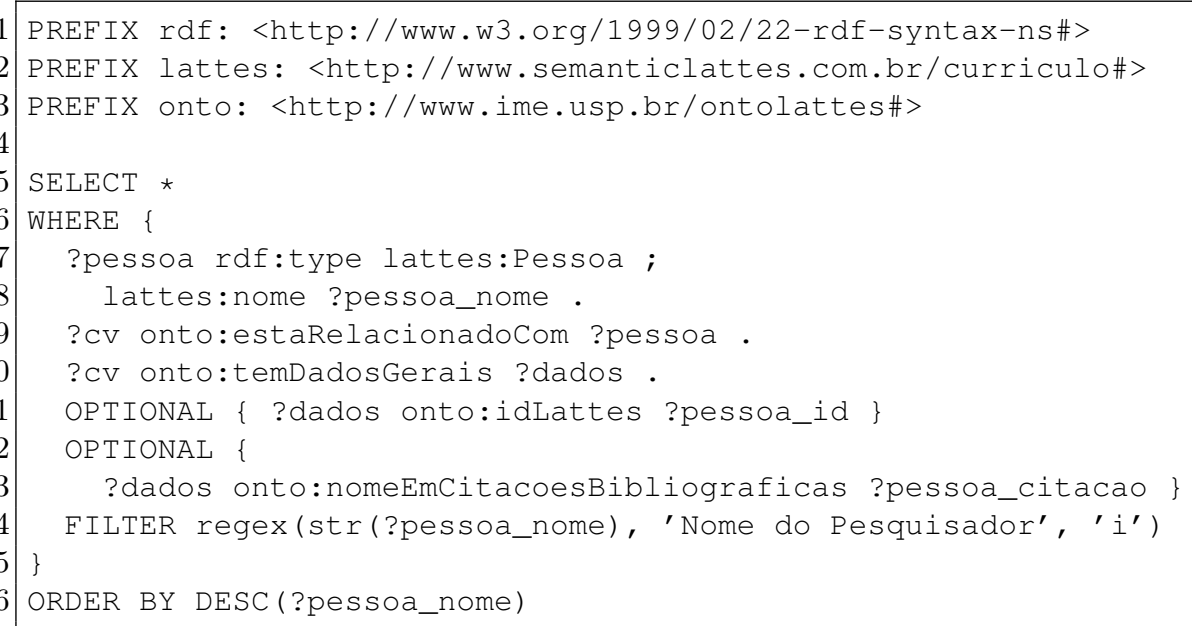

\section{Consulta para Sugestão de Novos Membros}

A consulta abaixo busca o nome de orientados com sugestão para inclusão de novos membros, desconsiderando os orientados já inclusos na lista.

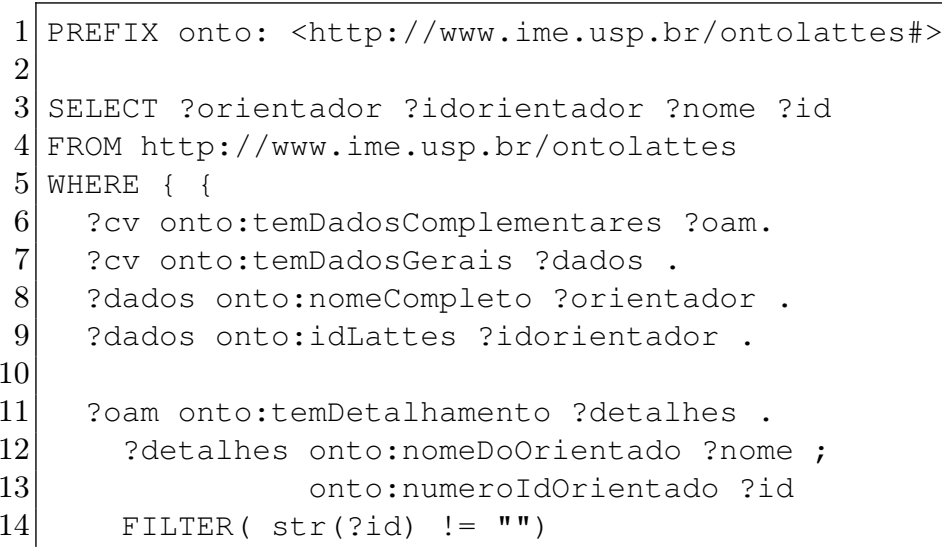


$15 \quad$ \} MINUS \{

16 ?dadosGerais onto: nomecompleto ?nome ;

$19\}$

20 ORDER BY ?orientador ?nome

\section{Consulta da Listagem de Produções Bibliográficas - Artigo}

A consulta abaixo retorna os dados referente à publicação de artigos. É utilizado na listagem de produções bibliográficas.

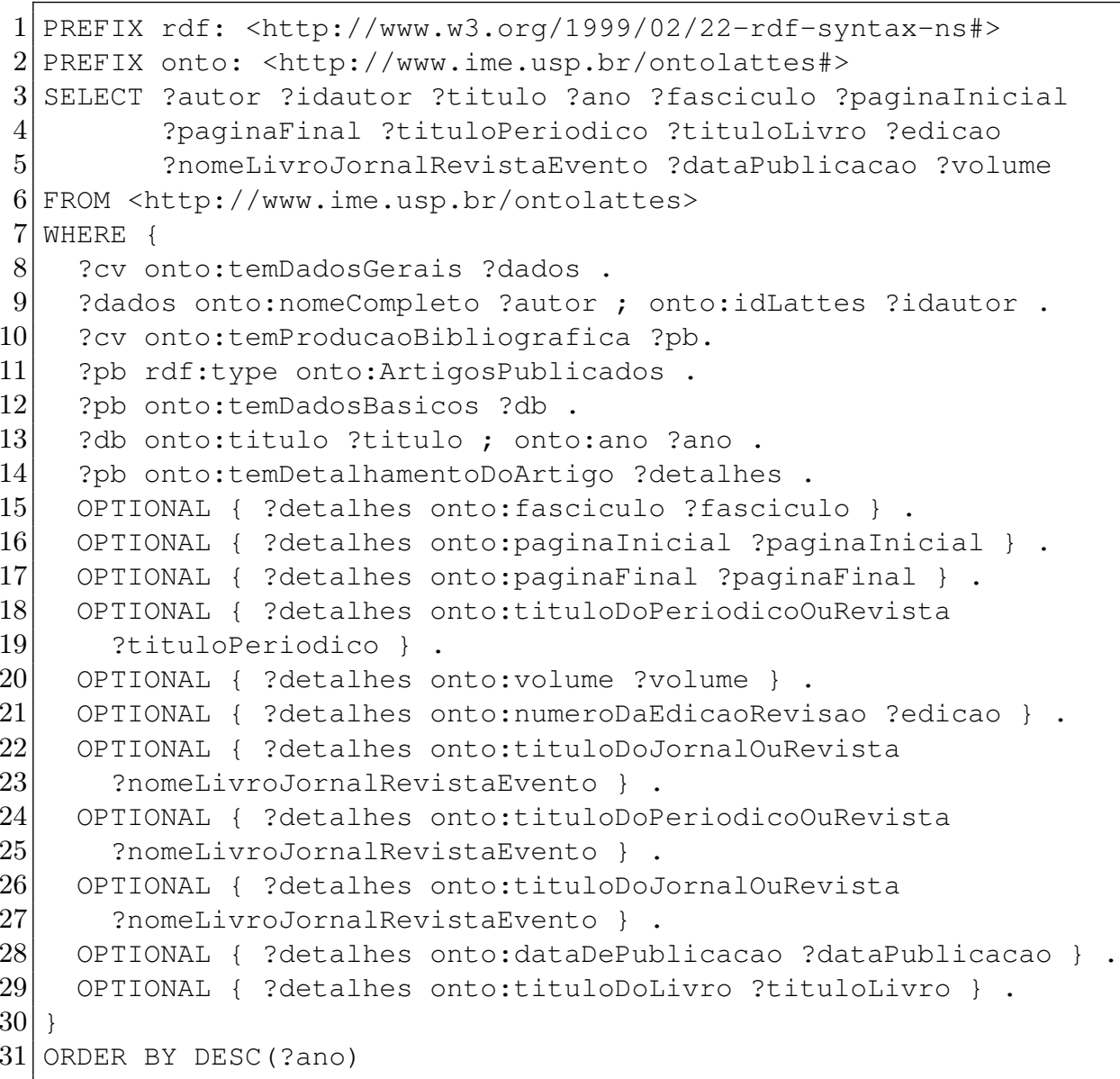

\section{Consulta da Listagem de Orientações em Andamento}

A consulta abaixo retorna os dados para formação da página de orientações concluídas.

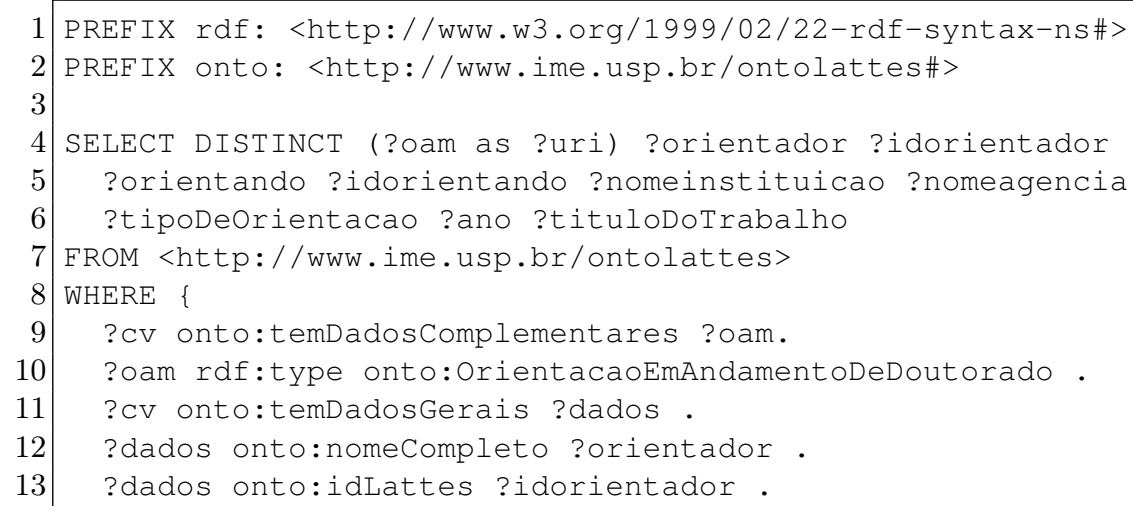


14 ?oam onto:temDadosBasicosDeorientacoes ?dbo ;

15 onto:temDetalhamento ?detalhes.

16 ?dbo onto:ano ?ano ;

17 onto:tituloDoTrabalho ?tituloDoTrabalho.

18 ?detalhes onto:tipoDeorientacao ?tipoDeorientacao.

19 OPTIONAL \{ ?detalhes onto:nomeDoorientado ?orientando . \}

20 OPTIONAL \{ ?detalhes onto:realizadoNaInstituicao ?instituicao.

21 ?instituicao onto:nomeInstituicaoEmpresa ?nomeinstituicao \}

22 OPTIONAL \{ ?detalhes onto:financiadoPelaAgencia ?agencia .

23 ?agencia onto:nomeAgencia ?nomeagencia . \}

$24\}$

25 ORDER BY DESC(?ano) 


\section{Apêndice B}

Este apêndice apresenta as regras de inferências criadas na base de conhecimento para geração de novas informações a partir dos dados já informados.

\section{Regra para Relacionar Membros entre OntoLattes e Semantic Lattes}

O que está sendo descrito nesta regra é: "Caso uma instância, digamos pessoa, seja do tipo Pessoa, e haja outra instância, digamos $c v$, e este possui relação com pessoa (por meio da propriedade estaRelacionadoCom) e haja nomeCompleto, então pessoa possui como nome o mesmo valor de nome Completo".

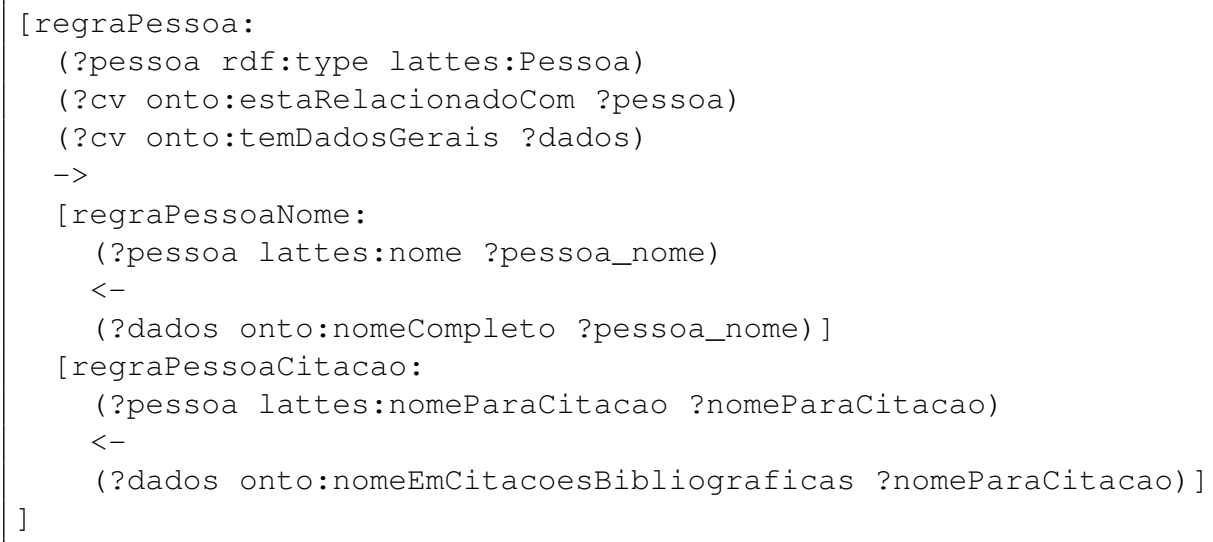

\section{Regra para Relacionar Artigos entre OntoLattes e Semantic Lattes}

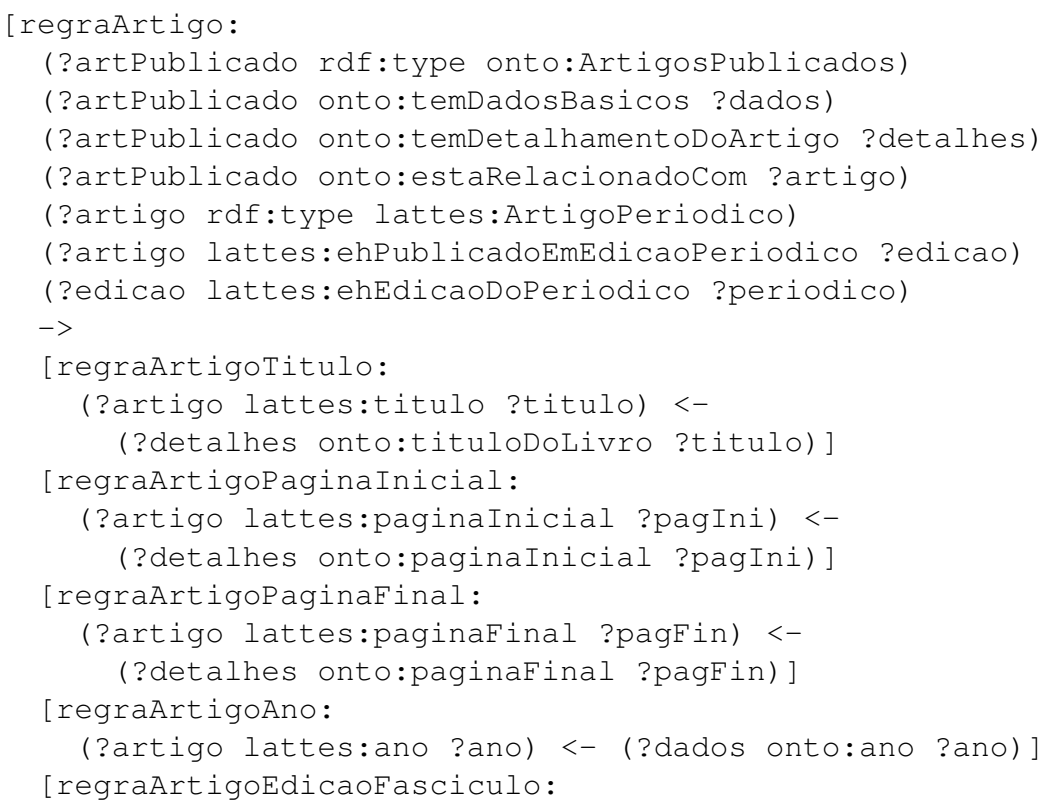


22 (?edicao lattes:fasciculo ?fasciculo) <-

23 (?detalhes onto:fasciculo ?fasciculo)]

24 [regraArtigoEdicaoVolume:

25 (?edicao lattes:volume ?volume) <- (?detalhes onto:volume ?volume)]

26 [regraArtigoperiodicoTitulo:

27 (?periodico lattes:titulo ?tituloperiodico)

$28<-$ (?detalhes onto:tituloDoPeriodicoOuRevista ?tituloperiodico)]

29 ]

\section{Regra para Determinar Título de Mestre}

O que está sendo descrito nesta regra é: "Caso uma pessoa possua uma formação acadêmica de nível Mestrado e haja ano de conclusão, então esta pessoa possui o título de Mestre".

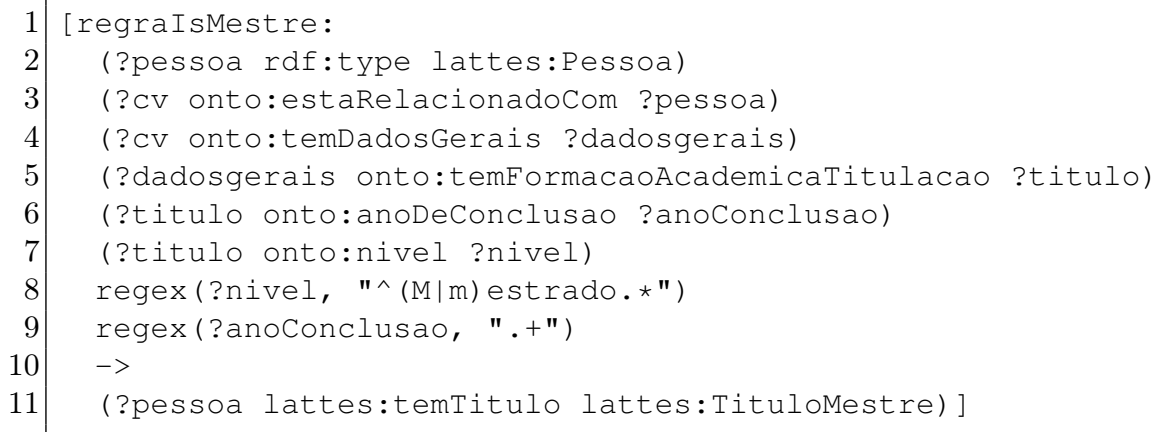

